UNIVERSIDADE DE SÃO PAULO

ESCOLA DE ENFERMAGEM

\title{
A ANSIEDADE E O PACIENTE CIRÚRGICO: ANÁLISE DAS VARIÁVEIS INTERVENIENTES
}

APARECIDA DE CASSIA GIANI PENICHE

SÃO PAULO 
APARECIDA DE CASSIA GIANI PENICHE

A ANSIEDADE E O PACIENTE CIRÚRGICO: ANÁLISE DAS VARIÁVEIS INTERVENIENTES

\author{
Tese de Livre Docência apresentada à \\ Escola de Enfermagem da Universidade \\ de São Paulo.
}

São Paulo

2005 
Aos meus pais e irmão:

Essência da minha evolução.

Ao Né:

Nenhum caminho é longo demais quando encontramos o amor como inspiração.

Gui, Gus, Glauco:

Definem a felicidade de uma forma que transcende a matéria. 


\section{Agradecimentos}

A vocês por me mostrarem as valiosas formas de crescimento e amadurecimento profissional e pessoal.

Ana Maria Kazue Miyadahira, Ângela Maria Geraldo Pierin, Ana Cristina Mancussi e Faro, Arlete Silva, Cibele Andruciolli de Mattos Pimenta, Diná de Almeida Lopes Monteiro da Cruz, Eliane Correa Chaves, Estela Regina Ferraz Bianchi, Kátia Grillo Padilha, Kazuko Uchikawa Graziano, Maria Alice Fortes Gatto, Maria do Carmo Querido Avelar, Maria de Fátima Fernandes Vattimo, Maria Julia Paes da Silva, Miako Kimura, Paolo Meneghin, Rita de Cássia Burgos de Oliveira Leite, Regina Márcia Cardoso de Sousa, Rúbia Aparecida Lacerda, Ruth Natália Tereza Turrini, Silvia Secoli, Sônia Aurora Grossi, Vera Lucia Conceição de Gouvêa Santos, Vilanice Püschell, Yeda Aparecida Oliveira Duarte, Maria Theodora Fernandes de Carvalho, Olinda de Fátima do Carmo Freire, Marisa Ignês Peres, Rosemeire de Souza Caetano, Elizabeth Aparecida Duarte Schubert, Verônica Cunha Rodrigues de Oliveira, Maria Cecília Toffoleto, Débora Cristina Alavarce, Carla Cristina Paz Félix, Josinete Aparecida da Silva Bastos, Neusa da Silva Oliveira, Nadir Aparecida Lopes, Neide Filet, Karen Dinar de Oliveira, Rodrigo Fernandes da Costa Neto, Ronaldo Lelis Albuquerque, Lygia de Oliveira Moraes, Rosileine Laiola, Léa Nunes de Oliveira, Verônica Cecília Calbo de Medeiros, Silvana Policastro, Márcia de Fátima da Silva, Márcia Cristina de Oliveira Pereira, Rosa Maria Fonseca Pelegrini, Ana Lúcia Siqueira Costa, Ana Lúcia Mirancos da Cunha, Janir Biazon, Maria Belen Salazar Posso, Vanda Maria Galvão Jouclas, Fernando Bueno Pereira Leitão, Edoilia, Leni Lanza...e a todos aqueles que, mesmo não tendo sido citados nominalmente, foram importantes e colaboraram de alguma forma em minha trajetória, alguns deles não procuro, basta-me saber que eles existem. Esta mera condição me encoraja a seguir em frente pela vida... mas é delicioso que eu saiba e sinta que os adoro, embora não declare e não os procure sempre.(Vinicius de Moraes)

Amizade não se improvisa. É obra do tempo, colaboração e harmonia. 


\section{Resumo}

O objetivo desta pesquisa foi analisar a influência da ansiedade no procedimento anestésico cirúrgico e suas implicações relacionadas ao período pós-operatório e às estratégias de enfrentamento em 4 protocolos de estudo: Protocolo 1: 40 pacientes ASA 1 ou ASA 2 submetidos a cirurgia ambulatorial de pequeno porte, sob anestesia local, sem sedação. Protocolo 2: 40 pacientes cirúrgicos submetidos à intervenção anestésico cirúrgica de pequeno e médio porte, sem medicação pré-anestésica no momento de aplicação dos questionários. Protocolo 3: 127 pacientes com indicação de revascularização de miocárdio, sem uso de ansiolítico no momento de aplicação dos questionários, sem apresentar infecção prévia, não ter diagnóstico de doença psiquiátrica e neoplásicas e com índice de massa corpórea de 20 a 40\%. Protocolo 4: 40 pacientes cirúrgicos ambulatoriais, submetidos à anestesia local sem sedação e a procedimentos de pequeno e médio porte. Os resultados mostraram que: Protocolo 1: ansiedade referida pelos pacientes no período pré e pós operatório é de média intensidade e a relação entre as mesmas não é estatisticamente significante( $\mathrm{Z}=0,267)$, assim como não apresentaram manifestações clinicas evidenciadas pela mesma. Protocolo 2: A amostra composta em sua maioria por pacientes do sexo feminino com uma idade média de 46 anos, com baixo grau de escolaridade, com experiência cirúrgica anterior, sem intercorrências e apresentando baixo e médio estado de ansiedade.As estratégias de enfrentamento mais comumente utilizadas foram as de suporte social e a de resolução de problemas.Com relação à ansiedade e às estratégias de enfrentamento, obteve-se uma correlação negativa entre o estado de ansiedade e o suporte social e estado de ansiedade e resolução de problemas, isto é, quanto menor o estado de ansiedade mais os pacientes se utilizaram das estratégias de suporte social e da resolução de problemas.Protocolo 3: Os pacientes submetidos à revascularização do miocárdio apresentaram em sua maioria $(51,20 \%)$ um médio estado de ansiedade no período pré-operatório imediato; Verificou-se a ocorrência de infecção do sítio cirúrgico em 11 pacientes (8,66\%); Não foi observada relação estatisticamente significante entre estado de ansiedade no período pré-operatatório imediato e a infecção do sítio cirúrgico nestes pacientes $(p=$ $0,120)$. Protocolo 4: A maioria dos pacientes cirúrgicos ambulatoriais no período pré-operatório apresentou baixo estado de ansiedade e com variação normal dos parâmetros clínicos, ou seja, compatíveis com o estado emocional apresentado. Os mecanismos de coping mais utilizados foram o de suporte social, seguido pelo de resolução de problemas e reavaliação positiva. Apesar de não existir uma correlação estatisticamente significante entre ansiedade e mecanismos de coping utilizados, encontra-se uma tendência na utilização do mecanismo de fuga e esquiva. Conclusão: $A$ ansiedade do paciente cirúrgico retrata a complexidade do ser humano e isto se reflete na urgência do aprofundamento teórico relacionada ao enfermeiro de centro cirúrgico. 


\section{Abstract}

The study had the objective to analyse the influence of anxiety in surgical anesthetic-surgical procedures and in immediate post operative period and coping strategies in 4 protocols: Protocol 1: 40 patients ASA1 ou ASA 2 undergoing ambulatory surgery, without local anesthesia and without sedation were inclued. Protocol 2: 40 patients undergoing eletive surgery without sedation in moment applicable instrument. Protocol 3: 127 patients submitted to myocardial revascularization, without sedation, without occurrence of infection and body mass. Protocol 4: 40 patients undergoing ambulatory surgery, without local anesthesia and without sedation. The results showed that: Protocol 1: anxiety patient was moderate and no correlation was observed with clinical signals. Protocol 2: the results showed that patient have low and moderate anxiety level and that the most used coping strategic during the preoperative period were social support and problem solution. In the relation between anxiety level and coping strategies, a significant correlation was observed. However, in the association between anxiety level and social support and anxiety level and problem solution, a negative correlation was found, that was most used coping strategies, also the lower anxious patients were in the preoperative period. Protocol 3: a sampling characterized a medium anxiety state. Related to infection during the post-surgical period, it was obtained 11 patients that presented infection in the surgical site. It was conclude that there were no statistically significant differences $(p=0.120)$ between anxiety and infection in the surgical site Protocol 4: the results showed that patient low anxiety level; the most used coping strategic during the preoperative period were social support problem solution and positive re assessment. Conclusion:The present results showed the human being complexity which emphasizes the necessity of the knowledge improvement of the operating room nurse. 


\section{SUMÁRIO}

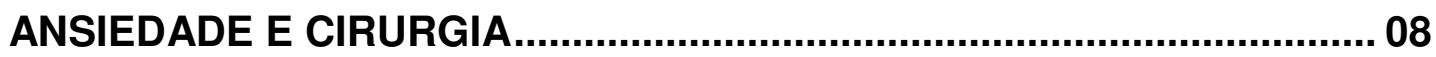

PROTOCOLO 1: A Influência dos Mecanismos de Coping na Ansiedade do Paciente Cirúrgico Ambulatorial 26

PROTOCOLO 2: A Influência da Ansiedade nas Estratégias de Enfrentamento utilizadas no Período Pré-Operatório. 42

PROTOCOLO 3: Ansiedade do Paciente no Período PréOperatório de Revascularização do Miocárdio como Fator de Risco de Infecção 73

PROTOCOLO 4: A Influência dos Mecanismos de Coping na Ansiedade do Paciente Cirúrgico Ambulatorial.

CONCLUSÕES 139

CONSIDERAÇÕES FINAIS. 142

REFERÊNCIAS BIBLIOGRÁFICAS 153

ANEXOS 


\section{ANSIEDADE E CIRURGIA}




\section{ANSIEDADE E CIRURGIA}

Mesmo com toda evolução tecnológica existente, dando suporte ao procedimento cirúrgico e anestésico, como o uso da robótica, da telemedicina e de fármacos de última geração, o homem continua, como no passado, a reagir às agressões. Isto significa dizer que, apesar da evolução científica, a forma de reação, continua sendo a mais primitiva e eficaz que se conhece, isto é a de lutar ou fugir.

"Nos fatos comuns da vida, o homem continua a reagir fisiologicamente a presença de seres vivos estranhos e especialmente aos competidores humanos ${ }^{(1)}$ A resposta lutar ou fugir, com todas as suas implicações bioquímicas hormonais e outras, sempre foi adaptativa e continua sendo. A sobrevivência do homem depende de sua capacidade de mobilização dos mecanismos do corpo. É através dela que o ser humano está capacitado a empenhar-se efetivamente em luta física ou fugir tão rapidamente quanto for possível.

Mas o homem, por meio de sua subjetividade e socialização, vivência processos somáticos e psíquicos resultados de estímulos que experimenta e "agora como no passado os seres humanos não reagem apenas às características objetivas de determinada situação, mas, tanto ou mais ainda, aos símbolos que a mesma representa para eles ${ }^{(1) " .}$

Descartes ${ }^{2)}$ em suas reflexões concebeu o ato de pensar como sendo a essência humana e uma atividade da alma (espírito, pensamento, razão): o que não era alma era parte extensa do ser humano, ou seja, matéria. As emoções (paixões) eram decorrentes das sensações provocadas na matéria. 
A despeito dessa divisão, Descartes ${ }^{(2)}$ já refletia sobre a ligação entre as duas partes do ser humano e prenunciava a participação do sistema endócrino nas reações do corpo, afirmando "a alma está unida a todas as partes do corpo e que não se pode dizer, que a alma esteja em qualquer parte do corpo porque ele é uno". Já pressupunha a existência de uma pequena glândula no cérebro onde a alma exercia suas funções irradiandoas para todo o resto do corpo, através dos nervos e do sangue, por um mecanismo complexo. A Figura 1 ilustra a ligação da alma e a máquina do corpo tal como ele concebia.

FIGURA 1 - Ligação da alma e a máquina do corpo tal como a concepção de DESCARTES.

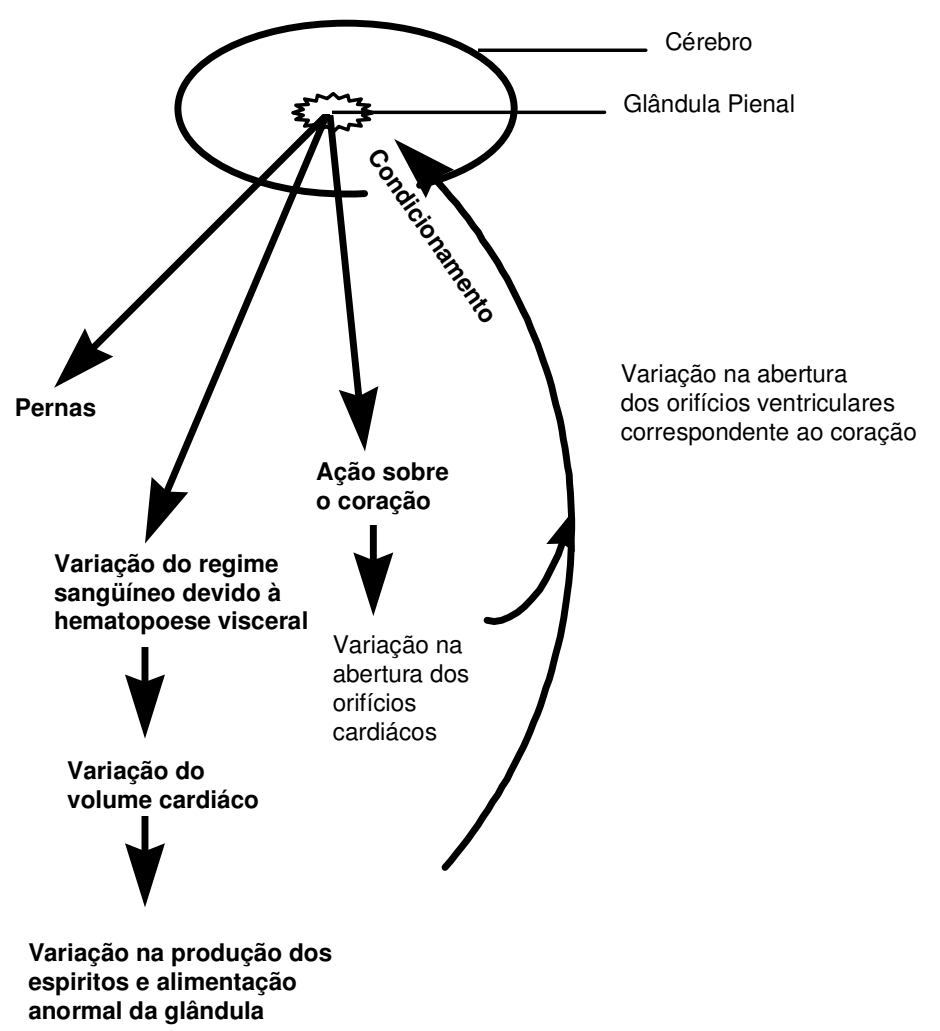

Atualizando algumas das idéias de Descartes ${ }^{(2)}$ para a nossa realidade, e usando a sua própria terminologia, podemos dizer que o ato 
anestésico cirúrgico engendra um encadeamento de "paixões" que provocam igualmente alterações hormonais como àquelas produzidas ao fugir ou ao enfrentar um animal selvagem e suas respostas aos estímulos terão resquícios das experiências passadas.

As alterações hormonais provocadas no homem pelo procedimento anestésico cirúrgico são descritas amplamente. Selye ${ }^{(3)}$ observou que pacientes com diagnósticos diferentes apresentavam as mesmas manifestações o que, na época, denominou de "síndrome de estar doente". Posteriormente desenvolveu estudos, agora, objetivando o estímulo agressor (temperatura, choque elétrico, sangramentos) e controlando a resposta do organismo de animais por meio de dados clínicos e observação pós-autópsia. Concluiu que existia um padrão de resposta biológica semelhante provocada por estímulos diferentes, que obedeciam a um encadeamento mais ou menos constante, configurando uma síndrome. Essa resposta biológica, Selye denominou stress e ao encadeamento da resposta, denominou Síndrome de Adaptação Geral (SAG), que após várias modificações conceituais pode ser descrita da seguinte maneira:

Fase de reação de alarme: caracterizada por reações corporais, resultando da exposição do organismo ao estímulo, ocasionando mudanças hormonais, desencadeadas pelo sistema nervoso central e pelo sistema nervoso autônomo simpático, preparando o corpo para luta ou fuga, com a participação dos hormônios glicocorticóides, mineralocorticóides e as catecolaminas, entre outros. $^{(4-5)}$ 
A rapidez com que esta fase é deflagrada deve-se à descarga adrenérgica da medula da supra-renal e da noradrenalina, em fibras pósganglionares, ocorrendo taquicardia, aumento da pressão arterial, alterações respiratórias, sudorese, aumento do fluxo sangüíneo muscular, diminuição do fluxo sangüíneo da pele, dilatação pupilar e diminuição da saliva ${ }^{(5)}$.

Se esta mobilização do organismo for bem sucedida ou se os estímulos desaparecerem, as funções e os órgãos voltam ao seu nível basal de funcionamento. Mas se estes fatores se mantiverem, o indivíduo enfrentará uma outra fase do SAG denominada fase de resistência.

Fase de resistência: aparece quando a exposição ao estímulo é prolongada. Os sinais decorrentes das mudanças hormonais desencadeadas na fase anterior diminuem. A predominância hormonal agora é mediada pelo hipotálamo, sendo que os hormônios liberados têm o objetivo de aumentar a capacidade adaptativa às demandas. Nessa fase, existe um esforço em manter a resistência por um período maior.

Fase de exaustão: ocorre falha dos sistemas envolvidos na fase anterior, ou seja, o organismo perde o poder adaptativo; há diminuição ou esgotamento dos mecanismos que o envolve podendo surgir patologias localizadas em órgãos específicos, resultante da falência de órgãos ou seu comprometimento. Esta fase corresponde à síndrome de adaptação local (SAL) fase essa nem sempre atingida. Também não é necessário o organismo desenvolver a fase de resistência se os mecanismos utilizados pelo sistema nervoso central e autônomo forem suficientes para reequilibrar suas funções e neutralizar o stressor ${ }^{(6)}$. 
A SAG, embora descrita em 3 fases, não ocorre assim de forma tão delimitada, isto é, a simultaneidade das fases e a rapidez evolutiva são suas características.

A teoria que Selye denominou Stress teve a importância científica de descrever as repercussões fisiológicas de um estímulo inespecífico no corpo (soma) de um indivíduo.

A definição de inespecífico para esse autor está ligada ao estímulo, ou seja, para qualquer estímulo, o organismo biológico apresenta o mesmo encadeamento de resposta que difere apenas de intensidade.

Mais tarde, Lazarus, Folkman ${ }^{(7)}$ foram além do modelo bioquímico de Selye. Ampliando o conceito de stress apresentado, incluíram a importância do aparelho cognitivo como mediador da intensidade das respostas aos estímulos, decorrentes das diferentes formas de avaliação feitas pelos indivíduos. Constataram que o ser humano está muito distante de ser apenas um ser biológico que obedece a um padrão mínimo de resposta. É um ser complexo o qual terá, que conviver com fatores que atuarão na sua estrutura biológica. Isto resultará em demandas psíquicas, as quais serão administradas com graus de competência e resolutividade de acordo com o substrato psíquico de cada um, sua maneira de interpretar os problemas, fazer a avaliação cognitiva, desencadeando alterações hormonais específicas.

Segundo esses autores, os processos cognitivos de avaliação direcionam as reações aos fatores externos e refletem a relação única e 
mutável que existe entre o homem, seus valores, suas percepções, seus compromissos, pensamentos e seu ambiente.

Lazarus, Folkman ${ }^{(7)}$ definem a avaliação cognitiva como "um processo de categorização de um encontro, com o foco no propósito ou no significado desse encontro". O significado de encontro para esses autores refere-se à aproximação de dois elementos, sendo que um deles é o sujeito e o outro é de natureza diversa e desencadeador do estímulo.

Nesse processo de categorização, são possíveis dois tipos de avaliação: a primária e a secundária.

Esses 2 tipos de avaliação feitas pelos indivíduos produzem respostas, desde as mais primitivas até as mais elaboradas, em função das diferentes áreas cerebrais que foram estimuladas.

A avaliação primária ocorre a partir do primeiro contacto do sujeito com o objeto, desencadeando uma apreciação que visa identificar o estímulo. Neste caso, a resposta ou reação classificará o estímulo em relevante ou irrelevante. A partir de então, se for considerado relevante, o homem mobilizar-se-á para a ação.

A avaliação primária diferencia-se em:

Benigna-positiva: ocorre quando o resultado é considerado positivo, podendo aumentar o bem-estar e as possibilidades. Embora as emoções envolvidas sejam consideradas positivas, podem estar presentes apreensões que dependem dos fatores pessoais envolvidos, havendo inclusive a possibilidade de gerar ansiedade e culpa. 
Dano ou perda e ameaça ou desafio: na avaliação de dano ou perda, a pessoa já tem suportado algum dano à sua auto-estima ou aceitação pessoal, de maneira que a expectativa já está diminuída, portanto, a energia mobilizada é relativamente pequena, visando controlar a frustração ou luto.

$\mathrm{Na}$ avaliação do encontro como ameaçador surgem implicações negativas de desempenhos futuros, focalizando os prejuízos potenciais. Embora ocorram sentimentos negativos, a ameaça permite um enfrentamento antecipado (coping) ${ }^{\star}$, possibilitando o planejamento com 0 intuito de vencer as dificuldades. Quando o sujeito avalia o objeto como desafiador, também se verifica a mobilização dos esforços de enfrentamento. Como o indivíduo vislumbra ganhar, essa situação envolve emoções de excitação, esperança e confiança.

Essas avaliações podem ocorrer simultaneamente, mas os seus componentes são distintos e devem ser considerados separadamente.

Ressalta-se que a relação entre ameaça e desafio pode mudar no decorrer de um encontro. Por exemplo, uma situação que é avaliada inicialmente como ameaçadora pode vir a ser avaliada como desafiadora devido aos esforços de coping, que permitem uma visão mais positiva frente às situações, e assim os indivíduos utilizam melhor os recursos disponíveis.

Coping foi definido por Lazarus, Folkman ${ }^{(7)}$ como estratégias desenvolvidas para enfrentar as situações. É um esforço cognitivo e comportamental, realizado para dominar, tolerar ou reduzir as demandas externas e internas e o conflito entre elas. Partindo do pressuposto de que 
as crenças individuais traduzem as idéias e julgamentos sobre a realidade vivenciada e que as normas fundamentam as condutas servindo de guia na compreensão do significado da realidade, é possível supor que ambas tenham influência sobre o coping e, portanto, estabeleçam estreitas relações com o processo de avaliação cognitiva.

O coping, além de representar os recursos do indivíduo no enfrentamento das situações para superar o problema ou reduzir a ansiedade, representa também uma tentativa de o indivíduo exercer algum controle sobre o ambiente onde ele se insere, relacionando-se com ele de forma mais adaptativa.

Outro tipo de avaliação é a secundária onde se torna necessária uma ação para o controle da situação. Envolve uma avaliação sobre o que deve ser feito. É um processo complexo que considera opções de coping disponíveis: expectativa de que uma dada opção de coping irá se realizar, expectativa de se utilizar uma estratégia particular eficaz.

$\mathrm{Na}$ avaliação secundária existe a contribuição de novas informações dadas pelo ambiente, gerando uma reavaliação. Assim o estímulo pode ser recategorizado como irrelevante, benigno, ameaçador ou danoso, criando uma sucessão de emoções e avaliações.

Para Vasconcellos ${ }^{(6)}$, a experiência vivida desencadeará um processo psicobiológico que inclui a avaliação cognitiva do evento e que redimensionará esta experiência. O indivíduo pode desenvolver estratégias que o tornem capaz de diminuir ou cessar a sensação de ameaça ou desafio 
provocados pela primeira avaliação, como também reconhecer sua incapacidade para controlá-la.

Vários autores desenvolveram pesquisas sobre o stress, salientando que a reação aos estímulos requer muito mais do que a resposta biológica do homem envolvendo aspectos psicológicos e sociais.

Como cita Chaves $^{(8)}$, os estímulos atuam na esfera biológica, psíquica e social, de forma não isolada, confundem-se, potencializam-se e manifestam-se em qualquer uma delas, de modo concomitante, mostrando que no ser humano a delimitação destas três esferas é possível apenas como exercício de abstração.

No que se refere ao ato anestésico-cirúrgico é possível supor que a antecipação deste evento, pelo paciente, desencadeará sentimentos e uma avaliação cognitiva, os quais, influenciados pelas diferenças individuais, resultarão em comportamentos de ajustes que têm por finalidade enfrentar o stress e a ansiedade provocados por esse momento.

Essa avaliação cognitiva será mais efetiva quanto mais dados da realidade o indivíduo tiver. Várias são as possibilidades de obtenção destes dados, desde experiências passadas até a formulação de dúvidas, questionamentos, hipóteses e associações de idéias relativas à cirurgia e à anestesia.

Segundo Lazarus, Folkman ${ }^{(7)}$ avaliação cognitiva é um processo de categorização de um encontro, com o foco no propósito ou no significado desse encontro. Estes autores definem encontro como a aproximação de 
dois elementos, sendo que um deles é o sujeito e o outro é de natureza diversa e desencadeadora do estímulo.

Para Spielberger ${ }^{(9)}$ se um estímulo interno ou externo ao sujeito for interpretado como perigoso ou ameaçador desencadeará uma reação emocional caracterizada como estado de ansiedade.

Esse autor define estado de ansiedade como uma reação emocional percebida pela consciência e caracterizada por sentimentos subjetivos de tensão, apreensão nervosismo e preocupação intensificando a atividade do sistema nervoso autônomo. Estas respostas incluem alteração da freqüência cardíaca, do padrão respiratório e da pressão arterial, inquietação, estremecimentos, tremores e aumento de sudorese. Afirma que a maneira como o indivíduo percebe a ameaça é mais importante do que a própria ameaça. Considera as diferenças na percepção e as reações às situações como traço de ansiedade, isto é, comportamentos individuais que permanecem latentes, até que em uma determinada situação são ativados. Estes comportamentos são influenciados por experiências passadas que levam os indivíduos a reagir de determinada forma.

Destaca-se neste processo uma estreita associação entre a percepção sensitiva e cognitiva, o surgimento da ansiedade e do estresse, e alterações fisiológicas perceptíveis decorrentes de uma ameaça. Sendo assim, tem-se que a avaliação cognitiva pode interferir na intensidade das alterações somáticas.

As manifestações fisiológicas são complexas e multifatoriais. Quanto ao componente humoral, ocorre um estímulo à produção de adrenalina e 
noradrenalina pela medula supra renal e sinapses nervosas. A adrenalina inibe a produção de insulina, enquanto estimula a glicogênese e a hidrólise de gordura dos depósitos em ácidos graxos livres. A inibição de insulina favorece a liberação de aminoácidos do músculo, passando a glicose. Procede-se então uma excreção aumentada de nitrogênio urinário. As alterações de perfusão originadas estimulam a produção de renina pelo aparelho justaglomerular renal. A ativação da cascata renina-angiotensina por sua vez desencadeia a liberação de aldosterona como medida de manutenção da pressão de perfusão e conservação de sódio e água, para preservação do volume circulante efetivo. A resposta humoral também é intensificada pelo estímulo hipofisário e elevação na concentração de glicocorticóides plasmáticos ${ }^{(4-5)}$.

Parece não haver dúvida entre os estudiosos da neuroendocrinologia das emoções que existe uma correlação estreita entre a percepção sensitiva e cognitiva de uma ameaça, o surgimento da ansiedade e do stress e as alterações fisiológicas perceptíveis clinicamente. No entanto, estas afirmações não são tão claras e definitivas em situações nas quais a avaliação cognitiva está ou esteve temporariamente abolida por qualquer motivo.

Sendo assim o processo anestésico-cirúrgico representa um exemplo de supressão temporária da consciência, o que implica na incompetência também temporária, do paciente em avaliar cognitivamente a situação a qual está submetido. Spielberger, Gorsuch, Lushene ${ }^{(10)}$ compararam o traço de ansiedade a uma energia potencial que the confere a qualidade de energia 
potencial latente existente em cada indivíduo e que pode ou não ser liberada em determinadas situações. Também é esperado que pessoas com alto traço de ansiedade apresentem elevação de estado de ansiedade, uma vez que elas tendem a considerar as situações como ameaçadoras. Concebem o mundo como mais perigoso do que as pessoas com baixo traço de ansiedade, reagindo mais intensamente ao estímulo.

Em virtude desta situação após a realização da cirurgia, encontra-se no período pós-operatório imediato, em sala de recuperação anestésica (SRA), o indivíduo numa fase de vulnerabilidade e instabilidades, com a sua capacidade psicológica adaptativa alterada, uma vez que o processo de questionamento e busca de dados, que dão suporte à avaliação cognitiva, sofre uma ruptura quando a pessoa é submetida a um procedimento anestésico. Neste caso, os medos e as incertezas tendem a aumentar em função da impossibilidade de se obter dados desse momento.

Surgirão em conseqüência desta experiência, alterações que neste momento, podem ser percebidas por meio de observações clínicas e medidas de parâmetros vitais que vão refletir as condições do paciente, no período de recuperação anestésica.

A complexidade existente na resposta dada pelo homem ao procedimento anestésico-cirúrgico evidencia que os resultados obtidos com a verificação dos parâmetros clínicos precisam ser interpretados como um reflexo do homem operado, isto é, não é só a dor que provoca taquicardia ou um aumento da pressão arterial, assim como estes, outros sinais também 
são decorrentes e potencializados pelos fatores ansiogênicos oriundos do procedimento anestésico-cirúrgico.

O resultado desta avaliação não pode ser interpretado puramente como uma manifestação biológica decorrente do processo anestésicocirúrgico, mas como uma resposta psicossomática de vivência deste evento.

Mesmo considerando as manifestações orgânicas do homem como respostas a estímulos na sua estrutura biológica e psíquica simultaneamente, na fase pós-operatória imediata essa consideração ainda não encontra espaço para identificação, uma vez que o universo subjetivo do homem e suas manifestações no período transoperatório correspondem a uma situação ainda inacessível dado as características dos instrumentos que se dispõe, até o momento, para avaliação de uma pessoa inconsciente ou semiconsciente.

Em outras palavras não se têm meios para precisar que tipo de manifestação emocional é possível ocorrer durante um processo anestésico, ou até se ela está mesmo presente ou não e, portanto, não se tem base para afirmar ou tão pouco negar que elas estejam interferindo nos parâmetros orgânicos da fase pós-operatória imediata.

A partir de então, surgiu uma primeira questão em torno do modo como a ansiedade se manifesta clinicamente, nesta situação específica, ou seja, como é a expressão somática do stress quando a subjetividade está embotada pelas drogas anestésicas?

$\mathrm{Na}$ busca de esclarecimentos, sobre esta questão realizou-se um estudo inicial para verificar a relação entre o traço e o estado de ansiedade 
no período pré-operatório do paciente, assim como a relação entre o estado de ansiedade, no período pré-operatório, e a sua manifestação nos parâmetros clínicos no período pós-operatório imediato. A amostra estudada constou de 33 pacientes internados nas unidades de Clínica Cirúrgica (ASA 1 e ASA 2) para a realização da intervenção anestésico-cirúrgica, sendo 69,75 (23) mulheres e 30,3\% (10) homens, distribuídos em uma faixa etária de 31 a 50 anos $(60,9 \%)$ e com experiência cirúrgica $(39,4 \%)$ submetido à anestesia geral (72,7\%). Utilizou-se o inventário validado por Spielberg, Gorsuch, Lushene ${ }^{(10)}$ para conhecer o traço-estado de ansiedade da amostra que apresentou médio traço de ansiedade $(51,5 \%)$ e baixo estado de ansiedade( 69,7\%). Obteve-se uma correlação estatisticamente significante e positiva entre o traço e o estado de ansiedade no período préoperatório, ou seja, houve uma variação do estado de ansiedade nos pacientes compatível com traço de ansiedade frente ao estímulo da cirurgia e da anestesia, porém o estado de ansiedade no período pré-operatório não interferiu nos parâmetros clínicos analisados no período pós-operatório imediato, ou seja, não houve uma correlação significativa entre estas duas variáveis correlacionadas.

Diante da complexidade do tema e pela vulnerabilidade que envolve as variáveis em questão, algumas perguntas ficaram sem resposta. São elas:

O contato prévio com os pacientes cirúrgicos pode ter influenciado no estado de ansiedade dos mesmos, no período pós-operatório e, 
conseqüentemente contribuído para a ausência de correlação entre o estado de ansiedade e a variação dos parâmetros clínicos medidos?

As patologias prévias, uma vez neste estudo realizado 18,2\% apresentavam hipertensão arterial ou diabetes mellitus controlados, interferiram no estado de ansiedade apresentado pelos pacientes?

As drogas pré-anestésicas e anestésicas utilizadas podem ter colaborado com os resultados apresentados, uma vez que têm como objetivos amnésia e sedação?

Quais as estratégias de enfrentamento utilizadas pelos pacientes que poderiam ter contribuído com os resultados obtidos?

Existe relação entre as estratégias de enfrentamento e a ansiedade?

Para respondê-las foram criados os protocolos a seguir:

\section{Protocolo 1 : (Ansiedade do paciente cirúrgico ambulatorial)}

Este estudo foi desenvolvido pela aluna de graduação da Escola de enfermagem da USP com bolsa de iniciação científica, modalidade PIBIC e teve como finalidade eliminar a interferência dos fármacos utilizados como drogas pré-anestésicas e anestésicas no período pós-operatório. Teve como amostra pacientes submetidos à cirurgia ambulatorial de pequeno porte sob anestesia local e com alta hospitalar prevista ao término da cirurgia . 
Protocolo 2: (A influência da ansiedade nas estratégias de enfrentamento utilizadas no período pré-operatório)

Esta pesquisa procurou evidenciar a relação entre ansiedade e as estratégias de coping utilizadas no pré-operatório, agora com pacientes internados em um hospital escola onde a visita pré-operatória é realizada pelo enfermeiro.

Protocolo 3: (Ansiedade do paciente no período pré-operatório de revascularização do miocárdio fomo fator de risco de infecção)

Esta investigação foi realizada com pacientes portadores de patologias como hipertensão, diabetes mellitus e dislipidemia submetidos à cirurgia de grande porte, como revascularização do miocárdio, e buscou-se a possível relação entre ansiedade e a ocorrência de infecção, pois apesar da cirurgia ser classificada como limpa, tem uma simbologia altamente desgastante para o paciente, uma vez que se trata do órgão ligado ao sentimento e emoção.

Protocolo 4: (A influência dos mecanismos de coping na ansiedade do paciente cirúrgico ambulatorial)

Protocolo realizado com pacientes cirúrgicos ambulatoriais e procurou-se identificar as estratégias de enfrentamento (coping) utilizadas por esses pacientes e a relação com a ansiedade evidenciada no préoperatório. 
Sendo assim, nos protocolos aqui colocados e analisados, procurouse evidenciar situações diferentes do ato anestésico cirúrgico, seja ela de curta duração como a cirurgia ambulatorial ou a de longa duração como a cirurgia cardíaca.

A partir da análise e discussão desses resultados, espera-se contribuir para o estudo da ocorrência da ansiedade e as manifestações fisiológicas, e assim subsidiar a atuação do enfermeiro junto aos pacientes submetidos ao ato anestésico cirúrgico. 
PROTOCOLO 1 


\title{
PROTOCOLO 1
}

\section{ANSIEDADE DO PACIENTE CIRÚRGICO AMBULATORIAL}

\author{
Moraes, L de O, Peniche, ACG
}

\section{Objetivos}

Identificar o traço e o estado de ansiedade do paciente cirúrgico ambulatorial no período pré-operatório e o estado de ansiedade no período pós-operatório;

Verificar a relação entre o estado de ansiedade no período préoperatório com o do período pós-operatório;

Verificar a relação entre o estado de ansiedade no período pósoperatório e sua manifestação nos parâmetros clínicos.

\section{Material e Método:}

A amostra estudada constou de pacientes internados na unidade ambulatorial de Clínica Cirúrgica de um hospital escola para a realização da intervenção cirúrgica.

Critérios de seleção da amostra: pacientes cirúrgicos ASA 1 ou ASA 2 alfabetizados em uma faixa etária de 20 a 70 anos submetidos à anestesia local, sem sedação, e à intervenção cirúrgica de pequeno porte.

Procedimento de coleta de dados: Após os trâmites legais da pesquisa foram contatados os pacientes cirúrgicos ambulatoriais que preenchiam os critérios de seleção da amostra, informando-os sobre a finalidade da 
pesquisa, da participação voluntária e da garantia do anonimato. A autorização foi formal e por escrito. Realizada entrevista com o paciente, onde foram avaliados os parâmetros clínicos, e aplicado o inventário traço estado de ansiedade. Estes dados foram coletados em duas fases. A $1^{\text {a }}$ fase realizada no ambulatório. No dia da cirurgia, os pacientes foram questionados quanto aos dados de identificação e foram avaliados os parâmetros clínicos. Logo em seguida, foi distribuído o inventário autoaplicável validado e conhecido como Inventário de Ansiedade Traço e Estado de Ansiedade (IDATE), que teve como finalidade de verificar a ansiedade do paciente cirúrgico nos períodos pré-operatório e pósoperatório. A $2^{\text {a }}$ fase 24 horas após a cirurgia, no ambulatório da clínica cirúrgica. Realizou-se novamente a avaliação dos parâmetros clínicos e do estado de ansiedade. Instrumentos: Formulário 1( Anexo 1): Parte I: composto por dados gerais de identificação como idade, hospitalização cirurgia anteriores e cirurgia proposta. Parte II: contém parâmetros clínicos considerados por diversos autores como constitutivos da avaliação de pacientes cirúrgicos ${ }^{(11-12-13-14-15-16-17)}$ além de estarem associados à atividade nervosa central autonômica e endócrina desencadeadas pela ansiedade ${ }^{(18-}$ 19). São eles: freqüência de pulso, pressão arterial, freqüência respiratória, temperatura, reflexos protetores (tosse, deglutição), dor, coloração, nível de consciência, comportamento e sinais vegetativos (vômito, náusea, sialorréia, sudorese).

As medidas de freqüência de pulso, pressão arterial, freqüência respiratória e temperatura obtidas no período pré-operatório foram 
consideradas como normais, embora se referissem ao basal do paciente, uma vez que, ao final da pesquisa, pretende-se verificar a possível associação entre a variação dos parâmetros clínicos ocorrida nos períodos pré e pós-operatório e o estado de ansiedade. Os demais parâmetros (reflexos protetores, coloração comportamento e sinais vegetativos) foram pontuados, com exceção da dor, com base nas variações propostas pelos autores $^{(11-12-13-14-15-16-17)}$, isto é, quando normal (0), alterado (1) e muito alterado (2). Quanto à avaliação do parâmetro referente à dor, foi baseada na escala proposta por Downie, apud Jensen, Karoly, Brauer ${ }^{(19)}$. Essa escala é composta por 11 números entre zero a dez ( 0 a 10). O zero (0) representa um extremo de dor (ausência) e o dez (10) representa o outro extremo (muita dor).

A pontuação dada pelo paciente nessa escala de dor foi categorizada nesta pesquisa em normal (0), quando o paciente avaliou sua dor, entre 0 a 3; alterada (1), quando o paciente avaliou sua dor entre 4 a 6 e muito alterada (2), quando a pontuação dada foi entre 7 a 10.

Com a soma dos escores obtidos pela variação de cada parâmetro avaliado, o paciente no período pré-operatório, foi categorizado em normal ( 0 a 6 pontos), alterado (7 a 12 pontos) e muito alterado (13 a 18 pontos).

Inventário: proposto por Spielberger, Gorsuch, Lushene ${ }^{(10)}$ composto por 2 questionários (Anexos 2 e 3) Esses questionários constam de 20 afirmações cada um, em que o sujeito indica a intensidade da ansiedade naquele momento (estado) ou a freqüência com que ocorre (traço), através de uma 
escala de quatro pontos ( 1 a 4). O escore total varia de 20 a 80 , sendo que os escores mais altos indicam maior ansiedade ${ }^{(8)}$.

Para avaliação dos escores obtidos com os questionários utilizou-se a categorização proposta por Chaves $^{(8)}$, ou seja: 20 a 40 pontos = baixa ansiedade; 40 a 60 pontos = média ansiedade; 60 a 80 pontos = alta ansiedade.

Formulário 2 ( Anexo 4) : Contém os mesmos parâmetros clínicos de avaliação investigada na fase pré-operatória pelo Formulário 1, Os sinais vitais receberam a classificação normal (0), alterado (1) e muito alterado (2), de acordo com a variação existente entre os valores obtidos nos períodos pré-operatório e o pós - operatório, conforme descrito no Quadro 1 a seguir :

Quadro 1 - Parâmetros clínicos com suas respectivas classificações utilizadas para avaliação do paciente no período pós-operatório.

\begin{tabular}{|c|c|c|c|}
\hline Parâmetros & Normal (0) & Alterado (1) & Muito Alterado (2) \\
\hline Pulso radial & $\begin{array}{l}\text { Variação de até } 20 \% \text { do } \\
\text { valor basal }\end{array}$ & $\begin{array}{l}\text { Variação de } 21 \text { a } 50 \% \\
\text { do valor basal }\end{array}$ & $\begin{array}{l}\text { Variação } \uparrow \text { de } 51 \% \text { ou } \downarrow \\
\text { de } 21 \% \text { do valor basal }\end{array}$ \\
\hline Pressão arterial & $\begin{array}{l}\text { Variação de até } 20 \% \text { do } \\
\text { valor basal }\end{array}$ & $\begin{array}{l}\text { Variação de } 21 \text { a } 50 \% \\
\text { do valor basal }\end{array}$ & $\begin{array}{l}\text { Variação } \uparrow \text { de } 51 \% \text { ou } \\
\downarrow \text { de } 21 \% \text { do valor basal }\end{array}$ \\
\hline $\begin{array}{l}\text { Freqüência } \\
\text { Respiratória }\end{array}$ & $\begin{array}{l}\text { Variação de até } 20 \% \text { do } \\
\text { valor basal }\end{array}$ & $\begin{array}{l}\text { Variação até } 21 \text { a } 50 \% \\
\text { do valor basal }\end{array}$ & $\begin{array}{l}\text { Variação } \uparrow \text { de } 51 \% \text { ou } \downarrow \\
\text { de } 21 \% \text { do valor basal }\end{array}$ \\
\hline Temperatura oral & Basal & $\begin{array}{l}\text { Variação de até } 1^{\circ} \mathrm{C} \text { do } \\
\text { valor basal }\end{array}$ & $\begin{array}{l}\text { Variação } \uparrow \text { ou } \downarrow \text { de } 1{ }^{\circ} \mathrm{C} \\
\text { do valor basal }\end{array}$ \\
\hline $\begin{array}{l}\text { Reflexos protetores } \\
\text { (tosse, deglutição). }\end{array}$ & Presentes & Deficientes & Ausentes \\
\hline Dor & $\begin{array}{l}\text { Sem dor } \\
(0.1 .2 .3)\end{array}$ & $\begin{array}{l}\text { Pouca dor } \\
(4.5 .6)\end{array}$ & $\begin{array}{l}\text { Muita dor } \\
(7.8 .9 .10)\end{array}$ \\
\hline Coloração & Róseo & $\begin{array}{l}\text { Pálido, marmóreo, } \\
\text { Ictérico }\end{array}$ & Cianótico \\
\hline Comportamento & Calmo & Agitado ou deprimido & Agressivo ou alheio \\
\hline Sinais vegetativos & Ausentes & 01 episódio & Mais de 01 episódio \\
\hline
\end{tabular}

No final obteve-se, pela diferença entre os parâmetros clínicos dos 
períodos pré e pós operatório, um escore que variou de zero (0) a dezoito (18). Para avaliação dos escores obtidos foi estabelecida a seguinte categorização: $0-06$ pontos $=$ normal; $7-12$ pontos $=$ alterado; $13-18$ pontos $=$ muito alterado

Tratamento Estatístico: Foram realizadas as médias, desvios padrões e os testes de Wilcoxon e Kruskal-Wallis.

\section{Resultados e discussão 1:}

\section{Caracterização da amostra.}

Participaram deste estudo 40 pacientes, sendo $50 \%$ do sexo feminino e $50 \%$ do sexo masculino. O gráfico abaixo, mostra a distribuição dos pacientes segundo a faixa etária. Encontrou-se 1 paciente com idade entre 20-30 anos; 1 paciente com idade entre 31-40 anos; 2 pacientes com idade entre 41-50 anos; 17 pacientes com idade entre 51-60 anos; e 17 pacientes com idade entre 61-70 anos, o que caracteriza uma amostra uma amostra composta principalmente por adultos (44\%) e idosos (45\%). Este resultado pode estar relacionado à especialidade de cirurgia ambulatorial uma vez que a facectomia parece ter uma maior incidência em idosos. 
Gráfico 1 - Distribuição dos pacientes segundo a faixa etária. São Paulo, 2000.

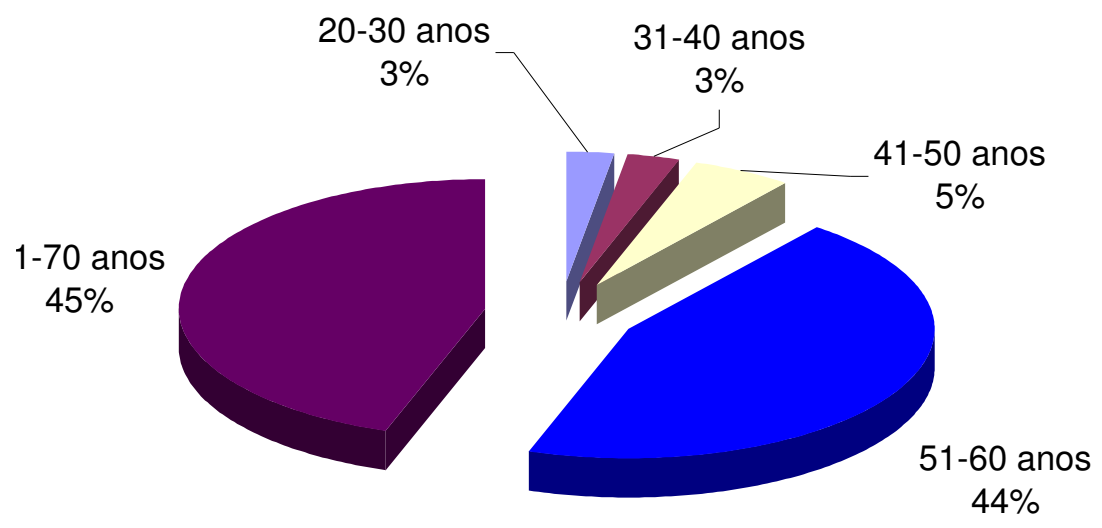

Com relação à experiência pregressa, 30 (75\%) pacientes tinham realizado cirurgia anterior e 10 pacientes (25\%) era a primeira vez que se submetiam a um procedimento cirúrgico. Estes dados são observados no gráfico 2.

Gráfico 2 - Distribuição dos pacientes segundo realização de cirurgias anteriores. São Paulo, 2000.

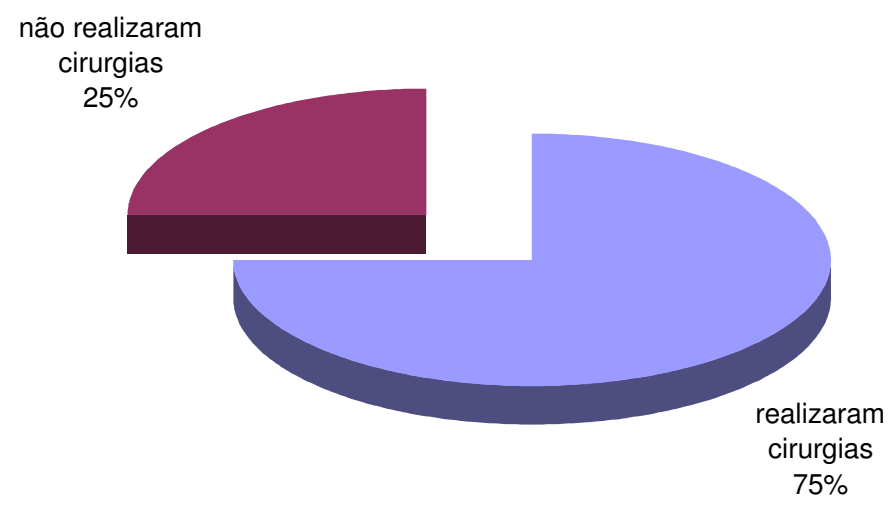


Considera-se esta porcentagem relevante e pressupõe-se que estes pacientes tenham referências simbólicas relacionadas ao processo anestésico cirúrgico armazenadas na memória.

Destes 30 pacientes $(75 \%)$ que apresentaram experiências anteriores é expressiva a porcentagem de pacientes 26 (87\%) que não apresentaram alterações dos parâmetros vitais no período pré-operatório. Se for possível considerar que o evento cirúrgico seja avaliado como ameaçador, espera-se uma alteração do estado de ansiedade acompanhada de um aumento da atividade do sistema nervoso simpático, ou seja, espera-se alteração de freqüência de pulso, respiração, pressão arterial, temperatura, sinais vegetativos (vômitos, sudorese, náuseas). Como mostram os dados esta variação não foi detectada neste grupo de pacientes no período préoperatório, o que indica uma possibilidade de que lembranças anteriores tenham contribuído positivamente nesta situação.

Ainda com relação aos dados referentes à ansiedade dos pacientes com e sem experiência cirúrgica anterior, as médias referentes ao traço e estado de ansiedade no período pré-operatório e do estado de ansiedade pós-operatório dos pacientes com cirurgias anteriores foram 39,9; 31,8 e 31,4 e para aqueles sem cirurgias anteriores foram $42 ; 34,1 ; 33,7$ respectivamente, isto é, maiores para os pacientes sem experiência cirúrgica anterior. E ainda, quando verifica-se a diferença entre as médias referentes ao traço-estado de ansiedade pré e estado de ansiedade pós-operatório dos pacientes já submetidos a cirurgias $(8,1$ e 8,5$)$ e compara-se com aquelas dos pacientes não submetidos à cirurgia $(7,9$ e 8.3) constata-se que, estes 
últimos, tiveram uma variação decimal, entre traço-estado de ansiedade pré operatório e estado de ansiedade pós-operatório menor do que os pacientes com cirurgia anterior. Ou seja, a experiência cirúrgica anterior parece não ter sido o único fator importante para a construção de respostas positivas ao estimulo, uma vez que a diferença apresentada entre os pacientes com e sem esta vivência foi decimal. Ao considerarmos o estado de ansiedade do período pré-operatório dos pacientes, que, em suas cirurgias anteriores apresentaram intercorrências, obteve-se uma média de 36,7 e, para aqueles pacientes submetidos a cirurgias anteriores sem intercorrências a média foi de 31,5. A diferença entre estas médias foi de 2,1. Fazendo este mesmo cálculo para o estado de ansiedade no período pós-operatório obteve-se como diferença -2,2 o que pressupõe que as intercorrências em cirurgias anteriores pode interferir positivamente ou não na resposta do indivíduo, salientando mais uma vez a importância da subjetividade nas avaliações feitas e os vários recursos utilizados na construção de estratégias de enfrentamentos.

Gráfico 3 - Distribuição dos pacientes quanto à variação individual referente ao traço e estados pré e pós-operatórios. São Paulo, 2000. 


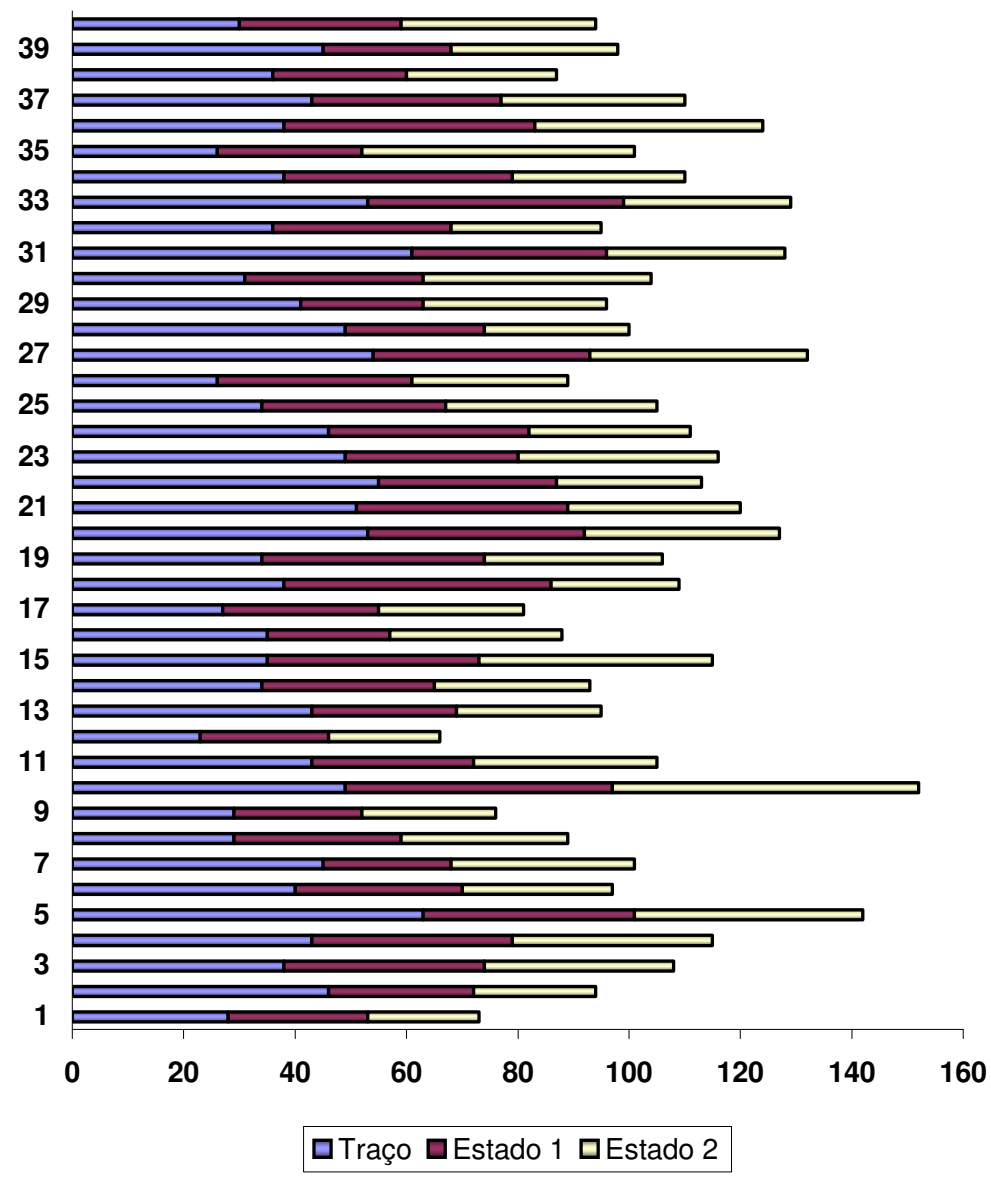

Com relação à distribuição de pacientes segundo variação individual de escores referentes ao traço de ansiedade e estado de ansiedade no período pré-operatório e estado de ansiedade no período pós-operatório, observa-se que a amostra constitui-se, em sua maioria, de indivíduos com baixo traço e estado de ansiedade no período pré-operatório. Porém, apesar desta característica dos pacientes, com relação ao estado emocional, houve uma inversão entre os escore de traço-estado de ansiedade em um número elevado de pacientes, isto é, em 24 pacientes (60\%) o estado 1 (préoperatório) foi menor que o traço, o que pode ser decorrente de mecanismos de enfrentamento eficazes utilizados pelos mesmos.

Costa $^{(20)}$ em seu estudo refere que a baixa pontuação do stress, em 
todas suas manifestações, o que inclui a ansiedade, na situação do préoperatório imediato, é resultante de mecanismos próprios de enfrentamento ou de adaptação diante de uma situação considerada estressante e que, alguns pacientes relatam estarem calmos para a intervenção cirúrgica e atribuem isto a resolução de seu problema de saúde. Neste estudo acreditase que pela antecedência com que foram agendadas as cirurgias ambulatoriais, foi permitido ao paciente, elaborar mecanismos que lhes dessem suporte. Associado ainda a este fato, a não internação em clínicas cirúrgicas com antecedência e a oportunidade de ver novamente, lembrando que a facectomia foi a cirurgia mais realizada. Sendo assim, é provável que estes fatores tenham colaborado positivamente.

O gráfico abaixo mostra as médias referentes ao traço de ansiedade e estado de ansiedade dos pacientes nos período pré e pós-operatório. 
Gráfico 4 - Valores referentes aos escores traço-estado de ansiedade no período pré e pós operatórios. São Paulo, 2000.

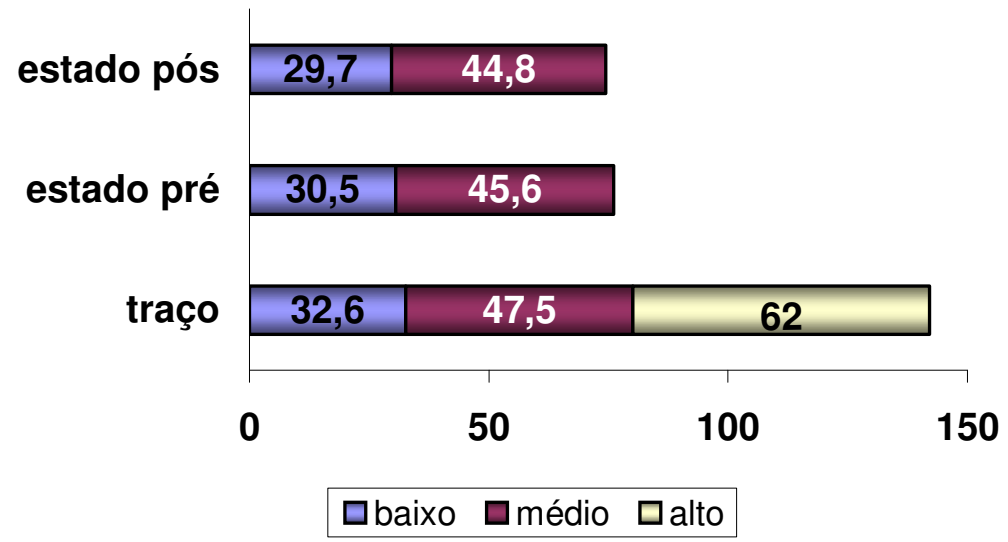

A amostra apresenta um total de 21 pacientes (52\%) com média de escore para baixo traço de ansiedade $(32,6) ; 17$ pacientes $(43 \%)$ com média de escore para médio traço de ansiedade $(47,5)$ e 2 pacientes $(5 \%)$ com média de escore para alto traço de ansiedade (62).

Nos valores referentes ao estado de ansiedade, neste mesmo período, foram encontrados 35 pacientes (88\%) com média de escore para baixa ansiedade (30) e 5 pacientes (12\%) com média de escore para média ansiedade $(45,6)$ e nenhum paciente com média correspondente a alta ansiedade (60-80 pontos). Com relação ao estado de ansiedade no período pós-operatório $34(85 \%)$ pacientes apresentaram média de escore para baixa ansiedade $(29,7)$ e 6 pacientes (15\%) com escore para média ansiedade $(44,8)$ e nenhum paciente com média de escore correspondente a alta ansiedade (60-80).

Estes resultados só confirmam os já obtidos até o momento, ou seja, uma amostra pouco ansiosa, respondendo com baixa ansiedade à cirurgia, 
sem apresentar alterações relacionadas ao aumento da atividade do sistema nervoso simpático no período pré-operatório decorrentes estado emocional.

Ao se comparar às médias do estado de ansiedade dos pacientes no período pré-operatório com as médias do estado de ansiedade no pósoperatório observa-se que a diferença existente foi de 0,8 tanto para os pacientes com baixa ansiedade como para os de média ansiedade, porém esta .diferença, entre os grupos não foi significante estatisticamente ( $z=$ 0,267).

Apesar deste resultado obtido, chama a atenção o fato da média referente ao estado de ansiedade no período pós-operatório (média $=29,7$ ) ser menor que a referente ao período pré-operatório (média $=30,5$ ), especialmente se considerar que os pacientes receberam alta e voltaram, no dia seguinte à cirurgia, para a retirada do curativo ocular, tendo outros estímulos, como as dificuldades de locomoção relacionadas ao retorno para casa e a expectativa com relação ao resultado da cirurgia. Este fato pressupõe, que retornar à rotina diária, ainda com a incerteza do resultado, ecoou positivamente em sua evolução no período pós-operatório, o que poderia ter amenizado as variações do estado emocional no período pósoperatório. E ainda que a pequena variação, não estatisticamente significante, entre as médias dos escores referentes ao estado de ansiedade nos períodos pré-operatório e no pós-operatório, em um número representativo de pacientes (39) com oscilações de pulso, pressão arterial, freqüência respiratória, temperatura, dor, coloração e comportamento, configurou a resposta fisiológica do organismo à agressão sofrida pelo 
trauma anestésico cirúrgico.

Embora sem significância estatística estes resultados devem ser utilizados como ponto de partida para investigações futuras.

A seguir encontram-se os resultados referentes às manifestações obtidas nos parâmetros clínicos.

Gráfico 5 - Distribuição de pacientes de acordo com a categorização estabelecida sobre a variação dos parâmetros no período pós-operatório. São Paulo, 2000.

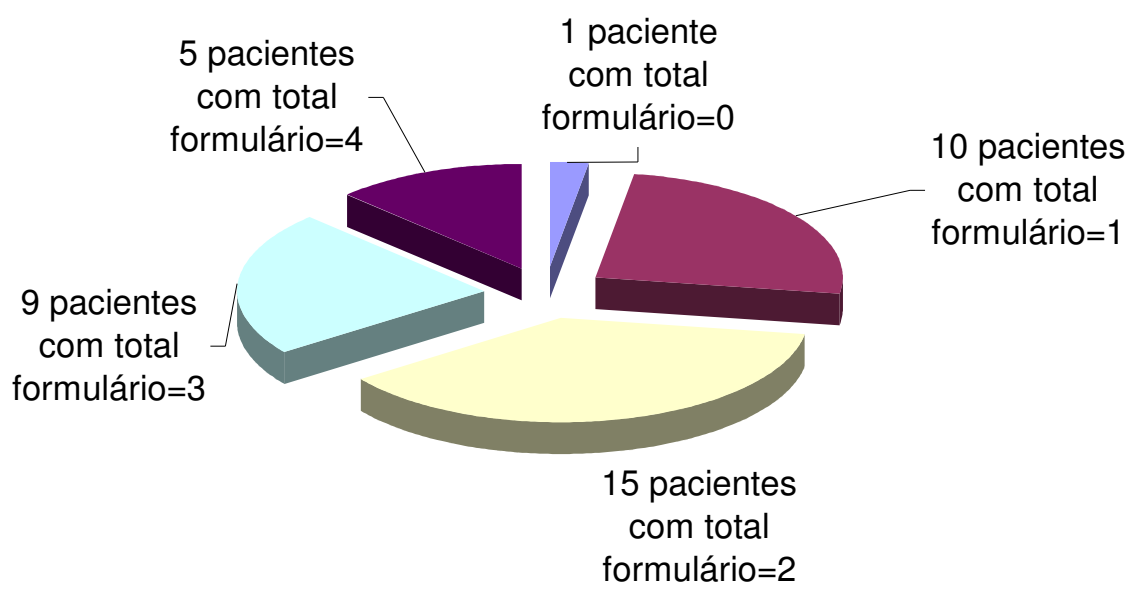

$\mathrm{Na}$ amostra de 40 pacientes, 39 pacientes foram classificados, segundo variação de seus parâmetros clínicos entre o período pré e pósoperatório, em 5 pacientes normais uma vez que a mesma não ultrapassou os 4 pontos, sendo compatível com os maiores valores de traço-ansiedade (42,6 pontos) e estado pré e pós-operatório ( 36,4 e 33,8 pontos respectivamente).

Um total de 9 pacientes apresentou pontuação 3, categorização obtida somente pela variação dos parâmetros clínicos referentes ao período 
pós-operatório e com uma média, referente ao estado de ansiedade neste período de 29,7 .

Quinze (15) pacientes com pontuação 2 apresentaram uma variação diversificada dos parâmetros clínicos.

Em relação aos pacientes com categorização dos parâmetros clínicos igual a 1 (que correspondeu a 10 pacientes), 9 apresentaram variação de temperatura. O outro paciente teve variação de medida pulso. Os pacientes deste grupo são os que apresentaram menor traço de ansiedade $(35,8$ pontos).

Cabe salientar que nesta amostra um paciente não apresentou nenhuma variação dos parâmetros clínicos avaliados, embora tenha sido àquele com maior variação, em números relativos, entre as médias de traço e o estado de ansiedade nos períodos pré (19) e no pós operatório (11) e classificado segundo esta variação em normal. Apesar de se utilizar médias aritméticas, este fato chama a atenção, para maneira como este paciente enfrentou a cirurgia, reduzindo os níveis de ansiedade e sublinhando mais uma vez a importância da subjetividade diante dos fatos.

Porém esta ocorrência não deve analisada unilateralmente, como cita Costa $^{(20)}$ em sua abordagem referente ao stress salienta que não se pode analisá-lo de maneira isolada como um fato em si, mas, como parte de um processo entre os fatores de estímulo e os meios adaptativos. Por meio desse processo, pode-se dizer que nem todos os estímulos considerados estressores, necessariamente, provocam manifestações clínicas possíveis de se mensurar. 
Se for possível associar de alguma forma a oscilação dos parâmetros clínicos com a presença de um estado emocional alterado, então neste estudo pode-se inferir que a amostra não apresentou alterações bruscas dos parâmetros clínicos, no momento em que foram coletados os dados, ou ainda que, ao responderem ao procedimento cirúrgico utilizaram capacidades de adaptação segundo suas características emocionais e comportamentais.

Os dados do protocolo 1 mostraram que a ansiedade referida pelos pacientes no período pré e pós operatório é de média intensidade e a relação entre as mesmas não é estatisticamente significante( $z=0,267)$, assim como não apresentaram manifestações clinicas evidenciadas. Esses resultados reforçam a questão apresentada anteriormente de que a ansiedade pode se manifestar de outra forma, ou seja, nem sempre detectada por alterações dos parâmetros clínicos marcadores de ansiedade. 
PROTOCOLO 2 


\title{
PROTOCOLO 2
}

\section{A INFLUÊNCIA DA ANSIEDADE NAS ESTRATÉGIAS DE ENFRENTAMENTO UTILIZADAS NO PERÍODO PRÉ- OPERATÓRIO.}

\author{
Medeiros, VCC de, Peniche ACG
}

\section{Objetivos}

Identificar o estado de ansiedade dos pacientes no período préoperatório;

Identificar as estratégias de enfrentamento, utilizadas pelos pacientes, no período pré-operatório;

Verificar a relação entre estado de ansiedade e estratégias de enfrentamento desses pacientes no período pré-operatório.

\section{Material e método:}

O estudo foi realizado no hospital Universitário da Universidade de São Paulo. Esta instituição tem como característica uma filosofia assistencial implantada onde o paciente recebe uma orientação pré-operatória da enfermeira do Centro Cirúrgico. Esta orientação é realizada durante a visita pré-operatória e tem como objetivos não só iniciar uma interação com os pacientes como também identificar os possíveis problemas a serem abordados, além de intervir no estado emocional do paciente se necessário. Critérios de seleção da amostra: A amostra estudada constou de 40 pacientes, que se submeteram às intervenções anestésico-cirúrgicas, 
internados na Unidade de Clínica Cirúrgica. Os pacientes selecionados preencheram os seguintes critérios de seleção:

- alfabetizados; faixa etária entre 18 e 65 anos; pertencentes ao programa de cirurgias eletivas; submetidos a procedimento anestésico cirúrgico de pequeno e médio porte; sem medicação pré-anestésica no momento da aplicação dos questionários. O propósito desta exclusão foi preservar o estado de consciência e alerta dos pacientes para que respondessem os questionários sem a interferência dos fármacos no estado emocional.

Com relação ao porte cirúrgico, como não foi possível encontrar este conceito na própria instituição, baseou-se no manual de Normas e Rotinas do Hospital das Clínicas da Faculdade de Medicina da Universidade de São Paulo, 1994, que sugere a seguinte classificação: cirurgias de pequeno porte são aquelas com duração de até 2 horas e as de médio porte são as cirurgias com duração de até 4 horas. Com base nesta classificação, considerou-se procedimentos anestésico cirúrgicos de pequeno porte as cirurgias de oftalmologia, endoscopia e otorrinolaringologia e as de médio porte, as cirurgias de cabeça e pescoço, geral, ginecológica, ortopédica, urológica e plásticas.

Procedimento da coleta de dados: Deu-se em duas etapas. $\mathrm{Na} 1^{\circ}$ etapa foi encaminhada, à comissão de ética e pesquisa, do Hospital Universitário da Universidade de São Paulo, uma solicitação para a realização do estudo, juntamente com o estudo, para análise. Após autorização foi feito contato 
com o departamento de enfermagem do hospital, para explicações a respeito da pesquisa.

$\mathrm{Na} 2^{\circ}$ etapa, realizada na enfermaria, da unidade de clínica cirúrgica, foram averiguados os prontuários dos pacientes quanto à possibilidade de participarem do estudo. Os pacientes foram informados sobre os objetivos da pesquisa, da sua participação voluntária e do anonimato. Após o consentimento, dos mesmos, foi lido o termo de consentimento informado e assinado pelos mesmos. Após a formalização desta etapa, foi iniciada a coleta de dados com a caracterização do paciente (Anexo 5). A seguir foi entregue o questionário auto-aplicável (Anexo 6), conhecido como questionário de estado de ansiedade, com a finalidade de verificar o estado de ansiedade do paciente no período pré-operatório. Logo em seguida foi distribuído o inventário de coping (Anexo 7), auto-aplicável, para identificar as estratégias de enfrentamento que o paciente utilizaria naquele momento.

\section{Instrumentos:}

Para a coleta dos dados foram utilizados três instrumentos.

\section{Formulário 1 ( Anexo 5)}

Composto por dados gerais de caracterização: registro geral, sexo, idade, tipo e porte de cirurgia, tipo de anestesia, cirurgias e intercorrências anteriores. 


\section{Questinário 1 ( Anexo 3)}

Foi utilizado o questionário correspondente ao estado de ansiedade que compõe o inventário validado e conhecido IDATE, proposto por Spielberger; Gorsush ,Lushene ${ }^{(10)}$. Apresenta como característica principal a mensuração de aspectos inespecíficos que permeiam as situações problemáticas ou estressantes, por exemplo: tensão, nervosismo, irritabilidade, preocupação, apreensão e outros. É um instrumento que não enfoca os aspectos somáticos advindos da hiperestimulação autonômica, nem os aspectos cognitivos envolvidos na ansiedade ${ }^{(10-21)}$. O IDATE apresenta dois questionários independentes, ansiedade-traço e ansiedadeestado, os quais enfocam abordagens distintas de ansiedade, ou seja, são escalas utilizadas para medir conceitos subjetivos. O conceito de ansiedade traço é definido como propensão a ansiedade, isto é, a tendência do indivíduo perceber as situações como ameaçadoras, ou seja, como ele se sente geralmente. Mensura uma tendência de ação baseada na percepção de situações ameaçadoras. Neste estudo optou-se em não utilizar este conceito uma vez que em pesquisa realizada por Spielberger; Gorsush, Lushene $^{(10)}$, ao avaliarem a reação emocional de pacientes cirúrgicos encontraram escores altos para o estado de ansiedade, independente do traço de ansiedade dos mesmos. O estado de ansiedade é definido como intensidade dos sentimentos de ansiedade em um momento particular do tempo. O estado de ansiedade, segundo Andreatini,Leite ${ }^{(22)}$, seria transitório, caracterizado por sentimentos desagradáveis conscientemente percebidos, podendo modificar-se com o tempo e influenciado por fatores externos. Este 
questionário consta de 20 afirmações, onde o paciente indica a opção, através de uma escala de 4 pontos, que vai de 1 a 4 . O escore da escala de estado de ansiedade variará de 20 a 80 , sendo que os escores mais altos indicarão maior nível de ansiedade ${ }^{(10)}$

Nos itens $1,2,5,8,10,11,15,16,19,20$, da escala de estado de ansiedade, as pontuações devem ser invertidas. Ao invés de serem pontuadas de 0 a 4 , serão de 4 a 0 , devido ao conteúdo das afirmações, contidas no inventário, serem opostas às afirmações dos demais itens.

Dentre as escalas de medida de ansiedade, o IDATE é a mais utilizada, apesar de algumas dificuldades terem sido apresentadas durante a sua aplicação, como: dificuldade na interpretação da afirmação, as diferenças culturais dos pacientes entrevistados, o grau de cooperação dos mesmos e a veracidade das informações. Estas dificuldades também já foram apontadas por Spielberger ${ }^{(9)}$

Para avaliação dos escores obtidos, no inventário, foi feita a categorização utilizada por Chaves $^{(8)}$ :

- $20-40$ pontos = baixa ansiedade

- $40-60$ pontos = média ansiedade

- $60-80$ pontos $=$ alta ansiedade

Ao final de cada avaliação, obteve-se um escore referente ao estado de ansiedade.

Inventário de Coping (Anexo 7): Foi utilizado o inventário de estratégias de coping elaborado por Lazarus, Folkman ${ }^{(7)}$. É composto por 66 afirmações, que abordam pensamentos e ações que as pessoas utilizam para lidar com 
demandas internas ou externas de determinado evento estressante. Cada aplicação do questionário está centralizada no processo de enfrentamento, apenas de uma situação particular, vivida e não no enfrentamento como estilo ou traço de personalidade ${ }^{(7-23)}$. Existem outros instrumentos construídos para verificação das estratégias de enfrentamento, como o de Stone,Neal ${ }^{(23)}$ que abrange uma lista de 55 itens, incluíndo a descrição de como os sujeitos haviam lidado com a situação estressora; o de Lipp ${ }^{(24)}$ que agrupa, em seu inventário de controle de estresse, as estratégias de enfrentamento em 4 grupos: aspectos fisiológicos, sistemas de apoio, trabalho voluntário e habilidades interpessoais e de controle; e o de McCrae ${ }^{(25)}$, que desenvolveu um instrumento com 118 itens e dentre estes 66 itens são pertencentes ao inventário de Lazarus Folkman ${ }^{(7)}$, distribuídos em 28 categorias.

Aldwin $^{(26)}$, Cerqueira ${ }^{(27)}$, observando estes inventários sobre enfrentamento encontraram diferenças importantes quanto ao número de variáveis envolvidas, ao seu conteúdo, ao número de fatores, aoseu significado e à compreensão de enfrentamento como um estilo ou processo. Este fato decorre da origem dos inventários serem pautados em considerações empíricas, guiadas pela observação de possíveis comportamentos no ambiente, sem consenso científico no assunto. .

Diante desta situação optou-se em aplicar o inventário já referido anteriormente, proposto por Lazarus, Folkman ${ }^{(7)}$ uma vez que foi validado para a língua portuguesa, mesmo com as dificuldades apontadas durante a aplicação do questionário, como: certo grau de dificuldade no entendimento 
das questões, as diferenças culturais e lingüísticas entre os pacientes, a veracidade das respostas e o grau de cooperação do sujeito.

Apesar de validado para nosso idioma considerou-se pertinente a verificação da consistência interna, a partir dos 8 fatores propostos por Savóia ${ }^{(28)}$. Desta verificação surgiu um novo agrupamento, apresentado a seguir:

Fator 2 - afastamento (itens no: 41, 44, 21, 06, 16,10)

Fator 4 - suporte social (itens $\mathrm{n}^{0}: 42,45,08,31,22$ )

Fator 5 - aceitação de resposta (itens $\mathrm{n}$ o: $51,09,52,29,25,62$ )

Fator 6 - fuga-esquiva (itens $n^{\circ}$ : 58,59 )

Fator 7 - resolução de problemas (itens no: 49, 26, 46)

Fator 8 - reavaliação positiva (itens no: $38,56,60,30,20,63,23$ )

O teste realizado para a verificação da consistência interna será apresentado oportunamente no item referente ao tratamento estatístico, e justificará a eliminação do fator 1 , confronto, composto pelos itens 47,17 , 40, 34, 07e 28; e fator 3, auto-controle, formado pelos itens 15, 14, 43, 54 e 35.

Para a categorização, foi feita a comparação das pontuações relativas de cada fator, a que apresentou maior pontuação foi considerada como estratégia de enfrentamento mais utilizada, pelos indivíduos, no período préoperatório.

Para obtenção desta pontuação cada afirmação do inventário foi assim classificada:

Zero = não usei esta estratégia 
Um = usei um pouco

Dois = usei bastante

Três = usei em grande quantidade

Tratamento estatístico: Em uma primeira etapa do tratamento estatístico verificou-se a consistência interna (coeficiente de alfa ou alfa de Cronbach) do inventário de coping, validado por Savóia ${ }^{(28)}$

Entende-se por coeficiente de alfa ou alfa de Cronbach, um índice de confiabilidade que estima a coerência interna ou a homogeneidade de uma medida, composta por vários itens. E a consistência interna é um índice quantitativo, que costuma oscilar em valor de 0,00 a 1,00, que oferece uma estimativa de quanto confiável é um instrumento ${ }^{(29)}$.

Sendo assim agruparam-se as variáveis obedecendo à caracterização existente dos 8 fatores, utilizados por Savóia ${ }^{(28)}$ : fator 1: confronto; fator 2: afastamento; fator 3: autocontrole; fator 4: suporte social; fator 5: aceitação de responsabilidade; fator 6: fuga e esquiva; fator 7: resolução de problemas; fator 8: reavaliação positiva. Destes oito fatores obtive-se os respectivos alfas, apresentados na tabela 1 a seguir. 
Tabela 1 - Distribuição dos mecanismos de enfrentamento, obtidos pela análise de consistência interna. São Paulo, 2001.

\begin{tabular}{lc}
\hline Mecanismos de enfrentamento & Alpha de Cronbach \\
\hline Fator 1 - Confronto & 0,4366 \\
Fator 2 - Afastamento & 0,5326 \\
Fator 3 - Autocontrole & 0,3660 \\
Fator 4 - Suporte social & 0,7798 \\
Fator 5 - Aceitação respons. & 0,6057 \\
Fator 6 - Fuga e esquiva & 0,7262 \\
Fator 7 - Resolução de problemas & 0,4577 \\
Fator 8 - Reavaliação positiva & 0,8225 \\
\hline
\end{tabular}

Avaliando-se os alfas obtidos e processando alguns ajustes nas respostas a serem consideradas para o cálculo de cada fator, obtiveram-se os resultados apresentados na tabela 2.

Tabela 2 - Cálculo dos fatores, com ajustes nas respostas. São Paulo, 2001.

\begin{tabular}{lcc}
\hline Fator & Excluindo a resposta & Alpha de Cronbach \\
\hline Confronto & 47 & 0,4779 \\
Afastamento & 13 & 0,6000 \\
Autocontrole & 43 & 0,4945 \\
Suporte social & 18 & 0,7821 \\
Aceitação de responsabilidade & 48 & 0,6131 \\
Fuga e esquiva & - & 0,7262 \\
Resolução de problemas & 1 & 0,6489 \\
Reavaliação positiva & 36 & 0,8320 \\
\hline
\end{tabular}


Para que os fatores obtivessem os respectivos alfas de Cronbach apresentados acima, foi necessária a retirada de algumas respostas, sendo que no fator 1: confronto, retirou-se a resposta 47; no fator 2: afastamento retirou-se a resposta 13; no fator 3: autocontrole, retirou-se a resposta 43; no fator 4: suporte social, a resposta 18; no fator 5: aceitação de responsabilidade, a resposta 48; no fator 6 : fuga e esquiva, não houve a necessidade de retirada de resposta; no fator 7: resolução de problemas, retirou-se a resposta 1 e no fator 8: reavaliação positiva, houve a retirada da resposta 36 .

Observa-se na tabela 2, que os fatores 1: confronto e fator 3 : autocontrole apresentaram alfa abaixo de 0,60 , mesmo com exclusão das respostas 47 e 43 respectivamente para cada fator, assim sendo estes fatores não foram considerados nesse estudo. Com relação aos demais fatores obtive-se com a exclusão das respostas relacionadas acima uma mudança no alfa (alfa $=0,60$ ), referente ao fator 2 , afastamento quando excluiu-se a resposta 13 , o alfa de 0,5326 passou para 0,6000 ; no fator 4 , suporte social, quando retirou-se a resposta 18 , o alfa de 0,7798 passou para 0,7821 ; no fator 5 , aceitação de responsabilidade, quando retirada a resposta 48 , o alfa passou de 0,6057 para 0,6131 ; no fator 6 , fuga e esquiva, não foi necessária a exclusão de respostas; no fator 7 , resolução de problemas, na exclusão da resposta 1 , o alfa passou de 0,4577 para 0,6489 ; e no fator 8 , reavaliação positiva, quando excluiu-se a resposta 36 , o alfa passou de 0,8225 para 0,8320 . 
Dando continuidade ao tratamento estatístico, inseriram-se os dados em um banco para organização e análise. Estes serão apresentados em forma de tabela, diagramas e gráficos, em números absolutos e percentuais.

Para as variáveis quantitativas (idade, estado de ansiedade, fatores de enfrentamento) a análise foi feita pelos valores mínimos e máximos e pelo cálculo de médias, desvios-padrão e medianas.

Para as variáveis qualitativas (sexo, tipo de anestesia, cirurgia, intercorrências, escolaridade) calcularam-se as freqüências absolutas e relativas.

As relações entre as variáveis foram realizadas com os escores obtidos na avaliação do estado de ansiedade e com os escores obtidos nas estratégias de enfrentamento aplicando-se os testes não paramétricos da prova "U" de Mann-Whitney e o coeficiente de correlação de Spearman.

A prova "U" de Mann-Whitney foi utilizada na comparação dos grupos considerados independentes. A opção por esta técnica se deve ao fato dos escores de enfrentamento não apresentarem uma distribuição normal ${ }^{(31) .}$

O coeficiente de correlação de Spearman ( $r$ de Pearson) é uma medida útil para mensurações do tipo ordinal e permite prova de relação entre às variáveis estado de ansiedade e as estratégias de enfrentamento. Utilizou-se o método de Spearman para verificar a correlação entre estas variáveis.

Coeficientes de correlação ( $r$ de Pearson) negativos, que vão de 0,00 a $-1,00$, expressam aquilo que é conhecido como relação negativa ou inversa, ou seja quando duas variáveis estão inversamente relacionadas, os 
incrementos em uma das variáveis são associados às reduções na segunda variável. Deve ser observado que quanto mais elevado o valor absoluto do coeficiente (independente do sinal), maior a relação ${ }^{(29) .}$

Tanto a prova de Mann-Whitney como o coeficiente de correlação de Spearman, o nível de significância utilizado foi de 5\%.

\section{Resultados e Discussão:}

\section{Caracterização da amostra}

Participaram deste estudo 40 pacientes, submetidos a cirurgias eletivas, sendo 25 (62 \%) mulheres e 15 (38\%) homens, a maioria da amostra foi constituída por mulheres submetidas a cirurgias de pequeno e médio porte(ginecológicas e os de vias biliares).

Gráfico 6 - Distribuição dos pacientes cirúrgicos, segundo a faixa etária. São Paulo, 2001.

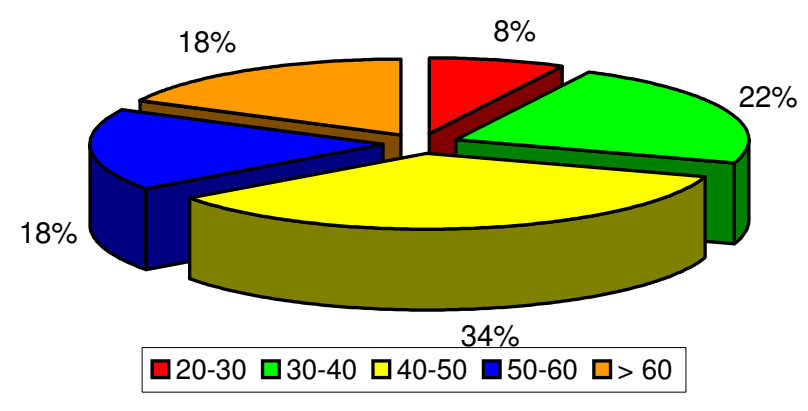

Com relação a faixa etária a amostra ficou assim distribuída: entre 2030 anos, 3 (8\%) pacientes; na faixa etária de 30-40 anos, 9 (22\%) pacientes; enquanto $14(34 \%)$ pacientes pertenceram à faixa etária de 40-50 anos; 7 
(18\%) pacientes entre $50-60$ anos e 7 (18\%) pertenceram à faixa acima dos 60 anos. Esta distribuição caracterizou uma amostra composta por indivíduos adultos com uma média de 46 anos $(\mathrm{DP}=11.24)$. Este resultado pode estar relacionado a uma maioria feminina que a compõe a amostra, uma vez que é nesta faixa etária que se iniciam os programas de controle e prevenção do câncer, sendo a cirurgia o tratamento curativo de escolha.

Gráfico 7 - Distribuição dos pacientes cirúrgicos, segundo grau de escolaridade. São Paulo, 2001.

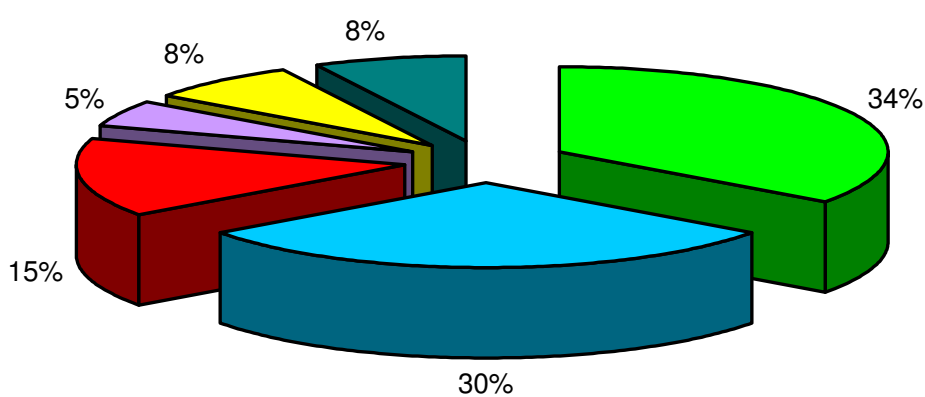

$\square$ primário completo $\square$ médio incompl. $\square$ médio completo
$\square$ superior incompl. $\square$ superior completo $\square$ pós graduação

Dos pacientes que compuseram a amostra $14(34 \%)$ tem o ensino fundamental completo; $12(30 \%)$ dos pacientes, o ensino médio incompleto; $6(15 \%)$ pacientes com ensino médio completo; enquanto $2(5 \%)$ pacientes o ensino superior incompleto e 3(8\%) o ensino superior completo, e com curso de pós-graduação somente 3(8\%) pacientes. Estes dados caracterizam uma amostra com baixo grau de escolaridade. $O$ fato de este hospital estar 
inserido em uma região carente da região de São Paulo, contribuiu para maior incidência de baixos níveis educacionais da amostra.

Gráfico 8 - Distribuição dos pacientes cirúrgicos, segundo experiências cirúrgicas anteriores. São Paulo, 2001.

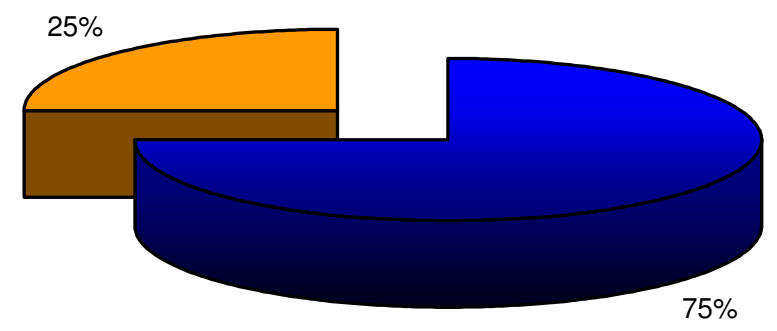

$\square \operatorname{sim}$ ロnão

Com relação às cirurgias anteriores, 10 (25\%) dos pacientes nunca se submeteram ao procedimento anestésico-cirúrgico anteriormente e 30 (75\%) dos pacientes tinham sofrido algum tipo de intervenção cirúrgica, o que resulta em um número representativo de pacientes com experiência prévia em relação a exposição ao estresse, aqui considerado o procedimento anestésico-cirúrgico e todas as suas implicações. Este fato pode influenciar na avaliação da situação e nas estratégias de enfrentamento utilizadas por esses pacientes.

Segundo Dally; Harrington ${ }^{(30)}$, quando se evoca um fato, ativando a memória, há um desencadeamento de respostas modificando o estado emocional, que vai depender das emoções guardadas e resgatadas pela lembrança. $\mathrm{Na}$ amostra estudada observou-se que $75 \%$ dos pacientes 
tiveram uma experiência cirúrgica anterior, armazenada em suas memórias, com isto pressupõe-se que as respostas à situação atual devem estar impregnadas pelas experiências anteriores, o que poderá influenciar no estado emocional, como também na avaliação e construção de estratégias de enfrentamento atuais, modulando a reação emocional, e conseqüentemente o estado de ansiedade.

Gráfico 9 - Distribuição dos pacientes cirúrgicos, segundo intercorrências apresentadas em cirurgias anteriores. São Paulo, 2001.

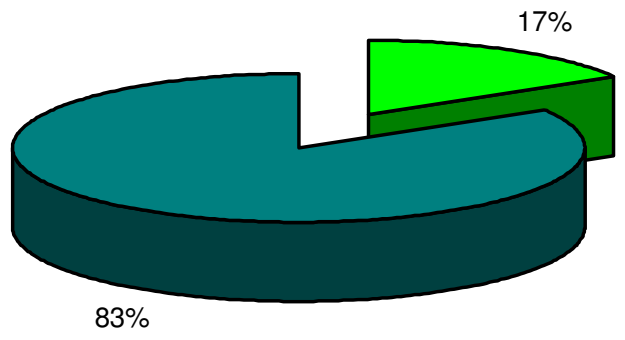

$\square \operatorname{sim} \square$ não

Dos 30(100\%) pacientes com experiência prévia, 25(83\%) relataram não apresentar intercorrências no procedimento cirúrgico realizado anteriormente, apenas 5(17\%) apresentaram alguma, dentre elas: queimadura e convulsões no intra-operatório, inconsciência por 24hs após a cirurgia, hemorragia, hipertensão e hipotensão no pós-operatório imediato. Não se pode desconsiderar a gravidade das mesmas e a influência que exercerão na reavaliação, feita pelo paciente, deste novo encontro como ameaçador. 
Segundo Lazarus;Folkman ${ }^{(7)}$, apesar das implicações negativas, a ameaça permite um enfrentamento antecipado, possibilitando o planejamento com o propósito de vencer as dificuldades. E ainda se o indivíduo deseja vencer essa situação, avaliando-a como um desafio, haverá a mobilização de esforços de enfrentamento associado à vitória, envolvendo emoções positivas como excitação, esperança e confiança. Tais pacientes, embora em número reduzido, devem ser considerados, uma vez que, devido à experiência prévia vivida, os mesmos foram levados a utilizarem diversas estratégias de enfrentamento e com isso ter seu o grau de ansiedade alterado.

Sendo assim a realização de uma outra cirurgia pode desencadear, dependendo da subjetividade do paciente, um misto de emoções gerando confiança e esperança de tratamento e cura, ou insegurança e desesperança.

Gráfico 10 - Distribuição dos pacientes cirúrgicos, segundo tipo de cirurgia realizada. São Paulo, 2001.

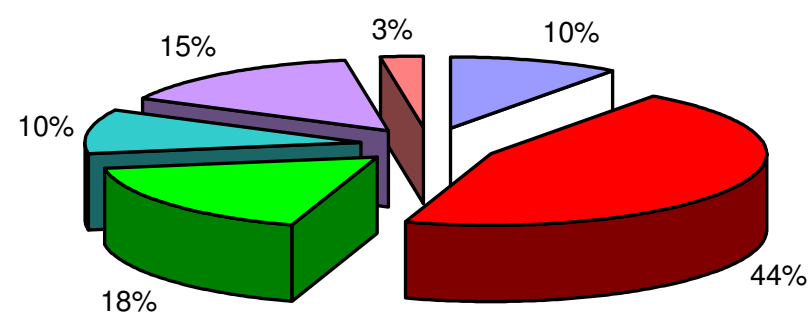


Observa-se que os $40(100 \%)$ pacientes que compuseram a amostra, submeteram-se a cirurgias de médio porte, ou seja, 18(44\%) pacientes à cirurgia geral; 7(18\%) pacientes à cirurgia ginecológica ; 6(15\%) pacientes à cirurgia urológica; 4(10\%) pacientes foram submetidos à cirurgia de cabeça e pescoço; 4(10\%) pacientes à cirurgia ortopédica; e 1(3\%) paciente submeteu-se à cirurgia plástica. Dentre as cirurgias de médio porte existiu uma maior concentração de pacientes submetidos ao grupo denominado de geral, ou seja, de hemorroidectomia, colecistectomias convencional e laparoscópica, fissurectomias, fistulectomias, hernioplastias, ressecção de cisto pilonidal, ressutura de deiscência.

Independente do porte cirúrgico considera-se que a mesma exige do paciente uma resposta adaptativa com a mobilização dos mecanismos protetores do corpo não só somáticos como também psíquicos.

Gráfico 11 - Distribuição dos pacientes cirúrgicos, segundo tipo de anestesia realizada. São Paulo, 2001.

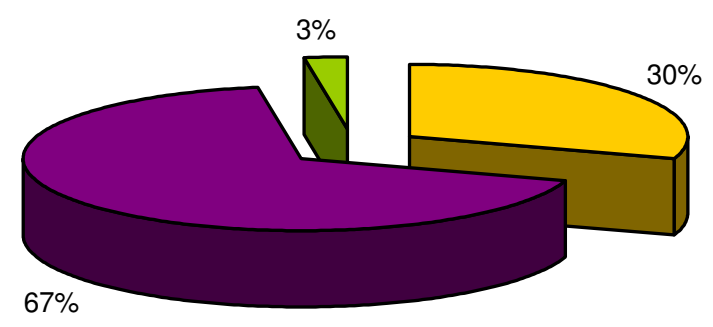

$\square$ geral $\square$ bloqueio $\square$ local

Os dados do gráfico mostram que 12(30\%) pacientes realizaram anestesia geral e $28(70 \%)$ pacientes submetidos a bloqueio 
anestésico regional, fazendo parte deste grupo àqueles submetidos à epidural e subaracnóidea. Esta maior proporção, de anestesia regional, pode estar relacionada ao tipo de cirurgia realizada, pois as cirurgias ginecológicas (7), ortopédicas (4), urológicas (6) e das 18 gerais (10) foram responsáveis pelo maior número de bloqueios.

A escolha por um ou outro tipo de anestesia fica a critério do cirurgião, do paciente e do anestesiologista e depende das condições físicas e fisiológicas do paciente, se tem algum tipo de patologia que contra-indique o tipo de anestesia, como: infecção, hérnia de disco, distúrbios de coagulação, condições psicológicas e o procedimento cirúrgico a ser realizado, o tempo e o tipo de cirurgia, o regime ambulatorial ou de internação ${ }^{(31,32)}$. Alguns pacientes não se sentem confortáveis ao saber que permanecerão acordados durante o ato cirúrgico, assim o anestesiologista associa a técnica escolhida à necessidade emocional do paciente.

Os bloqueios anestésicos subaracnóideo e epidural estão bem indicados quando oferecem ótima qualidade anestésica sem efeitos adversos para o paciente ${ }^{(35)}$. Quando se decide entre uma técnica ou outra, deve-se levar em consideração o tempo de cirurgia e o uso de técnica contínua ou não. Se o procedimento for curto e se deseja início mais rápido, é mais propício um bloqueio subaracnóideo. Se o procedimento requer maior analgesia pós-operatória, a epidural contínua é indicada. As mais importantes contra-indicações para os bloqueios são: a recusa do paciente, impossibilidade de posicioná-lo para a punção e o aumento da pressão 
intracraniana, coagulopatias, infecções dermatológicas, hipovolemia e doenças neurológicas préexistentes ${ }^{(33,34)}$.

Com relação à anestesia endovenosa, esta determina maior estabilidade hemodinâmica e reduz a atividade do SNC, diminuindo a atividade cognitiva, reduzindo assim, a ansiedade, além da analgesia pósoperatória proporcionada pela infusão de opióides durante 0 procedimento $^{(35)}$. Apesar de todos os pacientes da amostra terem sido avaliados antes mesmo da administração da medicação pré-anestésica, julgou-se necessária esta discussão uma vez que se tem, em estudo realizado por Mitchell ${ }^{(36)}$, em um serviço de cirurgia ambulatorial, que o procedimento anestésico associado à espera na unidade pelo procedimento, a possibilidade de dor e desconforto são aspectos que aumentaram a ansiedade, no período pré-operatório. Dessa maneira os pacientes, ao responderem os questionários, nesse período, poderiam ter seu estado emocional alterado em decorrência das dúvidas e incertezas relacionadas não só ao procedimento cirúrgico, mas também à anestesia. 
Gráfico 12 - Caracterização da amostra segundo o escore do estado de ansiedade. São Paulo, 2001.

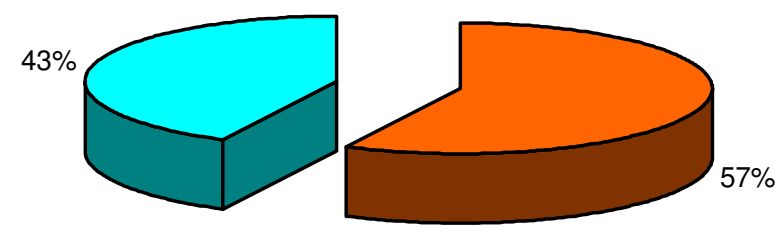

$\square$ baixa $\square$ media

Com relação ao escore estado de ansiedade, o GRÁFICO 12 mostra que $23(57 \%)$ dos pacientes apresentam baixo estado de ansiedade e $17(43 \%)$ médio estado de ansiedade, o que caracteriza uma amostra, em sua maioria, pouco ansiosa, com relação ao evento anestésico-cirúrgico, apresentando uma média de 38.02 ( $d . p=9.7$ ) e mediana de 36 , composta em sua maioria. por mulheres.

Alguns estudos indicam as mulheres responsáveis pelo aumento da ansiedade da amostra estudada. Ortenzi ${ }^{(32)}$, aponta que a ansiedade é maior em mulheres, principalmente naquelas consideradas obesas (acima de $70 \mathrm{~kg}$ ) e naquelas que nunca se submeteram a uma anestesia.

Para Molina ${ }^{(37)}$ a mulher é mais vulnerável à ação das catecolaminas como resultado de estresse agudo ou crônico.

Embora Peniche ${ }^{(38)}$ tenha encontrado um aumento de ansiedade nas mulheres, constatou que elas responderam positivamente, 
quando expostas à cirurgia, o que refletiu na diferença entre traço e o estado de ansiedade quando comparadas aos homens.

Estudo feito por Martin ${ }^{(39)}$, em pacientes cirúrgicos, mostrou que as mulheres apresentaram alteração maior no estado de ansiedade do que os homens, o que poderia estar relacionado ao fato de elas terem se submetido a cirurgias que mudaram a sua auto-imagem.

Enfim não há um consenso se a ansiedade está relacionada ou não ao sexo. Acredita-se que a amostra ter se apresentado, em sua maioria, como sendo de baixa ansiedade, pode ser justificado, talvez pelas estratégias de enfrentamento que utilizaram ou por razões associadas à resposta do questionário como, problemas de compreensão do mesmo, diferenças culturais dos pacientes e a veracidade das informações.

Em estudo feito por Spielberger ${ }^{(9)}$, que avaliou a reação emocional dos pacientes submetidos à cirurgia, o autor chamou a atenção para a ansiedade inconsciente não detectada por vários testes. Observou que a ansiedade, apesar de estar presente, não era detectada, levando a uma falsa avaliação.

Apesar de a amostra estudada se apresentar em sua maioria como pouco ansiosa, obteve-se um número representativo, 17 (43\%) de pacientes com média ansiedade Segundo Cade ${ }^{(40)}$, a ansiedade média apresentada tende a ser benéfica para o paciente, pois faz com que haja uma ativação de comportamento e motivação, tendo um resultado mais efetivo na avaliação da situação e na construção das estratégias de enfrentamento. 
Outra suposição a ser considerada, na tentativa de compreender os respectivos resultados obtidos se refere à forma estruturada de orientação pré-operatória (SAEP), implantada no hospital e que permite aos pacientes receberem orientações relacionadas ao ato anestésico-cirúrgico e aos períodos pré e pós-operatório, além da estrutura física da Unidade facilitar o convívio com outros pacientes, o que possibilita compartilhar as emoções do momento, buscando ou trocando informações.

Embora não tenha sido objetivo deste estudo é provável que estes pacientes possuam traço de ansiedade baixo e médio, o que os levem a responder com um estado de ansiedade também baixo e médio, pois, percebem as situações como algo menos complexo, com menores possibilidades de danos. Os resultados obtidos vão contra o estudo feito por Spielberger, Gorsuch, Lushene, ${ }^{(10)}$ em que a correlação entre traço-estado de ansiedade é maior quando envolve ameaça de auto-estima ou quando a pessoa percebe ser avaliada em sua capacidade, em situações onde há perigo real de acontecer.

Outra suposição é que estes pacientes podem apresentar estratégias de enfrentamento que não exijam confronto e autocontrole para lidar com a situação em questão, gerando menos tensão e ansiedade, apresentando comportamentos passivos ou se utilizem de estratégias eficientes para confrontar o problema

Segundo Kaplan;Sadock ${ }^{(41)}$, entre as muitas estratégias de enfrentamento existentes, o que determina sua eleição é a natureza do estressor, as circunstâncias em que ele se reproduz, a história prévia de 
confronto e pelo próprio estilo que caracteriza o sujeito, ou seja, como ele enfrentou situações passadas. Há dois tipos básicos de indivíduos, aqueles que tem tendência evitadora ou minimizadora e aquelas com estilo afrontativo ou vigilante. Estes pacientes apresentarão reações que levarão a uma ação. Esta ação pode ser construtiva e neste caso, a pessoa usa mecanismos de enfrentamento, se a ação é principalmente consciente ou deliberada; ou mecanismos de defesa, se o comportamento é determinado por forças inconscientes.

Tabela 3 - Distribuição das estratégias de enfrentamento. São Paulo, 2001.

\begin{tabular}{lcccccc}
\hline Variáveis & $\mathbf{N}$ & Média & d.p. & Mediana & Mínimo & Máximo \\
\hline Fator 2 & 40 & 0.67 & 0.50 & 0.67 & 0 & 2.17 \\
Fator 4 & 40 & 1.63 & 0.81 & 1.80 & 0 & 2.80 \\
Fator 5 & 40 & 0.77 & 0.53 & 0.57 & 0 & 1.86 \\
Fator 6 & 40 & 1.26 & 0.96 & 1.00 & 0 & 3.00 \\
Fator 7 & 40 & 1.75 & 0.88 & 1.83 & 0 & 3.00 \\
Fator 8 & 40 & 1.12 & 0.67 & 1.11 & 0.11 & 2.44 \\
\hline
\end{tabular}

Os dados da tabela 3 mostram, que as estratégias mais utilizados foram o fator 4 ( suporte social), com uma média de 1,63 ( $d p=0,81$ ), que pode estar relacionado ao suporte encontrado no ambiente ou nas pessoas e a resolução de problemas ( fator 7 ), com uma média de $1,75(\mathrm{dp}=0,88$ ), que descreve comportamentos que levam a pessoa a lidar com o estresse de maneira mais efetiva e adaptada, voltada a uma resolução.

Segundo Lazarus, Folkman, ${ }^{(7)}$ estes pacientes utilizaram estratégias de enfrentamento centradas no problema, onde a preocupação maior está 
na resolução do mesmo, escolhendo uma ação. São estratégias voltadas para a realidade, sendo mais adaptativas, capazes de modificar as pressões ambientais, diminuindo ou eliminando a fonte de estresse. Embora a estratégia suporte social, supostamente, tenha função emocional, não se pode afirmar que a escolha dessa estratégia resulte na conseqüência específica da emoção,

Segundo Cade $^{(40)}$, há vários estudos que tentam desvendar as estratégias mais comumente utilizadas, tanto em situações específicas, como em situações gerais, porém os resultados são difíceis de ser generalizados, por causa da diferença nas amostras populacionais das situações estudadas e nos instrumentos utilizados para verificação das estratégias, os quais categorizam as estratégias de enfrentamento de distintas formas.

Para alguns pesquisadores, quanto maior o repertório de estratégias de enfrentamento, maior a possibilidade de resposta efetiva frente à demanda vivenciada ${ }^{(42)}$.

De acordo com o modelo interacionista cognitivo de Lazarus,Folkman, (7), há variáveis situacionais, pessoais ou cognitivas e externas implicadas no processo de enfrentamento.

O enfrentamento é determinado por várias condicionantes, dentre elas estão: as características da situação, quanto à sua magnitude e controle da mesma; qualidade e quantidade da ameaça percebida; possibilidade de opções para resolver a situação; observação de como os resultados são 
vislumbrados; recursos utilizados e barreiras encontradas para utilização destes recursos de ${ }^{(7)}$.

Esses condicionantes, por sua vez, estão atrelados ao processo cognitivo, constituído pelas crenças, que podem ser positivas, funcionando como uma maneira de enfrentamento, ou negativa, podendo bloqueá-la, pelos valores, pela memória de situações vividas, pela visão de si mesmo e do mundo. Estas estruturas cognitivas expressam as experiências de vida, direcionam as escolhas de ação de forma subjetiva e são menos vulneráveis às mudanças. Desencadeiam diferentes emoções de acordo com a avaliação emitida, inter-relacionando cognição e emoção na escolha de um comportamento de enfrentamento ${ }^{(43)}$.

\section{Comparação entre as variáveis estado de ansiedade e estratégias de} enfrentamento.

Uma vez que a amostra não apresentou uma distribuição homogênea relacionada às estratégias de enfrentamento, entre os grupos de baixa e média ansiedade, considerou-se pertinente aplicar o teste de Mann Whitney com a finalidade de se comparar estes dois grupos. 
TABELA 4 - Distribuição dos pacientes segundo associação do estado de ansiedade e estratégias de enfrentamento (fatores). São Paulo, 2001.

\begin{tabular}{ccccccccc}
\hline Fator & Ansiedade & $\mathbf{N}$ & Média & d.p. & Mediana & Mínimo & Máximo & $\mathbf{P}^{*}$ \\
\hline $\mathbf{2} 2$ & Baixa & 23 & 0,48 & 0,39 & 0,50 & 0,17 & 1,33 & $\mathbf{0 , 0 1 1 2}$ \\
& Média & 17 & 0,92 & 0,54 & 0,83 & & 2,17 & \\
\hline \multirow{2}{*}{$\mathbf{4}$} & Baixa & 23 & 1,76 & 0,82 & 1,80 & & 2,80 & 0,2064 \\
& Média & 17 & 1,44 & 0,79 & 1,40 & 0,20 & 2,80 & \\
\hline \multirow{2}{*}{$\mathbf{5}$} & Baixa & 23 & 0,71 & 0,49 & 0,57 & & 1,71 & 0,5632 \\
& Média & 17 & 0,84 & 0,58 & 0,57 & 0,14 & 1,86 & \\
\hline \multirow{2}{*}{$\mathbf{6}$} & Baixa & 23 & 1,15 & 1,04 & 1,00 & 0 & 3,00 & 0,3324 \\
& Média & 17 & 1,41 & 0,85 & 1,50 & 0 & 2,50 & \\
\hline \multirow{2}{*}{} & Baixa & 23 & 1,89 & 0,97 & 2,00 & 0 & 3,00 & 0,1591 \\
& Média & 17 & 1,54 & 0,73 & 1,67 & 0 & 2,67 & \\
\hline \multirow{2}{*}{$\mathbf{2}$} & Baixa & 23 & 1,03 & 0,68 & 1,00 & 0,11 & 2,33 & 0,3171 \\
& Média & 17 & 1,24 & 0,66 & 1,33 & 0,33 & 2,44 & \\
\hline
\end{tabular}

* nível descritivo do teste não-paramétrico de Mann-Whitney $(p<0,05)$.

Observa-se que há uma diferença significante entre os valores do fator 2 (afastamento) em relação aos grupos de ansiedade $(p=0,0112)$. Os pacientes com ansiedade média apresentaram valores significantemente maiores que os dos pacientes com ansiedade baixa, ou seja, os pacientes com média ansiedade se utilizaram mais do fator 2 (afastamento) como estratégia de enfrentamento. Analisando as questões que compõem este fator, elas mostram um comportamento mais defensivo, ou seja, não têm o objetivo de eliminar o problema.

Segundo Lazarus,Folkman ${ }^{(7)}$ tal estratégia de enfrentamento está centrada na emoção, pois correspondem a estratégias defensivas, em que o indivíduo evita confrontar-se com a ameaça não modificando a situação. 
Ainda segundo estes mesmos autores este tipo de enfrentamento pode ser considerado como um processo de reavaliação cognitiva, em que o indivíduo realiza manobras cognitivas (fuga, afastamento) com a finalidade de mudar o significado da situação vivida, não importando-se de forma realista ou com distorção da realidade.

Os resultados encontrados confirmam a retirada dos itens referentes ao fator 1 ( confronto) e fator 3 (autocontrole) ao se realizar a consistência interna do inventário para a amostra estudada.

Quanto aos demais fatores, observou-se que não houve uma diferença significante $(p>0,05)$ entre estes em relação aos grupos de ansiedade.

\section{Relação entre as variáveis estado de ansiedade e estratégias de enfrentamento estado de ansiedade e estratégias de enfrentamento}

Na figura abaixo há uma tendência significante positiva ( $p=0,0655$ e $r=0,2941$ ) entre a estratégia de enfrentamento de afastamento (fator 2) e o estado de ansiedade. Significa dizer que, aumentando a ansiedade o indivíduo se utiliza do afastamento como estratégia de enfrentamento. $\mathrm{O}$ afastamento implica um comportamento mais defensivo, sem o intuito de enfrentar o problema.

Ainda com relação a figura não houve correlação significativa entre ansiedade e estratégias de enfrentamento, aceitação de responsabilidade fator 5) com $r=0,013$ e $p=0,9366$; fuga e esquiva( fator 6 ) com $r=0,0105$ e $p=0,9487$; e a reavalição positiva (fator 8 ) com $r=0,054$ e $p=0,7407$. Porém as estratégias de suporte social (fator 4) com $r=-0,3123$ e $p=0,0498$; e 
resolução de problemas( fator 7) com $r=-0,405$ e $p=0,0095$, apresentaram uma correlação significante negativa entre o estado de ansiedade e o fator 4 (suporte social) e estado de ansiedade e fator 7 ( resolução de problemas), isto é, quanto menor a ansiedade maior a utilização do suporte social e a resolução de problemas como estratégias de enfrentamento.

Para Lazarus; Folkman ${ }^{(7)}$ a comunicação efetiva e o comportamento são facilitadores na formação de vínculos consistentes e aumentam a possibilidade de o indivíduo pedir suporte em situações estressantes. Provavelmente, foi esta a situação vivenciada pela maioria dos componentes da amostra deste estudo como a maioria dos pacientes (23) associado ao baixo estado de ansiedade

A utilização da estratégia de enfrentamento justifica a correlação entre a a diminuição do estado de ansiedade e a habilidade de resolução de problemas, pois inclui a interação social para a obtenção de informações e recursos.

Os pacientes deste estudo parecem se favorecer da filosofia da assistência de enfermagem perioperatória, que facilita a interação com o ambiente e com os profissionais, na busca de informações relativas ao procedimento anestésico cirúrgico. 
Figura - Correlações entre estado de ansiedade e as estratégias de enfrentamento (fatores). São Paulo, 2001
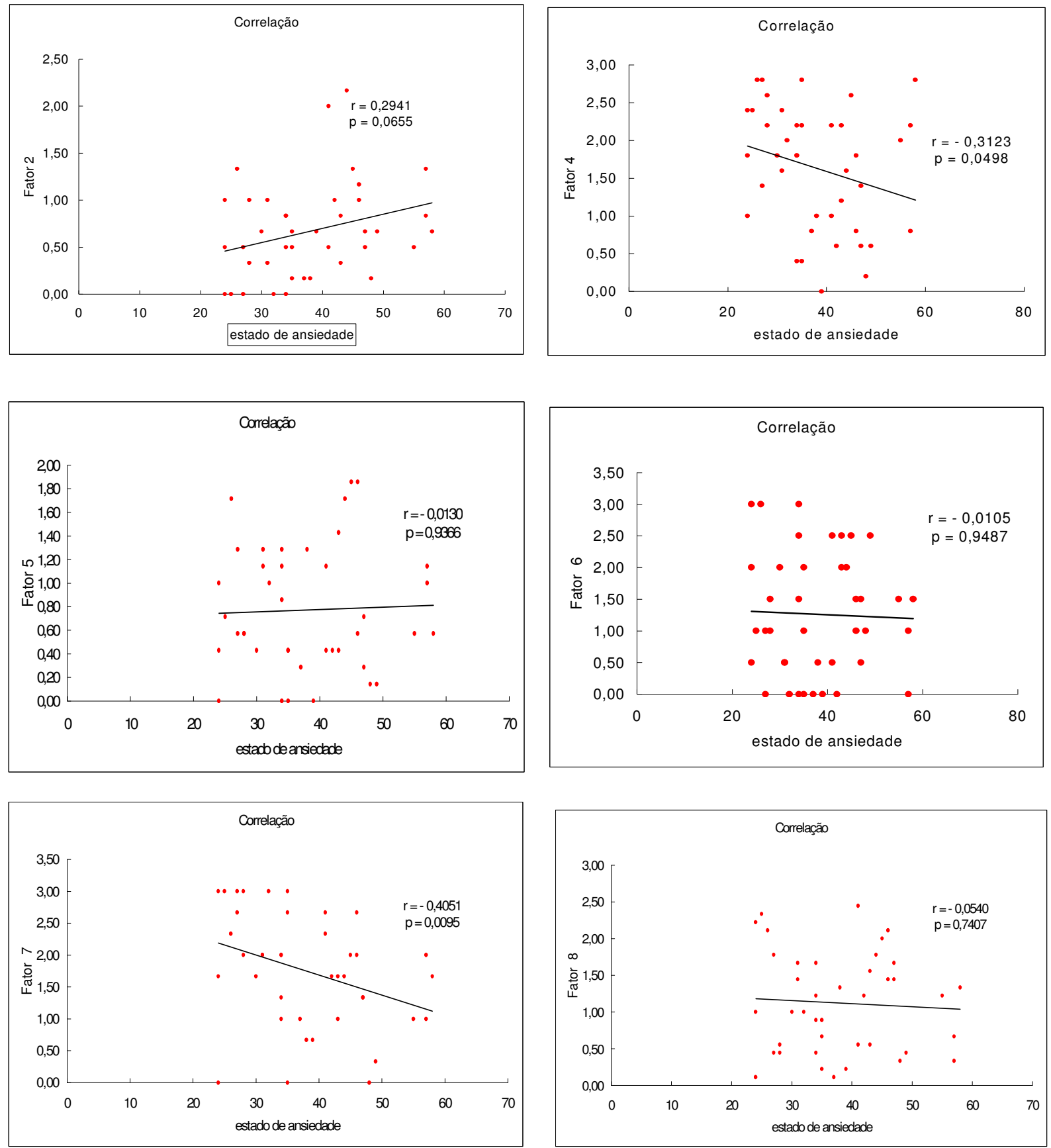

Os resultados do protocolo 2 apontam para uma:

A amostra composta em sua maioria por pacientes do sexo feminino 
com uma idade média de 46 anos, com baixo grau de escolaridade, com experiência cirúrgica anterior, sem intercorrências e apresentando baixo e médio estado de ansiedade.

As estratégias de enfrentamento mais comumente utilizadas foram as de suporte social e a de resolução de problemas.

Com relação à ansiedade e às estratégias de enfrentamento, obtevese uma correlação negativa entre o estado de ansiedade e o suporte social e estado de ansiedade e resolução de problemas, isto é, quanto menor o estado de ansiedade mais os pacientes se utilizaram das estratégias de suporte social e da resolução de problemas.. 
PROTOCOLO 3 


\title{
PROTOCOLO 3
}

\section{ANSIEDADE DO PACIENTE NO PERÍODO PRÉ- OPERATÓRIO DE REVASCULARIZAÇÃO DO MIOCÁRDIO COMO FATOR DE RISCO DE INFECÇÃO .}

\author{
Silva, M de F, Peniche, ACG
}

\section{Objetivos}

Identificar, no período pré-operatório, o estado de ansiedade de pacientes com indicação de revascularização do miocárdio;

Verificar a ocorrência de infecção do sítio cirúrgico nos pacientes submetidos à revascularização do miocárdio;

Relacionar estado de ansiedade no período pré-operatório e ocorrência de infecção no sítio cirúrgico no período pós-operatório.

\section{Material e método:}

A pesquisa foi realizada na enfermaria de coronária do Instituto Dante Pazzanese de Cardiologia, (IDPC). Hospital, pertencente à Secretaria de Estado da Saúde do Estado de São Paulo, com 245 leitos, especializado no atendimento a indivíduos portadores de doenças cardiovasculares.

Critérios de Inclusão da amostra: O cálculo do tamanho da amostra baseou-se na proporção dos pacientes infectados, precisão da estimativa e nível de significância. Sendo assim para se manter um nível de significância de $5,0 \%$ e uma precisão absoluta de 5,0\% foi preciso uma amostra mínima de pacientes submetidos ao procedimento cirúrgico de revascularização do 
miocárdio. Portanto, fizeram parte da amostra 127 pacientes que obedeceram aos seguintes critérios de inclusão : ter assinado o termo de consentimento livre e esclarecido para pesquisa;Ter indicação de revascularização do miocárdio;Não fazer uso de ansiolítico no momento de aplicação do questionário auto- aplicável ( Anexo 8) ;Não apresentar infecção prévia ou suspeita de infecção;Não ter diagnóstico de doença psiquiátrica e neoplásicas; Estado nutricional , com índice de massa corpórea de 20 a $40 \%$ proposto por Blackbur; Bistrian ${ }^{(44)}$. Estar consciente e orientado; Ser submetido ao procedimento de revascularização do miocárdio por uma única equipe cirúrgica.

Procedimento de coleta de dados: Após a tramitação, apreciação e aprovação da pesquisa pela Comissão de Ética, ( $n^{\circ}$ do protocolo NOCE3.012/2001), a pesquisadora entrou em contato com os pacientes escolhidos, 12 horas antes do procedimento cirúrgico, solicitando seu consentimento na participação, por meio da assinatura do Termo de Consentimento Livre e Esclarecido. O procedimento visou atender aos dispositivos da Resolução 196/96 do Conselho Nacional de Saúde, que regulamenta os aspectos éticos de pesquisas, envolvendo seres humanos.

No contato com os pacientes cirúrgicos, que preenchiam os critérios de seleção da amostra, estes foram informados sobre a finalidade da pesquisa, da participação voluntária e da garantia de anonimato.

Foram realizadas entrevistas com os pacientes em ambiente tranqüilo, de preferência quando estivessem sós. $\mathrm{Na}$ oportunidade, 
colheram-se dados necessários para se obter os objetivos da pesquisa. Estes dados foram colhidos em duas fases:

\section{Primeira fase:}

Realizada na enfermaria até 12 horas antes da realização do ato cirúrgico, os pacientes foram questionados quanto aos dados demográficos contidos no formulário 1( parte1- Anexo 8). A seguir, era solicitado após esclarecimentos quanto ao preenchimento, que respondessem ao questionário auto-aplicável (parte 2- Anexo 8). Este é conhecido como questionário de ansiedade-estado apresentou o objetivo de identificar a ansiedade do paciente cirúrgico no período pré-operatório.

\section{Segunda fase:}

Realizada com o propósito de identificar a infecção do sítio cirúrgico após a cirurgia. Feito acompanhamento do paciente durante 25 dias de pósoperatório, obedecendo assim aos critérios adotados pela comissão de controle de infecção hospitalar da instituição. Para esta fase, utilizou-se o formulário 2 (Anexo 13) também composto por duas partes (l e II) referentes a dados pertinentes ao período intra-operatório e ao período pósoperatório respectivamente.

\section{Instrumentos}

\section{Formulário 1 (Anexo 8)}

Parte I: refere-se aos dados demográficos e fisiopatológicos como: nome, $\mathrm{n}^{\circ}$ de registro, idade, sexo, escolaridade, peso, altura, data de internação, tempo de doença coronariana, patologias preexistentes 
Parte II: refere-se ao questionário auto-aplicável para avaliação do estado de ansiedade e é parte integrante de um inventário conhecido como IDATE.

O IDATE é composto por dois questionários: um se refere ao traço e outro ao estado de ansiedade. Tem como objetivos medir respectivamente a propensão à ansiedade, isto é, a tendência do indivíduo perceber as situações como ameaçadoras e o estado transitório caracterizado por sentimentos desagradáveis, conseqüentemente, percebidos e modificandose com o tempo, sendo influenciados por fatores externos. Foram traduzidos e validados por Biaggio et al $^{(45)}$.

Embora Spielberger, Gorsuch, Lushene ${ }^{(10)}$, considerem que os indivíduos com capacidade de leitura estejam aptos a responder o inventário sem grandes problemas, várias dificuldades são apontadas em sua aplicação como, por exemplo, o grau de cooperação do indivíduo, a veracidade das informações e as diferenças culturais e lingüísticas entre os indivíduos, mesmo assim optou-se por utilizá-lo, visto que dentre as escalas de medidas de ansiedade, o IDATE continua sendo a de maior utilização, pela aplicabilidade em diversas pesquisas na área da saúde, incluindo aquelas com os pacientes cirúrgicos ${ }^{(8-21-22-38-46)}$.

Nesta pesquisa, optou-se por aplicar somente parte desse inventário ou seja, o questionário referente ao estado de ansiedade. Esta decisão foi pautada em pesquisa realizada por Spielberger, Gorsuch, Lushene ${ }^{(10)}$, que avaliando a reação emocional de homens submetidos à cirurgia, encontrou escores baixos e médios para estado de ansiedade, independente do traço 
de ansiedade dos mesmos. Concluíram com estes resultados obtidos que o ato cirúrgico elevou o estado de ansiedade da população do estudo em níveis altos e semelhantes, independentes do traço de ansiedade identificado.

O questionário referente ao estado de ansiedade consta de 20 afirmações. O sujeito assinala a intensidade com que as mesmas acontecem, isto é, avalia a situação marcando as alternativas: "não", "um pouco", "bastante" ou "totalmente".

Para categorização dos pacientes, optou-se por agrupá-los de acordo com as respostas dadas para cada afirmação (Anexos 9 e 10), isto é,

Grupo 1: pacientes com baixa ansiedade aqueles que escolheram como resposta característica "totalmente" aos itens 1, 2, 5, 8, 10, 11, 15, 16 , 19, 20, formando um grupo de baixa ansiedade.

Grupo 2: pertencente ao grupo média ansiedade, estão aqueles pacientes que tiveram como resposta característica "bastante", nestes mesmos itens citados anteriormente.

Grupo 3: os grupo de pacientes com alta ansiedade, foi considerado aquele que teve como resposta característica "um pouco" e "não" nos itens já referidos acima.

\section{Formulário 2 (Anexo 11)}

Este formulário contém duas partes (I e II ). Parte I : refere-se aos dados do paciente pertinentes a período intra-operatório, ou seja, início da cirurgia, tempo de intubação, tempo de circulação extracorpórea, tempo de cirurgia e intercorrências. Parte II: refere-se ao paciente já no pós- 
operatório, onde foi observada a sua evolução nesse período e conseqüentemente, a presença ou não de infecção. Para tanto, foram considerados os sinais indicativos de infecção utilizados pela instituição, ou seja, temperatura, dor, hiperemia local, presença de secreção, aspecto da mesma, especificações sobre o local da infecção do sítio cirúrgico.

Tais informações foram julgadas necessárias, uma vez que diversos autores ${ }^{(47,48)}$ preconizam que, na presença de sinais clínicos, instala-se a infecção do sítio cirúrgico.

Tratamento estatístico: Para análise dos dados, foram realizados testes estatísticos de associação, tais como o teste Qui-Quadrado $\left(X^{2}\right)$ e Teste Exato de Fisher. Estes testes foram feitos para medir a associação entre as variáveis estado de ansiedade, sexo, faixa etária, escolaridade, patologias preexistentes nos grupos ${ }^{(53)}$.

A probabilidade de ocorrência do erro de primeira espécie foi fixada em $5,0 \%$ e o valor crítico dos testes foi 0,05 .

Foi empregada a Análise de Correspondência de Múltipla que utiliza todas as variáveis correspondentes, isto é, os itens do questionário de "Estado de Ansiedade" para avaliar as semelhanças e diferenças entre os pacientes que o responderam. Este tipo de análise trata os dados como qualitativos e não agrega valor numérico às respostas obtidas, ou seja, um paciente que respondeu "não me sinto calmo", não tem peso maior ou menor do que aquele que respondeu, "sinto-me totalmente calmo", eles simplesmente são diferentes. 
A Análise de Cluster serve para auxiliar na interpretação da Análise de Correspondência Múltipla, pois mede as distâncias entre os pacientes no mapa de correspondência, colocando os indivíduos mais próximos entre si em um mesmo grupo e, os mais distantes em grupos diferentes. Desta forma, a proximidade entre dois pacientes no mapa, significa que estes pacientes responderam o questionário de forma semelhante.

Julga-se ser a técnica apropriada uma vez que tem por objetivo a redução conceitual das dimensões do observador, isto é, reduz a dimensão de 20 variáveis qualitativas que, teoricamente seriam representadas por 20 eixos a uma dimensão menor, de preferência em um plano de 2 eixos no qual a visualização é mais fácil para o leitor.

Sendo assim, consideram-se as 20 questões como 20 variáveis de ansiedade e uma comparação de todos os pacientes por intermédio de todas as respostas observadas.

Cada pergunta constitui uma variável e as respostas são as modalidades, nas quais o indivíduo optou por apenas uma.

Esta análise evita um erro muito comum de se utilizar tabelas de contingência, e para resumo dos dados selecionam-se aquelas que são julgadas como interessantes segundo o grau de significância estatística do teste de independência feito automaticamente sobre todas as tabelas, interpretando erroneamente em termos de "força da relação" entre duas variáveis.

A análise baseia-se na interpretação gráfica que avalia a proximidade entre pacientes e entre categorias de variáveis. A análise de Cluster ou 
Agrupamento serve para classificar os pacientes em grupos homogêneos, ou seja aqueles que tem proximidade no mapa de correspondência. Assim, tem-se a formação de grupos e a justificativa do porquê são grupos pelo tipo de respostas dadas.

\section{Resultados e Discussão}

\section{Caracterização da Amostra}

Participaram deste estudo pacientes submetidos à revascularização do miocárdio que atenderam os critérios preestabelecidos. Sendo assim a amostra foi constituída por 100 (78,7\%) homens e 27 (21,3\%) mulheres, isto é, a maioria homens.

Para Luepker ${ }^{(49)}$ os homens apresentam duas vezes mais predisposição à doença cardiovascular que as mulheres. Este fato decorre da proteção hormonal dada às mulheres pelo estrógeno. No entanto, recentemente, este quadro tem se alterado e as mulheres têm contribuído para aumentar a proporção de pacientes com problemas cardíacos.

Em virtude de hábitos adotados, tidos como próprios dos homens que, atualmente fazem parte da rotina feminina.

A participação da mulher na economia e em outros setores do país tem contribuído para mudanças de hábitos. Com a maior inserção da população feminina no mercado de trabalho, esta ficou exposta a fatores de risco que, até então, eram exclusivos dos homens como estresse, hipertensão, tabagismo, dislipidemia e etilismo. 
Gráfico 19 - Distribuição dos pacientes internados para revascularização do miocárdio no IDPC, segundo faixa etária. São Paulo, 2001.

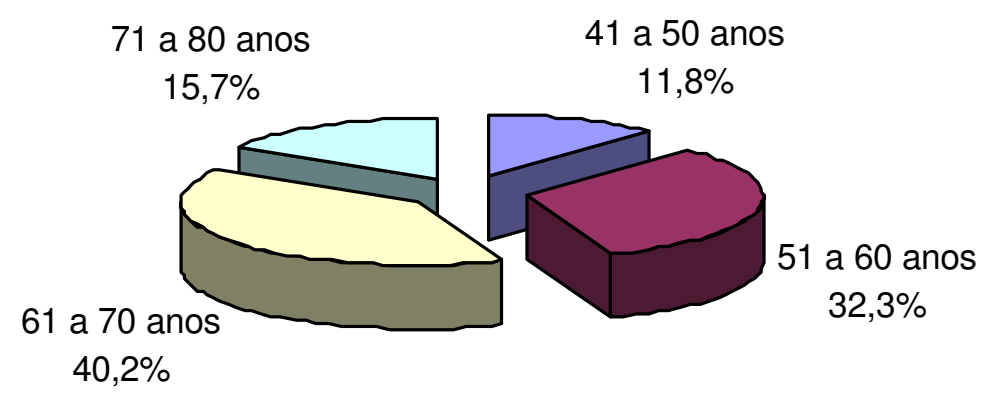

Com relação à faixa etária dos pacientes, apresentada no Gráfico 19, ficou assim distribuída 41 - 50 anos com 15 pacientes ( $11,8 \%) ; 51$ - 60 anos com 41 pacientes $(32,3 \%) ; 61$ - 70 anos com 51 pacientes $(40,2 \%) ; 71-80$ anos com 20 pacientes (15,7\%).

Esta distribuição caracteriza uma amostra composta em sua maioria por idosos, segundo critério adotado pela Organização Mundial da Saúde para países em desenvolvimento como o Brasil.

Estes resultados podem estar relacionados a patologia em estudo; isto é segundo Camargo ${ }^{(50)}$, é freqüente a ocorrência de doenças cardiovasculares em idosos.

Com o avanço da idade, o indivíduo tem alterações fisiopatológicas decorrentes do processo de envelhecimento, como por exemplo as do sistema cardiovascular.

Segundo Drain, Shipley ${ }^{(51)}$, a esclerose dos vasos é freqüente, assim como a atrofia das fibras miocárdicas, o retardo na recuperação da 
excitabilidade do músculo cardíaco, débito cardíaco diminuído, o que o expõe a dificuldades de resposta ao estresse e, conseqüentemente, aumentando a probabilidade de doença cardiovascular.

Este quadro vem se modificando e o número de pacientes, mais jovens, com problemas cardiovasculares tem aumentado.

Segundo Laurenti( ${ }^{(52),}$ em pesquisa realizada a requisitadas crenças dos portadores de doenças coronarianas e comportamentos de risco mostra que a incidência de problemas cardiovasculares tem aumentado progressivamente a partir da faixa etária de 40 anos. Segundo dados apresentados em 1991 (BANCO MUNDIAL) a cardiopatia é a principal causa de morte na população em idade produtiva no Brasil. Neste estudo, como pode ser observado há um número representativo de pacientes internados para revascularização do miocárdio na faixa etária de 51 a 60 anos. 
Gráfico 20 - Distribuição dos pacientes internados para revascularização do miocárdio no IDPC, segundo escolaridade. São Paulo, 2001.

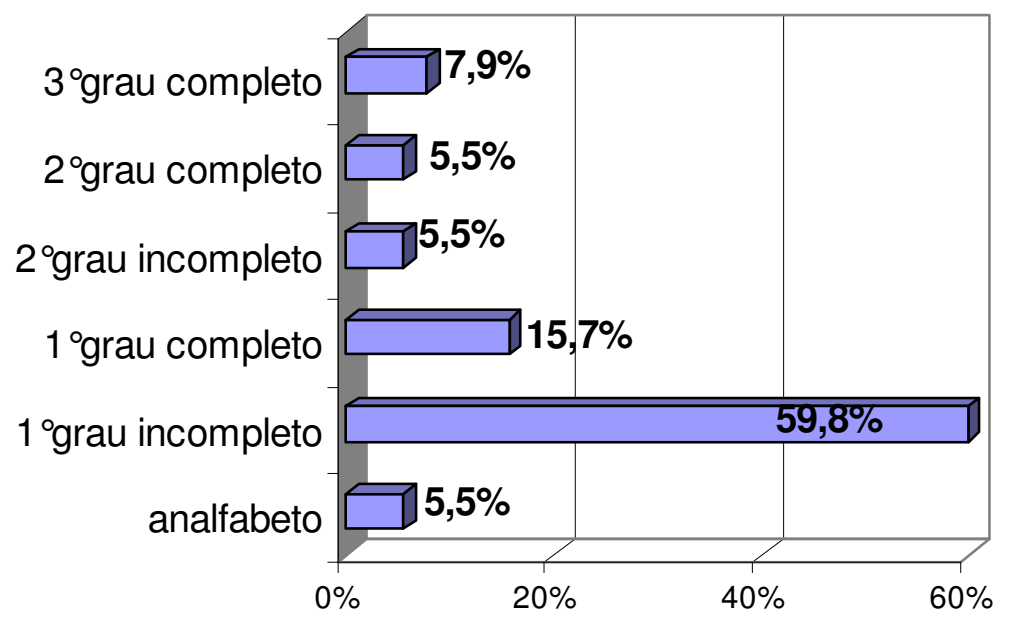

Em relação à escolaridade, observou-se que 7 pacientes $(5,5 \%)$ eram analfabetos, 76 pacientes $(59,8 \%)$ possuíam o $1^{\circ} \mathrm{grau}$ incompleto, 20 pacientes $(15,7 \%)$ concluíram $01^{\circ}$ grau , 7 pacientes $(5,5 \%)$ não finalizaram o $2^{\circ}$ grau , 7 pacientes $(5,5 \%)$ possuíam o $2^{\circ}$ grau completo, e 10 pacientes $(7,9 \%)$ concluíram o $3^{\circ} \mathrm{grau}$.

Estes dados caracterizam uma amostra com baixo grau de escolaridade. A educação está entre os muitos fatores que contribuem para uma baixa aderência ao tratamento clínico preventivo, sobretudo, quando relacionada às doenças crônicas e assintomáticas como, por exemplo, as cardiovasculares.

É possível supor que esta realidade tenha contribuído com a opção cirúrgica de tratamento da doença coronariana. 
Gráfico 21 - Distribuição dos pacientes internados para revascularização do miocárdio no IDPC, segundo fonte de renda. São Paulo, 2001.

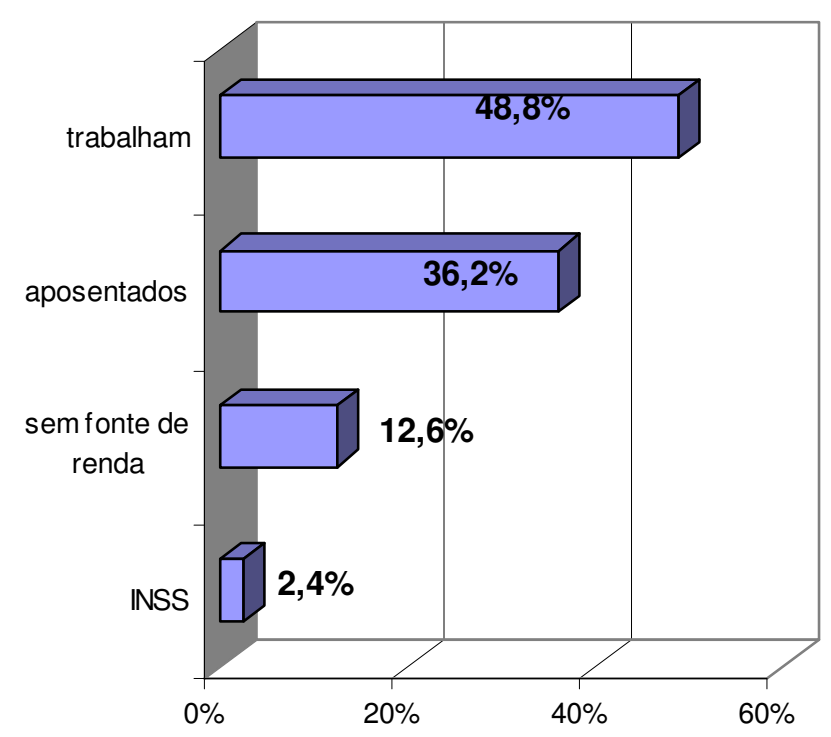

Em relação à fonte de renda desta amostra, observou-se que 62 pacientes $(48,8 \%)$ trabalhavam, 46 pacientes $(36,2 \%)$ eram aposentados, 16 pacientes (12,6\%) não possuíam fonte de renda e $(2,4 \%)$ eram vinculados ao INSS.

Em estudo realizado, a $\mathrm{OMS}^{(53)}$, diagnosticou que os fatores desencadeadores de ansiedade e estresse estavam relacionados às ocupações desenvolvidas pela população trabalhadora. Candeias et al $^{(54)}$ consideram que os componentes do ambiente de trabalho contribuem potencialmente para provocar reações disfuncionais e patogênicas no ser humano como decréscimo da atuação e da ocorrência de doença coronariana.

Neste estudo a amostra foi composta por uma grande parte de indivíduos com vínculo empregatício, o que nos faz inferir que, embora a 
patologia já esteja instalada, continuam a se expor aos fatores de risco da doença coronariana.

Apesar de se considerar o trabalho como fator de risco para os pacientes coronarianos, acredita-se que a ausência de renda ou uma renda insuficiente pode proporcionar transtornos fisiológicos, psicológicos e de comportamento tanto como aqueles desencadeados pela ocupação desenvolvida.

Em estudo realizado por Ferreira ${ }^{(55)}$, dentre os fatores de risco para doença coronariana, a renda familiar apresentou uma associação significativa com o estresse, ou seja a falta de condição econômica para manutenção de qualidade de vida torna-se também um fator desencadeante de ansiedade.

Observa-se que os fatores de riscos dependem da singularidade do indivíduo, ou seja, do momento e da avaliação subjetiva realizada de uma determinada situação. Conforme já foi apresentado anteriormente sempre que uma situação for considerada ameaçadora, independente de ser real ou imaginária, ocorre uma reação emocional definida como estado de ansiedade. ${ }^{(9)}$. 
Gráfico 22 - Distribuição dos pacientes internados para revascularização do miocárdio no IDPC, segundo estado civil. São Paulo, 2001.

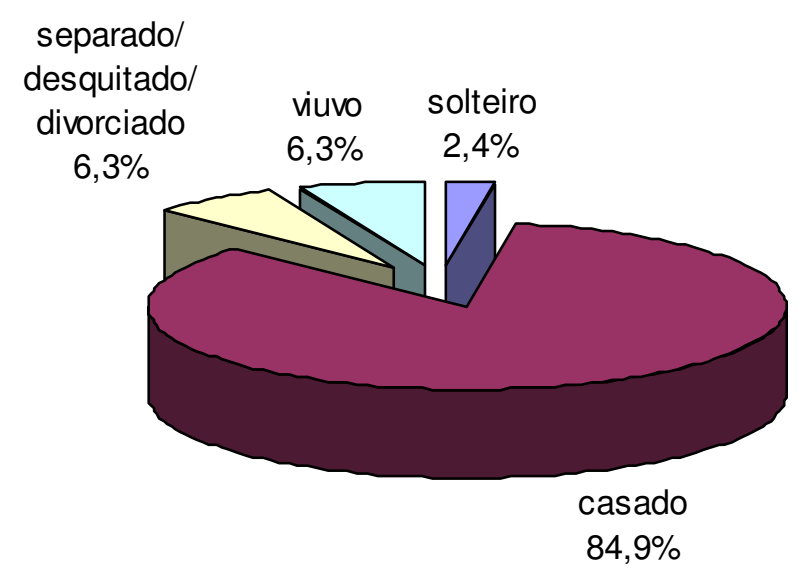

Com relação ao estado civil dos pacientes que responderam esta questão (125 pacientes) encontrou-se a seguinte distribuição: 107 (84,9\%) eram casados; 8 (6,3\%) eram separados ou divorciados; 8 (6,3\%) viúvos, 2 $(2,4 \%)$ solteiros. Sendo assim a maioria dos componentes da amostra é casada.

Gráfico 23 - Distribuição das patologias associadas em pacientes internados para revascularização do miocárdio no IDPC. São Paulo, 2001.

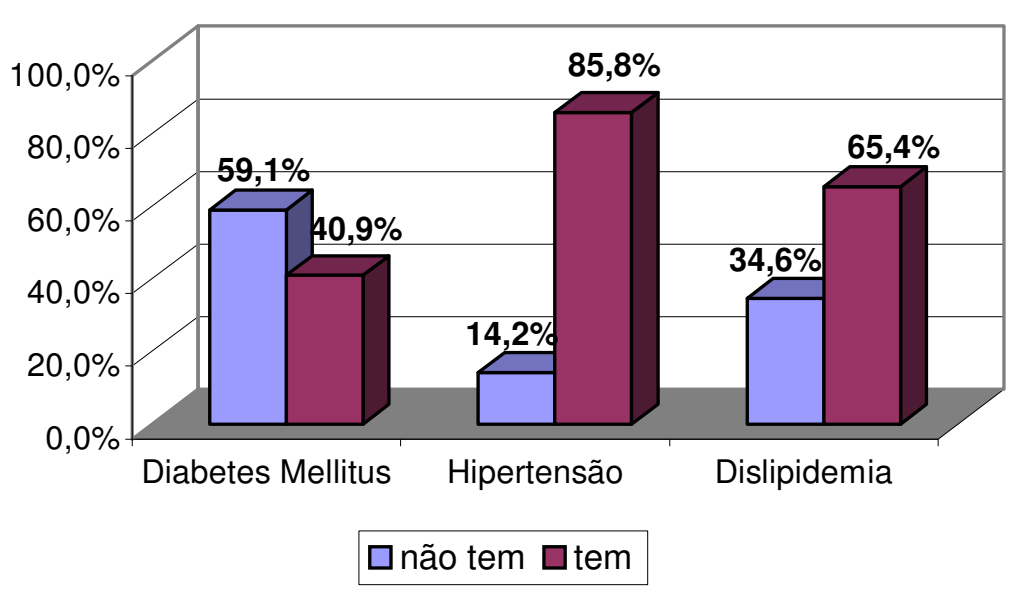

Verifica-se no Gráfico 23 que (40,9\%) dos pacientes são portadores de diabetes mellitus, $(65,4 \%)$ apresentam dislipidemia e $(85,8 \%)$ são 
hipertensos. Vale ressaltar a presença de mais de uma patologia associada a um mesmo indivíduo.

Estes dados corroboram os encontrados por Laurenti ${ }^{(52)}$ e confirmam a prevalência das doenças crônico-degenerativas como fator de risco às doenças cardiovasculares.

Estas patologias guardam entre si complexa relação com o modo de vida, estado emocional e herança genética do indivíduo.

Julga-se que a maior incidência de hipertensos $(85,8 \%)$ deve-se também à dificuldade de adesão do paciente ao tratamento.

A falta de conhecimento dos indivíduos sobre a doença hipertensiva, sua relação com as doenças coronarianas e a ausência de sintomas dificulta ainda mais a conscientização e a mudança de hábitos prazerosos dos pacientes, contribuindo para aumentar as taxas de morbimortalidade no Brasil. 
Gráfico 24 - Distribuição dos pacientes internados para a revascularização do miocárdio no IDPC, segundo o tempo de diagnóstico da doença coronária. São Paulo, 2001.

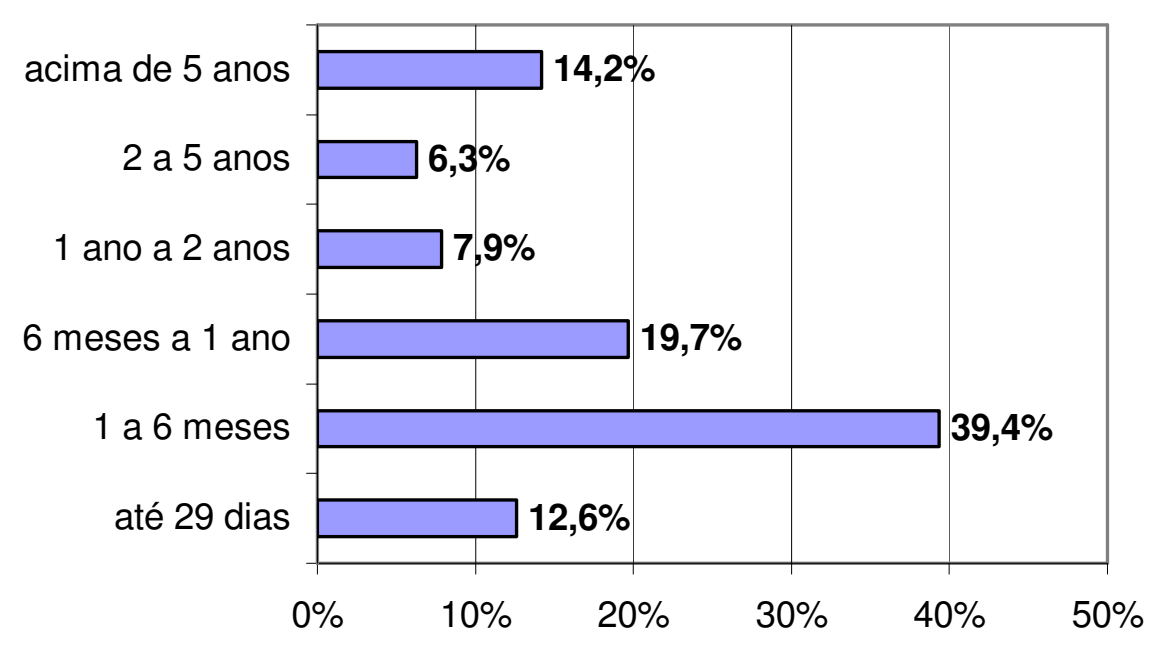

Com relação ao tempo de diagnóstico da doença coronariana, os dados do Gráfico acima demonstraram que 16 (12,6\%) dos pacientes detectaram a doença coronariana em um período de 29 dias, 50 (39,4\%) em um intervalo de 1 a 6 meses ; (19,7\%) entre 6 meses e 1 ano; $10(7,9 \%)$, em um período de 1 a 2 anos; 8 (6,3\%),de 2 a 5 anos; e 18 (14,2\%) acima de 5 anos.

O período de 1 à 6 meses para se diagnosticar a doença coronariana, é considerado como mais um fator de risco para o paciente.

Associado a isto, a falta de atendimento aos pacientes nos níveis primários de atendimentos à saúde resulta em ausência de diagnóstico precoce sobretudo quando se refere a patologias como dislipidemia, diabetes e hipertensão, conhecidas como fatores de risco para a doença coronariana $^{(56)}$.

Dando continuidade à caracterização da amostra e com o objetivo de facilitar a visualização de grupos de pacientes com relação a seu estado de 
estado de ansiedade, optou-se por apresentar no Gráfico abaixo, as respostas referentes a 20 questões, no qual cada uma tem apenas 4 itens do questionário auto-aplicável. Este gráfico é chamado mapa de correspondência, já que mostra os perfis de respostas obtidos pela amostra.

Gráfico 25 - Mapa de Correspondência para o Estado de Ansiedade. São Paulo, 2001.

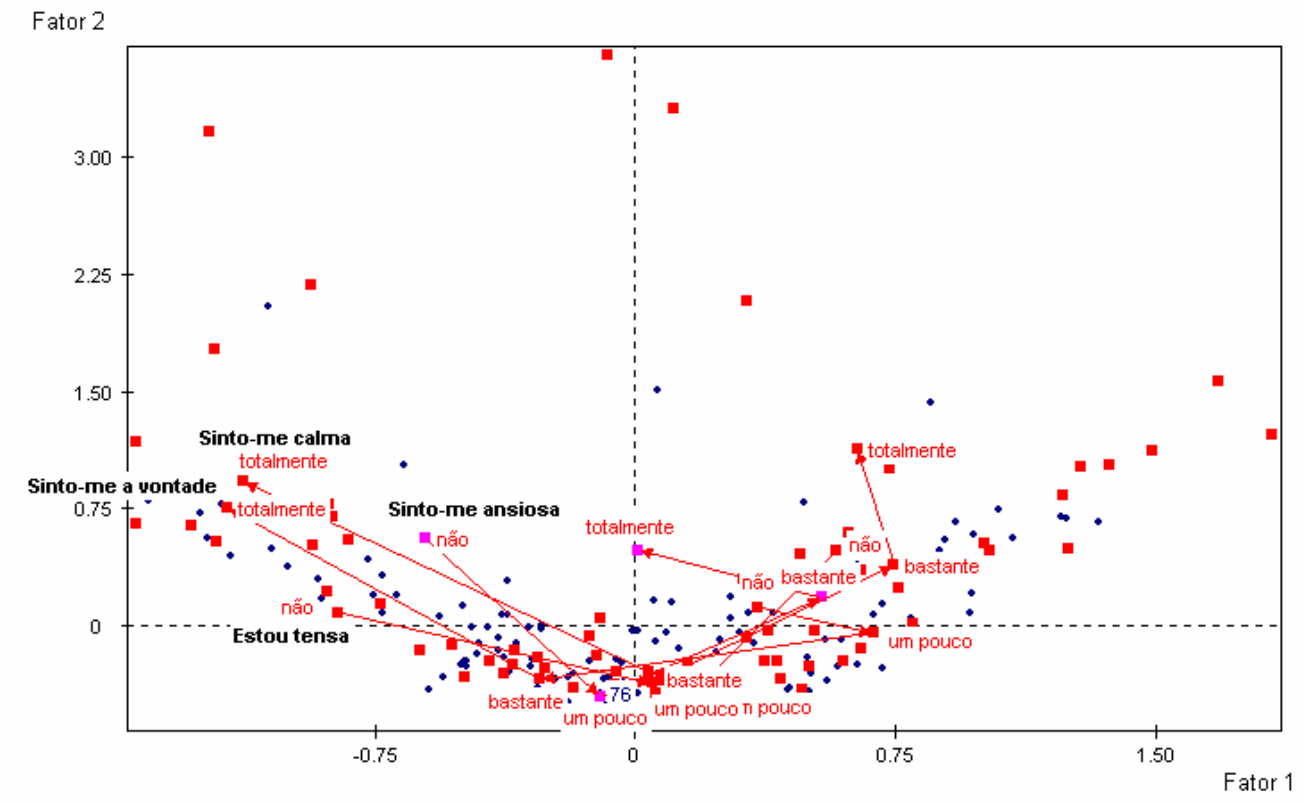

O Gráfico 25 ilustra que é possível formação de três grupos de pacientes (pontos azuis) assim como a formação de categorias de respostas (pontos vermelhos).

Cada paciente fica próximo às suas respostas. As informações completas encontram-se em Anexos (Anexos D e E).

Sendo assim o grupo $1 \mathrm{com} 17$ pacientes $(13,4 \%)$ localizado no lado esquerdo do mapa, é formado por aqueles pacientes que tiveram as respostas mais otimistas, ou menos ansiosas, considerados aqui como baixa ansiedade. 
O segundo, grupo 2 com 65 pacientes (51,2\%) localizado na parte central do mapa é formado por pacientes de média ansiedade, pois seu tipo de resposta é um pouco menos ansiosa do que o terceiro grupo .

O terceiro e último grupo, grupo 3 com 45 pacientes $(35,4 \%)$ é formado pelos pacientes de maior ansiedade, que, no geral, responderam de forma mais negativa às questões de ansiedade.

Condensando esta apresentação gráfica, tem-se o agrupamento dos pacientes em estudo, segundo o estado de ansiedade, apresentado no Gráfico 9, isto é, aqueles pacientes localizados no quadrante esquerdo do mapa, considerados mais otimistas pelas respostas dadas, foram classificados como representantes do grupo de baixa ansiedade (13,4\%). Aqueles que se localizaram no quadrante superior direito foram tidos como pertencentes ao grupo de alta ansiedade (35,4\%). Conseqüentemente, os pacientes localizados na parte central do mapa foram considerados com média ansiedade $(51,2 \%)$. 
Gráfico 26 - Distribuição dos pacientes internados para revascularização do miocárdio no IDPC, segundo estado de ansiedade. São Paulo, 2001.

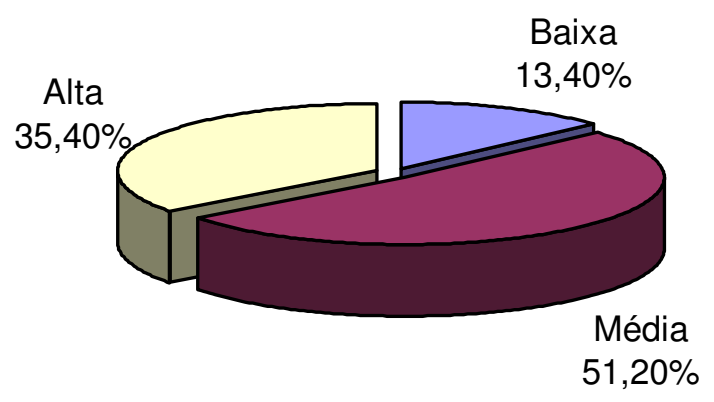

Embora exista uma forma estruturada de orientação pré-operatória na instituição, onde se efetuou a coleta de dados, observou-se que foi uma amostra representativa de 65 e 45 pacientes com média e alta ansiedade respectivamente.

Alguns autores acreditam que a orientação pré-operatória em pacientes cirúrgicos contribui para diminuir a ansiedade

Panza ${ }^{(57)}$ em estudo realizado para verificar o efeito das orientações pré-operatórias concluiu ser significativa a diminuição da variação emocional no período.

Caldwell ${ }^{(58)}$ em estudos realizados com pacientes cirúrgicos constatou que, alguns não se interessavam em receber mais informações referentes ao período pré-operatório, pois relatavam um aumento de ansiedade e estresse com o excesso de informações nesse período.

Costa ${ }^{(20)}$ considera que as informações e esclarecimentos de dúvidas, na fase pré-operatória devam ocorrer de forma que o paciente possa interagir e participar, cabendo ao enfermeiro observar, ouvir e descobrir as necessidades dos mesmos. 
Para Jouclas; Salzano ${ }^{(59)}$; Bianchi ${ }^{(60)}$, Silva ${ }^{(61)}$, Martins $^{(62)}$, a interação interpessoal é fundamental para diminuir a ansiedade do paciente cirúrgico.

Segundo Peniche ${ }^{(38)}$, o período de tempo existente para se realizar esta interação é pequeno, e a falta de conhecimento específico dos enfermeiros para a efetivar esta troca dificulta ainda mais a comunicação e, conseqüentemente, o procedimento terapêutico.

Nenhumas destas constatações feitas devem ser analisadas unilateralmente, pois é da natureza do ser vivo reagir às situações que enfrenta com oscilações de seu estado emocional e alguns fatores podem contribuir com maior ou menor intensidade nesta variação e na construção dos mecanismos protetores. Desde as informações recebidas, convívio com outros pacientes na enfermaria até, fatos resgatados da memória, como outras cirurgias realizadas, anteriormente, podem contribuir para avaliação da situação

Segundo Spielberger ${ }^{(9)}$, os processos mentais compostos por percepções, pensamentos, memórias e julgamento são importantes na avaliação subjetiva da situação que poderão levar ou não oscilações do estado de ansiedade.

Ainda segundo Spielberger ${ }^{(9)}$ a variação do estado de ansiedade não depende só da percepção e do julgamento, mas também da veracidade com que os pacientes respondem o questionário auto-aplicável. Este autor explica que, inconscientemente, os pacientes não fornecem as informações precisas o que compromete a fidedignidade das respostas. 
Ressalta-se que, embora, o IDATE seja reconhecido como fidedigno em relação à mensuração de ansiedade, observam-se algumas limitações na amostra estudada, tais como: dificuldade na compreensão dos itens que compõem o questionário, comprometendo a veracidade da resposta e a complexidade do vocabulário, o que poderia contribuir com os resultados aqui apresentados.

Gráfico 27 - Distribuição dos pacientes internados para revascularização do miocárdio no IDPC, segundo infecção do sítio cirúrgico. São Paulo, 2001.

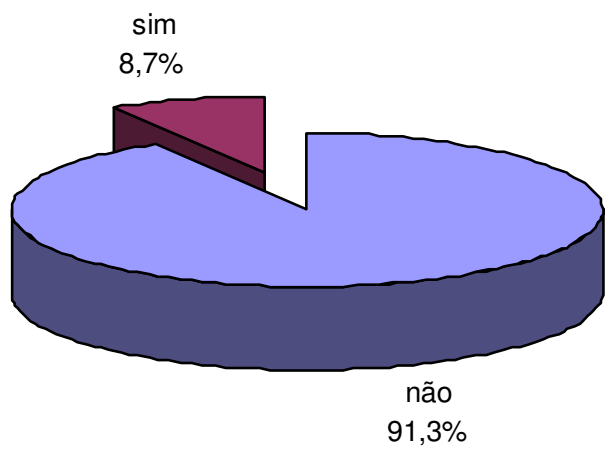

Dos 127 pacientes submetidos à cirurgia, $116 \quad(91,3 \%)$ não apresentaram infecção do sítio cirúrgico e 11 (8,7\%) demonstraram infecção da ferida cirúrgica. Destes, em nove verificaram-se secreções serosangüinolentas e em dois secreções purulentas em material coletado com presença de cultura para Enterococcus faecalis, Proteus penneri e Staphilococcus epidermidis o que caracterizam uma infecção bacteriana.

Segundo Lacerda et $a^{(47)}$, os patógenos que infectam as feridas cirúrgicas originam-se do próprio paciente, do ambiente hospitalar e do pessoal, e a flora do paciente é responsável pela maioria das infecções cirúrgicas exceto nas cirurgias limpas. A revascularização do miocárdio é 
considerada uma cirurgia limpa, acredita-se que esta infecção do sítio cirúrgico dos pacientes decorra de microorganismos exógenos, como aqueles encontrados em materiais, equipamentos e decorrentes das falhas de procedimentos.

Deseja-se salientar a preocupação da Instituição no controle da infecção hospitalar com os fatores relacionados ao procedimento cirúrgico.

Algumas rotinas quanto aos cuidados preestabelecidos para a tricotomia, material e equipamentos utilizados, revisão das técnicas de esterilização e cirúrgica, banho pré-operatório, preparo da pele (degermação), limpeza da unidade, cuidados com a ferida no pós-operatório, ventilação adequada no SO, antibioticoprofilaxia foram implantadas, alem da reciclagem das técnicas de paramentação cirúrgica, escovação para a equipe multiprofissional.

No ano de 1999, em levantamento feito nesta instituição em 79 pacientes submetidos à revascularização do miocárdio foram encontrados sete pacientes $(8,8 \%)$ com infecção do sítio cirúrgico . Comparando os resultados aqui obtidos com os de 1999, observa-se que se mantiveram aparentemente constantes. Em se considerando a infecção multideterminada, pode-se crer que as medidas tomadas pela instituição estão conseguindo, se não diminuir a infecção, pelo menos, contê-la.

Segundo a comissão de controle de infecção da instituição, este índice é considerado alto quando comparado a outros tipos de cirurgia.

Mesmo sendo instituídas várias medidas de controle de infecção, esta continua mantendo-se constante desde 1999. 
Uma justificativa para esta problemática, já que muito se tem investido no controle da infecção, seria a presença de um duplo fator de risco neste tipo de cirurgia, ou seja, na revascularização do miocárdio além da incisão esternal têm-se outros locais propensos a infecção como: região inguinal, ao longo dos membros inferiores e a radial.

Relações entre as variáveis: sexo, faixa etária, escolaridade, patologias preexistentes e o estado de ansiedade.

A seguir, são apresentadas as comparações referentes ao sexo, faixa etária, escolaridade, patologias preexistentes e estado de ansiedade nos pacientes submetidos à revascularização do miocárdio. 
Figura 2 - Gráficos referentes às relações sexo, idade, escolaridade e ansiedade dos pacientes submetidos à revascularização do miocárdio. São Paulo, 2001.

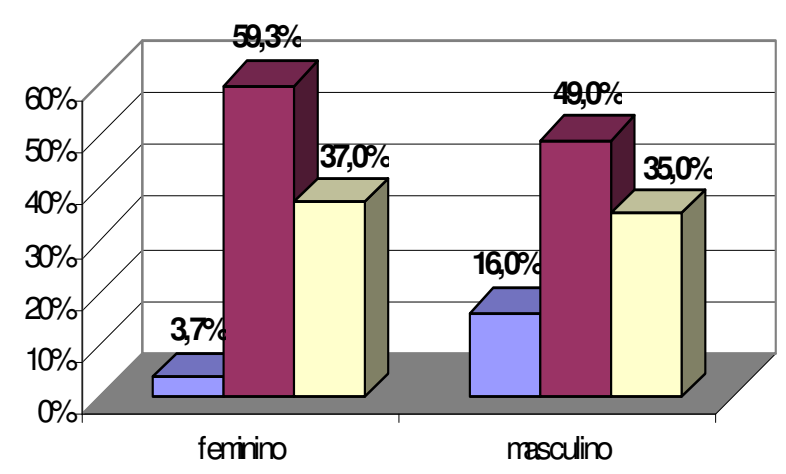

$\square$ Baixa $\square$ Méda $\square$ Alta

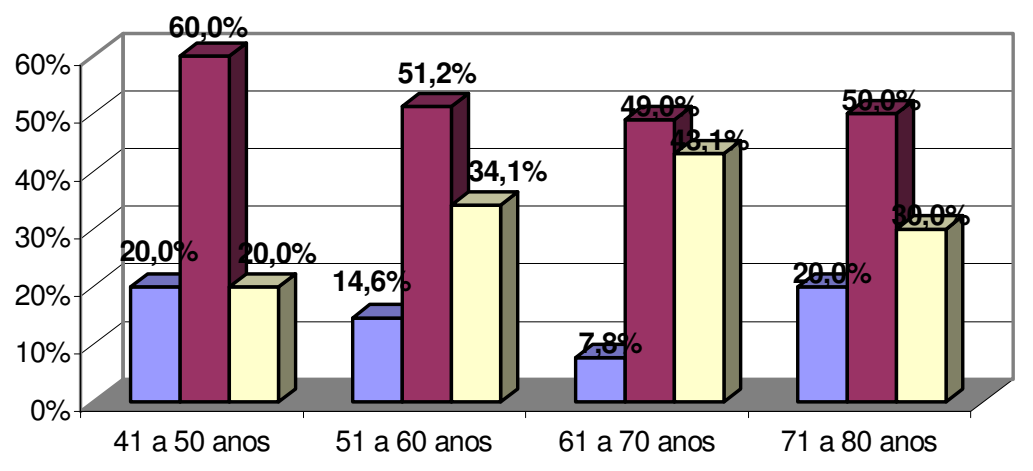

$\square$ Baixa $\square$ Média $\square$ Alta

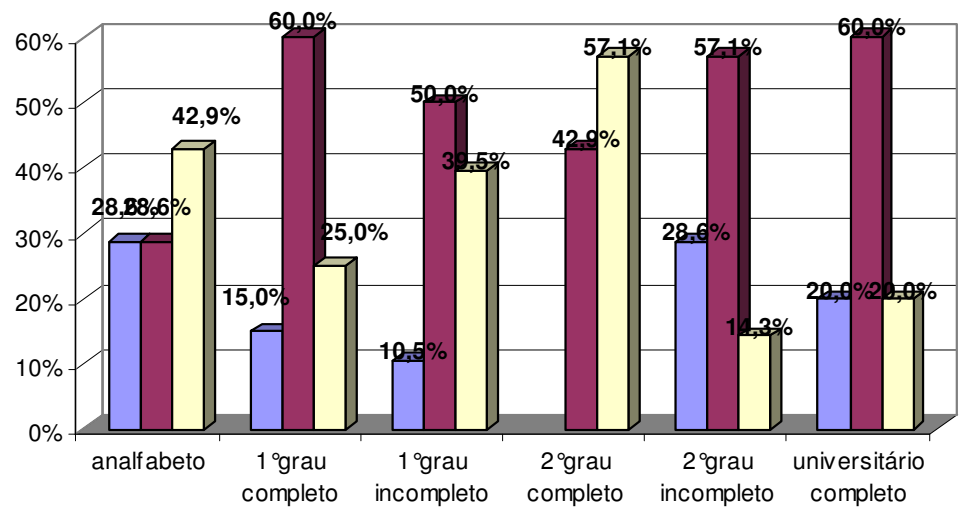

$\square$ Baixa $\square$ Média $\square$ Alta 
A associação entre as variáveis estudadas obteve resultados semelhantes aos encontrados na literatura, ou seja, não existe um consenso entre os estudiosos sobre a relação do estado de ansiedade, sexo, idade e escolaridade.

Esta figura ilustra, que não houve diferença estatisticamente significante entre o estado de ansiedade e as variáveis em questão, isto é, o estado de ansiedade independe do sexo, da idade e escolaridade.

Com relação ao sexo, embora as mulheres tenham respondido às questões de maneira mais ansiosa que os homens, esta diferença não foi significante estatisticamente ( $p=0,256)$ no período pré-operatório.

Segundo Biaggio, Natalicio ${ }^{(45)}$, ao apresentarem os dados normativos para a amostra brasileira do inventário de ansiedade traço-estado, apontaram que a população brasileira tem a mesma tendência que a norteamericana onde as mulheres demonstram maior ansiedade que os homens.

Peniche ${ }^{(38)}$ em estudo realizado sobre a influência de ansiedade nas respostas do paciente no período pós-operatório imediato, obteve resultados semelhantes aos aqui encontrados, ou seja, a média de ansiedade das mulheres foi maior do que dos homens, porém sem diferença estatisticamente significante. No entanto utilizaram mecanismos de enfrentamento do estresse e da ansiedade mais eficientes que os homens, uma vez que a diferença entre as médias do traço-estado de ansiedade foi menor quando comparada aos homens.

Acredita-se que o ser humano possui distintas formas de avaliar as situações que enfrenta, e estas diferenças não decorrem somente pela 
diversidade cultural, mas também do universo de cada um, independente do sexo. Esta diversidade subsidia a criação de estratégias de coping, eficazes ou não e que refletem o estado emocional do momento .

No que se refere à idade, também não encontraram diferenças significantes ( $p=0,544)$, ou seja, o estado de ansiedade não sofreu alteração dependente da idade. No entanto, observou-se um número maior de pacientes com elevação do estado de ansiedade, situados na faixa etária de 61 a 70 anos, porém não significante.

Como já citado anteriormente, o envelhecimento está associado à perda das reservas celulares e fisiológicas e conseqüentemente, esta diminuição torna o idoso mais vulnerável às situações de estresse. Mesmo considerando que o idoso pela sua maior experiência de vida e, conseqüente, maior capacidade de adaptar-se às várias situações tem consciência de sua brevidade, quando enfrenta algumas situações de risco como o procedimento anestésico cirúrgico.

Estas relações diretas como aumento de idade, adoecer e morrer são considerados por nós um processo unilateral que nega a subjetividade do ser humano, desconsidera sua capacidade criadora frente às adversidades, mas que não pode ser menosprezada sobretudo em se tratando de indivíduo idoso.

A escolaridade não apresentou relação estatisticamente significante $(p=0,460)$ com a ansiedade, porém observou-se um maior número de pacientes analfabetos $(42,9 \%)$ e de pacientes com $2^{\circ}$ grau completo $(57,1 \%)$ com níveis mais altos de ansiedade. 
Pelo índice nacional de analfabetismo existente em nosso país, é sabe-se que nas instituições hospitalares há um número considerado de pacientes analfabetos.

Em conseqüência dessa realidade, é comum nas orientações préoperatórias ocorrerem dificuldades de absorção e entendimento das informações dadas. Mas curiosamente, os pacientes com $2^{\circ}$ grau completo apresentaram uma similaridade com relação ao nível de ansiedade dos analfabetos, o que justifica os resultados aqui obtidos, ou seja, não há evidências para dizer que o nível de escolaridade interfira no estado emocional. No entanto, é possível supor que o paciente, independente de sua escolaridade possua capacidade para processar as novas informações, o que the possibilitaria fazer reavaliações desde as mais primitivas até as mais elaboradas e emitir respostas relevantes ou não, criando uma sucessão de emoções e avaliações. Acreditar nessa hipótese é considerar a capacidade intrínseca de todo ser humano de reagir às ameaças.

Sendo assim, é importante que o enfermeiro identifique as reais necessidades do paciente cirúrgico, independente de seu grau de instrução, pois a reação do indivíduo ao estímulo envolve aspectos não só educacionais, mas também, biológicos, psicológicos e culturais. 
Figura 3 - Gráficos referentes às relações hipertensão, dislipidemia, diabetes mellitus e ansiedade dos pacientes submetidos à revascularização do miocárdio. São Paulo, 2001.

A seguir na Figura 3 apresentam-se os gráficos referentes à associação entre hipertensão, dislipidemia, diabetes mellitus e ansiedade.
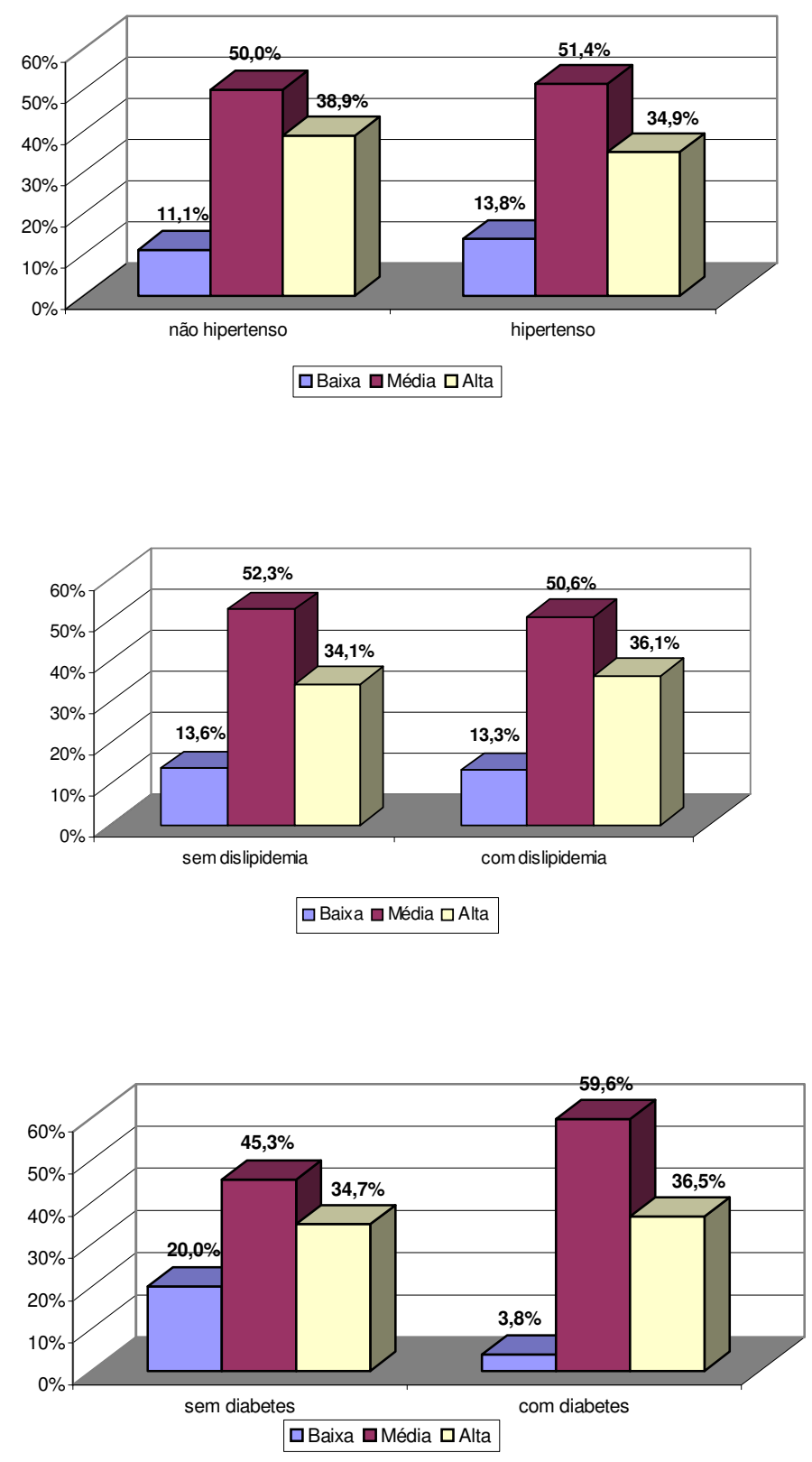

Com relação à hipertensão $(p=0,939)$ e dislipidemia $(p=0,974)$, observa-se que não houve relação estatisticamente significante com a ansiedade, porém o mesmo não ocorreu com pacientes portadores de 
diabetes que apresentaram uma significância estatística $(p=0,027)$ com a ansiedade.

Este resultado apresentado referente a diabetes pode estar relacionado ao medo, não só da cirurgia e da anestesia, como também das complicações pós-operatórias às quais o paciente diabético está exposto como, por exemplo, a acidose respiratória e metabólica e o próprio coma diabético.

A relação ao diabetes e infecção também deve ser considerada como estressante para o paciente cirúrgico portador dessa patologia. Segundo Smeltzer, Bare ${ }^{(63)}$, a alteração na fisiopatologia da cicatrização, as complicações vasculares e neuropatias e os efeitos inibitórios da hiperglicemia na atuação leucocitária na destruição bacteriana, resultam em diminuição da resistência às infecções .

Dados da Organização Mundial da Saúde (OMS) demonstram que 160 milhões de pessoas no mundo têm diabetes.

No Brasil, estudo realizado com apoio do Ministério da Saúde revelou que nos últimos 15 anos cerca de 7,5\% da população entre 30 e 69 anos adquiriram a doença.

Entretanto as dificuldades em possuir um controle dos hábitos alimentares e dos comportamentos adequados continuam contribuindo para elevar a incidência e a acentuação das complicações neuropáticas e vasculares e, conseqüentemente, o surgimento de infecções. 
A situação poderia ser melhor trabalhada se houvesse uma adesão ao tratamento, o que inclui hábitos e comportamentos mais saudáveis, sobretudo no período que antecede a cirurgia .

Estudos têm demonstrado, dentre eles, o de Surwit ${ }^{(64)}$, que na maioria dos casos, a doença responde ao tratamento com dieta e medicação, além de exercícios aeróbicos e técnicas de relaxamento que exercem importante função no consumo de glicose pelo organismo e no controle do estresse. 
Relações entre as variáveis: intercorrências no intra-operatório, pósoperatório, infecção e o estado de ansiedade.

Figura 4 - Relações entre as variáveis intercorrências nos períodos intra operatório e pós- operatório, a presença de infecção e o estado de ansiedade.

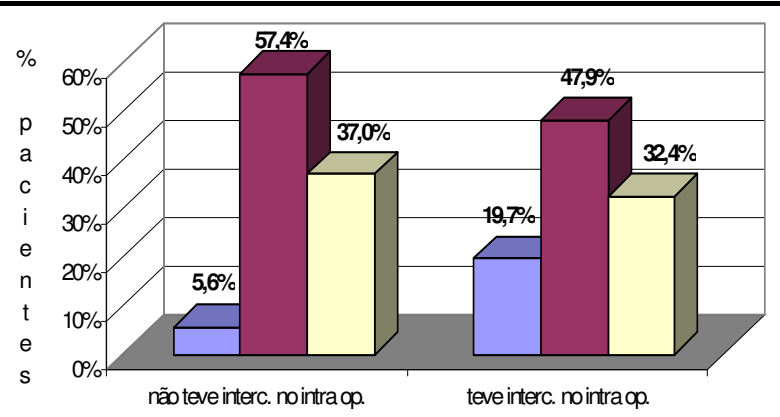

$$
\square \text { Baixa } \quad \text { Média } \square \text { Alta }
$$
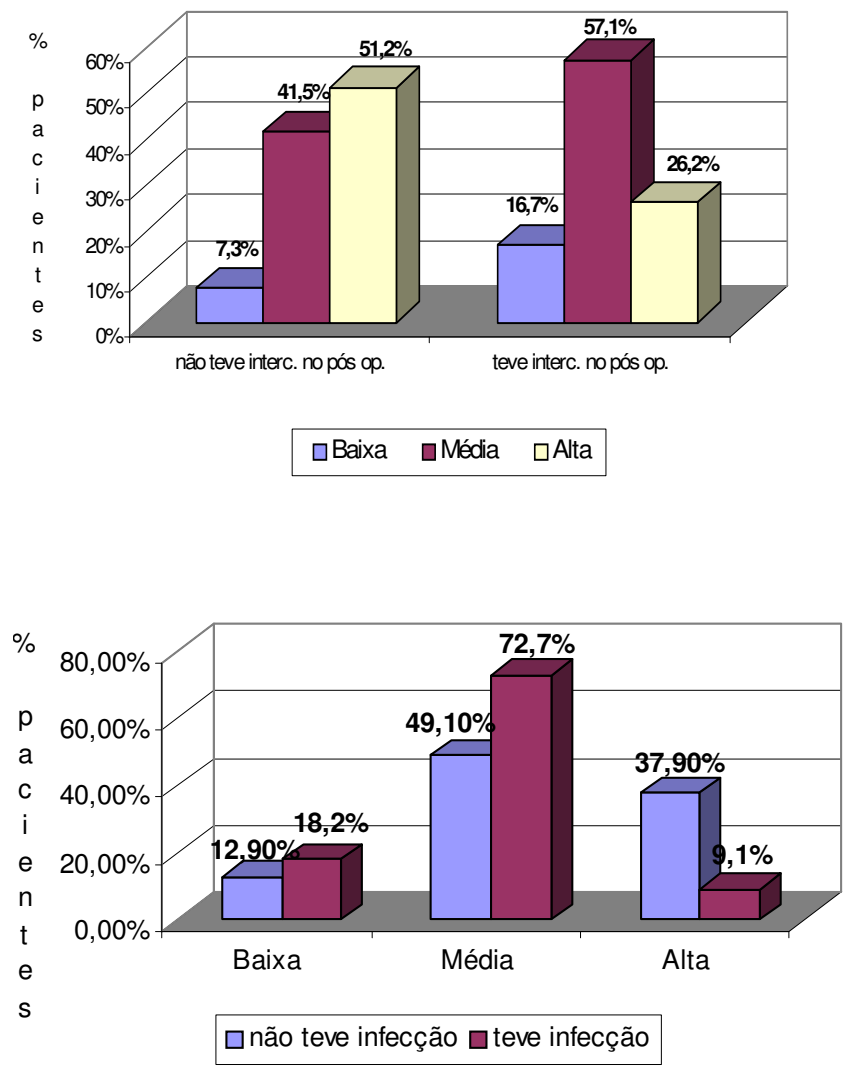
A figura anterior referem-se às relações entre intercorrência nos períodos intra e pós -operatório, infecção no sítio cirúrgico e ansiedade.

No que diz respeito à relação entre o estado de ansiedade e às intercorrências no período intra e pós operatório, não se obteve relação significante entre estas duas variáveis $(p=0,072) ; \quad(p=0,849)$ respectivamente, ou seja, apesar da aparente maior ansiedade entre os pacientes com intercorrências, esta relação não é significativa.

Neste estudo, as intercorrências apresentadas foram hipertensão arterial sistêmica, hiperglicemia, agitação psicomotora, hipovolemia, retenção urinária e arritmias.

De modo geral, estes parâmetros clínicos que se alteraram em resposta à agressão cirúrgica, mais especificamente, pressão arterial sistólica, freqüência de pulso e respiratória, agitação psicomotora e glicemia são manifestações clínicas da ansiedade.

Sendo assim, pode-se inferir que estas intercorrências apresentadas não se caracterizaram como tal, uma vez que os indivíduos ao serem submetidos a um procedimento anestésico cirúrgico respondem física e emocionalmente a esta intervenção, com alterações hormonais e dos parâmetros clínicos na busca de homeostase. A tendência desta resposta ao trauma anestésico cirúrgico, sobretudo, em indivíduos sadios (ASA1) ou portadores de uma única patologia preexistente (ASA2), é apresentar um período intra e pós-operatório sem grandes oscilações dos parâmetros relacionados com a manifestação da ansiedade. 
Em estudo realizado com pacientes ASA1 e ASA2 submetidos cirurgias ginecológicas e gerais, Peniche ${ }^{(38)}$ verificou não existir relação significante do estado de ansiedade com as variações dos sinais vitais no período pós operatório imediato.

Neste estudo, os pacientes, embora pertencessem às classificações ASA 3 e ASA 4, foram submetidos à circulação extracorpórea e tiveram um período maior de intubação, comportaram-se de forma semelhante no período pós operatório imediato. Ou seja, se for possível considerar as oscilações das respostas fisiológicas do indivíduo ao trauma anestésico cirúrgico como um sinal preditivo de intercorrências, estas não se destacaram tanto em quantidade como em qualidade, uma vez que não houve diferenças estatísticas entre o estado de ansiedade no período préoperatório e da pressão arterial, glicemia, atividade motora e retenção urinária nos períodos intra e pós-operatório .

Atualmente os novos fármacos utilizados como medicação pré anestésicas e anestésicas e as associações de técnicas anestésicas têm favorecido a evolução dos pacientes cirúrgicos, sobretudo, aqueles considerados críticos, atenuando a probabilidade de intercorrências e complicações.

Segundo Hoffer ${ }^{(31)}$; Collins ${ }^{(65)}$, a escolha do tipo de droga a ser utilizada nos pacientes está vinculada às condições fisiológicas dos mesmos, à patologia, às condições psicológicas e mentais do paciente, à duração do procedimento, à posição cirúrgica do paciente, às exigências do 
cirurgião à evolução pós-operatória e local onde se dará a recuperação anestésica.

Ainda segundo Collins ${ }^{(65)}$, as drogas anestésicas e pré-anestésicas têm atuação direta no sistema límbico e produzem relaxamento mental e emocional, redução dos estímulos sensoriais, redução de taxa metabólica, redução da exitabilidade reflexa, anti-estresse, anti-secretória, anti-reflexos das vias respiratórias durante o procedimento anestésico cirúrgico e período pós-operatório imediato.

Neste estudo, as drogas escolhidas com estes objetivos foram 0 midazolan (benzodiazepnico) e o fentanil. É possível supor que o midazolam, benzodiazepnico hidrossolúvel hipnótico e sedativo utilizado como droga pré anestésica e com propriedades ansiolíticas e amnestésicas, pode ter influenciado na ausência de significância estatística entre a ansiedade e as alterações por minimizar as influências do sistema límbico

Segundo White ${ }^{(66)}$, com relação a ação do fentanil na indução e manutenção da anestesia quando comparado, por exemplo ao propofol, em pacientes submetidos a cirurgias cardíacas com circulação extra-corpórea, o fentanil, apresenta menor estabilidade hemodinâmica, extubação tardia e despertar demorado.

No entanto, para se poder afirmar que as drogas utilizadas cumpriram seus princípios farmacológicos, protegendo os sistemas neurais envolvidos com os comportamentos de luta e fuga são necessários estudos clínicos específicos que comprovem a capacidade dos receptores cerebrais em reconhecê-las como tal. 
Com relação as intercorrências, referentes ao período pós-operatório mais tardio (25 dias após a cirurgia), ou seja, o aparecimento ou não de infeção no sítio cirúrgico obteve-se resultados não estatisticamente significantes $(p=0,120)$ o que implica afirmar que a ansiedade não interferiu no aparecimento da infecção.

Dos 127 pacientes, acompanhados durante 25 dias após a cirurgia, 116 não apresentaram infecção mesmo sendo alocados, segundo suas respostas ao questionário estado de ansiedade, em 15 (12,9\%) com baixa ansiedade, 57 (49,1\%) com média ansiedade e 44 (37,9\%) com alta ansiedade.

Dentre os 11 pacientes infectados, um classificado como muito ansioso por suas respostas ao questionário de estado de ansiedade permaneceu 35 dias na UTI evoluindo com deiscência de safena, broncopneumonia, infecção urinária, encefalopatia, e óbito após 720 horas de Unidade de Terapia Intensiva.

Os outros oito pacientes $(72,7 \%)$ com média ansiedade e dois $(18,2 \%)$ com baixa ansiedade.

É importante salientar que este dado não foi significante para a análise estatística, uma vez que esta se dá pela oscilação numérica das variáveis em questão.

Entretanto ao se focar somente o grupo de 11 pacientes com infecção tem-se um resultado relevante quando analisado segundo a literatura. Isto é, os pacientes submetidos a revascularização do miocárdio têm uma probabilidade maior de lesão pulmonar e complicações renais pelo uso da 
circulação extracorpórea. A maior ativação do sistema imunológico acontece no período pós-operatório tardio desencadeado pela diminuição dos complementos séricos e das imunoglobulinas, reduzindo a função neutrofílica ${ }^{(67)}$.

Ainda em estudos realizados por Stocche, Garcia, $\mathrm{Klamt}^{(5)}$, que apontam relações entre infecções virais ou bacterianas ao estresse, à depressão e à ansiedade, causando uma diminuição da atividade imune.

Caetano ${ }^{(68)}$ encontrou que mulheres desempregadas, por mais de nove meses apresentaram uma diminuição na proliferação de linfócitos $T$ e B.

O estado prolongado e constante de preocupação, ansiedade e estado de alerta têm sido implicados como fator de aumento da reatividade cardiovascular, elevação de catecolaminas e diminuição da resposta imune em vários estudos.

Rabhae, Filho, Fernandes ${ }^{(67)}$ referem que parte do enfraquecimento dessas funções imunológicas deve-se à cirurgia, ou seja, pois o rompimento da barreira epitelial desencadeia uma série de reações sistêmicas que facilitam o aparecimento de um processo infeccioso. Isto porque com a incisão cirúrgica ocorre além da hipoxia, alteração do $\mathrm{pH}$ e deposição de fibrina que dificultam a migração de neutrófilos e sua atividade microbicida.

Convém ressaltar também a relação do sistema nervoso e do imunológico constatada em experimentos realizados em cobaias que após lesões no hipotálamo teve seu timo diminuído com supressão da resposta de 
anticorpos. Estes resultados sugeriram que esta glândula seria a suposta base de integração entre o sistema nervoso e imunológico ${ }^{(69)}$.

Segundo Bianchi ${ }^{(70)}$, os resultados verificados com a finalidade de buscar uma correlação entre infecção, ansiedade e, conseqüentemente, estresse ainda estão em fase inicial. Em citação feita por Lazarus, Folkman ${ }^{(7),}$ alguns pesquisadores concluíram que há relação entre estresse e o sistema imunológico, porém não é somente o agente infeccioso responsável pela infecção. A vulnerabilidade e a resistência do indivíduo ao agente infeccioso são fatores importantes que devem ser considerados.

Segundo Rabhae, Filho Fernandes ${ }^{(67)}$, são três os fatores de contaminação do sítio cirúrgico, isto é, aqueles relacionados ao microrganismo, ao procedimento cirúrgico e ao próprio paciente.

Acredita-se que as duas principais variáveis em questão ansiedade e infecção são extremamente complexas, o que expressa a necessidade de novos estudos não só exploratório, mas também clínicos e experimentais que ofereçam uma visão mais ampliada desse universo subjetivo que é o homem e suas reações de luta e fuga frente às experiências vividas.

A análise dos resultados deste protocolo permitiu as seguintes constatações:

Os pacientes submetidos à revascularização do miocárdio apresentaram em sua maioria $(51,20 \%)$ um médio estado de ansiedade no período pré-operatório imediato.

Verificou-se a ocorrência de infecção do sítio cirúrgico em 11 pacientes $(8,66 \%)$. 
Não observada relação estatisticamente significante entre estado de ansiedade no período pré-operatatório imediato e a infecção do sítio cirúrgico nestes pacientes $(p=0,120)$. 
PROTOCOLO 4 


\title{
PROTOCOLO 4
}

\section{A INFLUÊNCIA DOS MECANISMOS DE COPING NA ANSIEDADE DO PACIENTE CIRÚRGICO AMBULATORIAL.}

\author{
Moraes, LO, Peniche, ACG
}

\section{Objetivos}

Identificar o estado de ansiedade em pacientes cirúrgicos ambulatoriais no período pré-operatório e seus parâmetros clínicos compatíveis com a atividade nervosa central autonômica;

Identificar os mecanismos de coping mais utilizados pelos pacientes cirúrgicos ambulatoriais;

Verificar a correlação do estado de ansiedade pré-operatório e mecanismos de coping.

\section{Material e Método:}

Como critérios para seleção da amostra foram determinados os 40 pacientes cirúrgicos ambulatoriais; alfabetizados; faixa etária de 20 a 70 anos; pertencentes ao programa de cirurgias ambulatoriais; submetidos à anestesia local sem sedação; submetidos à intervenção cirúrgica de pequeno e médio porte, segundo Faintuch, Faintuch ${ }^{(71)}$; sem distúrbios orgânicos, fisiológicos, bioquímicos ou psiquiátricos, estado físico 01 (ASA 01) ou com anormalidades fisiológicas, bioquímicas de pequena intensidade, como diabetes mellitus ou hipertensão arterial leve e compensada, estado 
físico 02 (ASA 02) de acordo com o American Society of Anesthesiology. ( ${ }^{31-}$ $\left.{ }^{71}\right)$.

Procedimento de Coleta de Dados: A coleta de dados foi realizada no Hospital Universitário da Universidade de São Paulo, mais precisamente na Unidade de Clínica Cirúrgica Ambulatorial onde, após a tramitação e aprovação do projeto pela comissão de Ética da Instituição, manteve-se contato com os pacientes cirúrgicos que preenchiam os critérios de seleção da amostra, sendo que os mesmos foram informados sobre a finalidade da pesquisa, da participação voluntária e da garantia do anonimato. A autorização formal e por escrito.

Foram realizadas entrevistas com os pacientes, além da avaliação de seus parâmetros clínicos e aplicação dos questionários, sendo que no dia da cirurgia, aproximadamente 2 horas antes de seu encaminhamento ao Centro Cirúrgico, os pacientes foram questionados quanto aos dados de identificação contidos no formulário 01 . A seguir, foi solicitado ao paciente ficar em posição mais confortável possível para serem avaliados os parâmetros clínicos contidos na segunda parte deste mesmo formulário.

Logo em seguida, foram distribuídos os questionários auto-aplicáveis 01 e 02 que verificaram respectivamente, o estado de ansiedade do paciente cirúrgico ambulatorial no período pré-operatório e os mecanismos de coping utilizados.

Instrumentos: Foram utilizados dois formulários. O formulário 01 (Anexo 12) é composto por 02 partes. Parte I: composto por dados gerais de identificação como registro geral, idade, sexo, hospitalização com cirurgias anteriores e intercorrências. Parte II: composta por parâmetros clínicos considerados por 
diversos autores $(11,12,13,14,15,16,17)$, como constitutivos da avaliação de pacientes cirúrgicos e por estarem associados à atividade nervosa central autonômica e endócrina desencadeadas pela ansiedade ${ }^{(18)}$. São eles: freqüência de pulso, pressão arterial, freqüência respiratória, temperatura, reflexos protetores como a tosse e a deglutição, expansibilidade torácica, atividade muscular, sensibilidade cutânea, dor, coloração, nível de consciência, comportamento, sinais vegetativos como vômito, náusea, sialorréia e sudorese.

Os parâmetros utilizados para avaliação clínica no período préoperatório foram pontuados, com exceção da dor, com base nas variações propostas pelos autores ${ }^{(11-12-13-14-15-16-17)}$ e a partir daí criou-se três possibilidades de escores: normal (0), alterado (1) e muito alterado (2).

Quanto à avaliação do parâmetro referente à dor, foi baseada na escala proposta por Downie, et al citado por Jensen, Karoly, Brauer ${ }^{(19)}$. Essa escala é composta por 11 números entre zero a dez ( 0 a 10). O zero (0) representa um extremo de dor (ausência) e o dez (10) representa o outro extremo (muita dor). A pontuação dada pelo paciente nessa escala foi classificada nesta pesquisa em normal (0), quando o paciente avaliar sua dor, entre 0 a 3; alterada (1), quando o paciente avaliar sua dor entre 4 a 6 e muito alterada (2), quando a pontuação dada for entre 7 a 10.

Para a categorização destes pacientes considerou-se qual parâmetro clínico estava alterado e o quanto este se encontrava modificado, por exemplo, o paciente "A" apresentou variação nos seguintes nos parâmetros clínicos: temperatura (alterada $=1$ ) e a pressão arterial (muito alterada $=2$ ) e os outros dentro da normalidade (normal $=0$ ) resultando no total de 03. Esta soma de 
escores embasou a correlação feita entre os mecanismos de coping e estado de ansiedade e os parâmetros clínicos.

O outro formulário( Anexo 3) utilizado foi parte do inventário conhecido como Ansiedade Traço-Estado (IDATE) proposto por Spielberger, Gorsuch, Lushene $^{(10)}$ sendo que apenas as questões referentes à Ansiedade-Estado foram abordadas visto que em pesquisa realizada por Spielberger ${ }^{(9)}$ sobre ansiedade em pacientes cirúrgicos os escores encontrados eram altos para o estado de ansiedade independente do traço de ansiedade. E também pelo motivo de tornar a entrevista muito demorada o que poderia prejudicar o andamento normal das rotinas da unidade.

Essa escala consta de 20 afirmações, em que o sujeito indica a intensidade naquele momento (estado) através de uma escala de quatro pontos (1 a 4). O escore da escala varia de 20 a 80 , sendo que os escores mais altos indicam maior nível de ansiedade.

Em alguns itens deste inventário, as pontuações devem ser invertidas, já que o conteúdo das afirmações nele contidas é oposto às afirmações dos demais itens. São eles: 1, 2, 5, 8, 10, 11, 15, 16, 19 e 20. Para avaliação dos escores obtidos com o inventário 01 foi utilizada a categorização proposta por Chaves ${ }^{(20)}$ onde, uma pontuação de 20 a 40 pontos é considerada como baixo estado de ansiedade, de 40 a 60 pontos como médio estado de ansiedade e uma pontuação de 60 a 80 pontos considerada como alto estado de ansiedade. Ao final de cada avaliação, obteve-se um escore referente ao estado de ansiedade. 
Para a identificação dos esforços cognitivos e comportamentais, foi aplicado pela autora o inventário de estratégias de coping (Anexo 7), elaborado por estes, que constam de 66 itens, que englobam pensamentos e ações que as pessoas utilizam para lidar com demandas internas ou externas de um evento estressante específico. Cada administração do questionário centraliza-se no processo de coping de uma situação particular e não no coping como estilos ou traços de personalidade.

Savoia ${ }^{(28)}$ validou este inventário para a língua portuguesa obtendo 8 fatores, porém consideramos necessária a verificação da consistência interna a partir dos fatores existentes. Desta verificação um item foi eliminado dos fatores já existentes apresentados a seguir:

Fator 1 - Confronto: 47, 17, 40, 34, 07, 28. Fator 2 - Afastamento: 41, 13, 44, 21, 06, 16, 10. Fator 3 - Autocontrole: 15, 14, 43, 54, 35. Fator 4 - Suporte Social: 42, 45, 08, 31, 18, 22. Fator 5 - Aceitação de Responsabilidade: 51, 09, 52, 29, 48, 25, 62. Fator 6 - Fuga e Esquiva: 58,59. Fator 7 - Resolução de Problemas: 49, 26, 46, 01 . Fator 8 - Reavaliação Positiva: 38, 56, 60, 30, 39, 20, 36, 63, 23.

Para a obtenção do escore referente ao coping, cada item do inventário foi categorizado em:

Zero - não utilizei tal estratégia, um - utilizei pouco, dois - utilizei bastante tal estratégia, três - utilizei em grande quantidade.

Para o tratamento estatístico da pesquisa foi realizado primeiramente o teste de alfa de Cronbach onde se verificou a consistência interna do instrumento de coping através de um índice de confiabilidade que oscila entre valores de 0,00 e 
1,00. Neste estudo, considerou-se como confiabilidade um alfa de Cronbach de 0,50. O fator 3 - autocontrole apresenta alfa abaixo de 0,50, porém com a retirada do item 35 conseguimos aumentar o alfa não sendo então necessária a retirada deste fator no estudo

Tabela 5 - Resultado dos valores de alfa de Cronbach, obtidos pela análise de consistência interna do inventário de coping. São Paulo, 2002.

\begin{tabular}{lc}
\hline Mecanismos de coping (fator) & Alfa de Cronbach \\
\hline Fator 1 - Confronto & 0,52 \\
Fator 2 - Afastamento & 0,60 \\
Fator 3 - Autocontrole & 0,45 \\
Fator 4 - Suporte Social & 0,78 \\
Fator 5 - Aceitação de Responsabilidade & 0,68 \\
Fator 6 - Fuga e Esquiva & 0,50 \\
Fator 7 - Resolução de Problemas & 0,67 \\
Fator 8 - Reavaliação Positiva & 0,80
\end{tabular}

Para as seguintes análises do estudo foram realizados os cálculos de média-padrão, considerados os valores de mínimos e máximos, desviospadrão e medianas.

As relações entre as variáveis estado de ansiedade e estratégias de enfrentamento foram obtidas, aplicando-se os testes não paramétricos de prova de "U" de Mann-Whitney e o coeficiente de relação de Spearman.

Para as seguintes análises do estudo foram realizados os cálculos de médiaspadrão, considerados os valores de mínimos e máximos, desvios-padrão e medianas. 
As relações entre as variáveis estado de ansiedade e estratégias de enfrentamento foram obtidas, aplicando-se os testes não paramétricos de prova de "U" de Mann-Whitney e o coeficiente de relação de Spearman.

\section{Caracterização da amostra:}

A amostra deste estudo foi constituída por 40 pacientes sendo deste total, 21 pacientes do sexo masculino (52\%) e 19 pacientes do sexo feminino (48\%).

Em relação à faixa etária obteve-se 09 pacientes com idade entre 20 e 30 anos (22\%), 07 pacientes com idade entre 31 e 40 anos (18\%), 05 pacientes com idade entre 41 e 50 anos (13\%), 10 pacientes com idade entre 51 a 60 anos (24\%) e 09 pacientes com idade entre 61 e 70 anos $(23 \%)$.

Estes dados estão representados no gráfico 28. 
Gráfico 28 - Distribuição dos pacientes cirúrgicos ambulatoriais segundo a faixa etária. São Paulo, 2002.
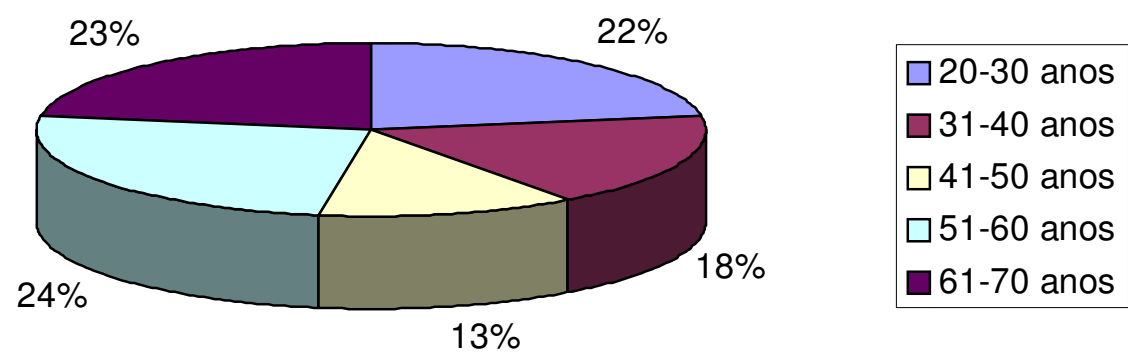

Com relação à experiência cirúrgica pregressa, 12 pacientes não haviam realizado cirurgias anteriores (30\%) e 28 pacientes já realizaram (70\%), ou seja, a amostra que apresenta uma maioria de indivíduos com experiências cirúrgicas anteriores e que provavelmente tem armazenado em suas memórias referências simbólicas relativas a esta vivência.

Segundo Peniche ${ }^{(38)}$ isto possivelmente trará para a avaliação da situação atual, sentimentos e enfrentamentos impregnados das situações anteriores e expressos no estado emocional atual assim como nos parâmetros clínicos avaliados.

Dos 28 pacientes que tiveram experiências anteriores, 19 não relataram a presença de intercorrências em suas cirurgias (68\%) e 09 relataram intercorrências (32\%). Estes dados encontram-se abaixo representados no gráfico 29. 
Gráfico 29 - Distribuição dos pacientes ambulatoriais segundo a presença de intercorrências em cirurgias anteriores. São Paulo cirúrgicos, 2002.

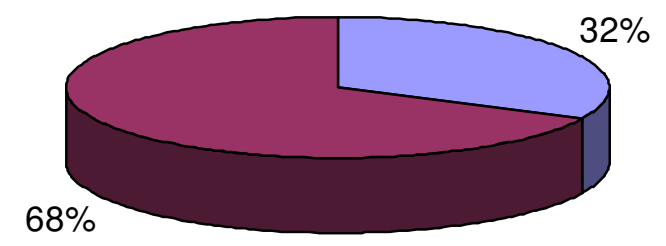

Mesmo tendo um número elevado de pacientes sem intercorrências no procedimento anestésico cirúrgico, não se pode desconsiderar o fato dos 19 pacientes (68\%) terem suas avaliações e comportamentos marcados pelas lembranças e que essas podem estar contribuindo atualmente na construção de mecanismos que os auxiliem nesta experiência.

Com relação ao estado de ansiedade encontramos, 26 pacientes com baixo estado de ansiedade (64\%), 12 pacientes com médio estado de ansiedade (33\%) e 02 pacientes com alto estado de ansiedade (3\%). Estes dados encontram-se no gráfico 30. 
Gráfico 30 - Distribuição dos pacientes cirúrgicos ambulatoriais segundo a variação dos valores do estado de ansiedade pré-operatório. São Paulo, 2002.

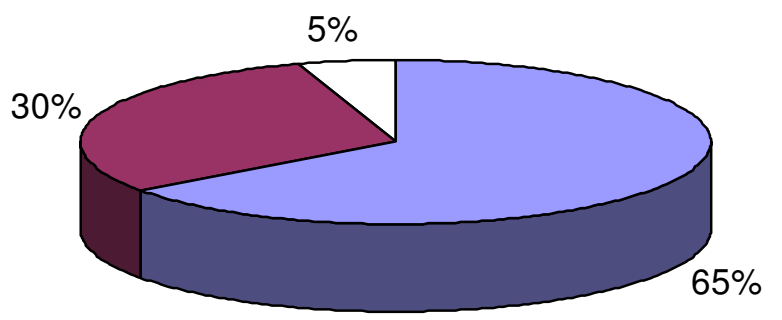

Estes dados caracterizam uma amostra composta por pacientes com baixo estado de ansiedade (65\%).

$\mathrm{Na}$ maioria dos estudos realizados tem-se encontrado pacientes com baixo estado de ansiedade o que leva a questionar sobre a verocidade das informações obtidas com o questionário. Para Spielberger ${ }^{(9)}$ a existência da ansiedade inconsciente, que apesar de estar presente não pode ser detectada por vários testes, pode levar a uma falsa avaliação.

Mitchell ${ }^{(36)}$ em seu estudo, em um serviço de cirurgia ambulatorial constatou que $97 \%$ dos pacientes experimentaram algum grau de ansiedade. Quando indagados quais aspectos aumentaram a ansiedade sentida, os sujeitos apontaram com maior freqüência: o procedimento anestésico (anestesia geral), a espera na unidade pelo procedimento cirúrgico e a possibilidade de dor e desconforto; quando questionados quais os aspectos que minimizam a ansiedade, os pacientes responderam com maior incidência: as informações recebidas da enfermeira, o ambiente da unidade e as informações recebidas do anestesista e a permanência destes ao seu lado. 
É possível supor com isso que o fato das cirurgias serem ambulatoriais sem anestesia geral e em um hospital que prioriza a orientação do paciente tenha contribuído com os resultados aqui obtidos.

Independentemente do grau de ansiedade esta, desencadeará uma reação simpática que neste estudo se expressou com alterações dos valores dos parâmetros clínicos basais.

Do total de pacientes, encontramos 10 pacientes com variação de 0 ponto no formulário de parâmetros clínicos (25\%), 12 pacientes com variação de 1 ponto (30\%), 10 pacientes com variação de 2 pontos (25\%), 04 pacientes com variação de 3 pontos (10\%) e 02 pacientes com variação de 4 pontos e 02 com variação de 5 pontos no formulário de parâmetros clínicos (5\% respectivamente).

Encontramos esses dados representados no gráfico 31.

Gráfico 31 - Distribuição dos pacientes cirúrgicos ambulatoriais segundo a categorização estabelecida sobre a variação dos parâmetros clínicos no período pré-operatório. São Paulo, 2002.
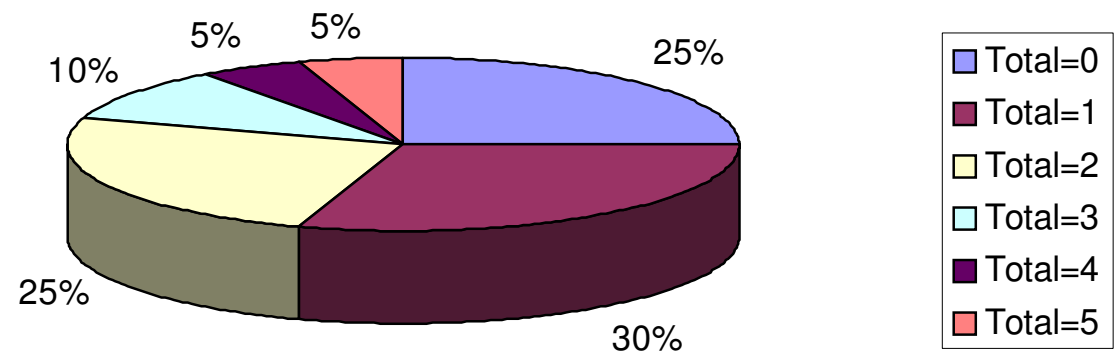

Segundo Handly, Neff ${ }^{(78)}$ nem todas as pessoas reagem ao estresse de forma igual, ou seja, os órgãos e sistemas que reagem ao estresse também variam de pessoa para pessoa. Enquanto para uns a manifestação se dá no trato gastrointestinal, para outros pode ser no sistema 
cardiovascular ou músculo-esquelético. O resultado imediato do estresse transitório ou crônico é a adaptação que pode ser uma resposta patológica ou fisiológica de diferente intensidade, duração ou qualidade.

A seguir apresenta-se a identificação dos mecanismos de coping utilizados pelos pacientes cirúrgicos ambulatoriais da pesquisa.

Verifica-se, observando a tabela 06 que 0 agrupamento do mecanismo de coping mais utilizado, em média $(1,57)$, pelos pacientes cirúrgicos ambulatoriais é o de suporte social. Seguido pelos agrupamentos de resolução de problemas $(1,44)$ e reavaliação positiva $(1,41)$.

Acredita-se que os pacientes da amostra contaram com o apoio de parentes e amigos, assim como com a procura de mais informações sobre a cirurgia encontrando-os na própria filosofia institucional que proporciona ao paciente o acesso para o esclarecimento de suas dúvidas e incertezas.

O agrupamento resolução de problemas pertence à classificação de enfrentamento centrado no problema e pode ajudar o indivíduo a reduzir a emoção eliminando as demandas ambientais, por meio da busca de informações e ações de solução de problemas.

Enquanto o agrupamento de reavaliação positiva está classificado no enfrentamento centrado na emoção e tende ao desenvolvimento de planos de ação para minimizar as emoções negativas, por meio da regulação afetiva ou da descarga emocional adequando a resposta emocional ao problema. O indivíduo tenta atenuar o desconforto emocional, dando uma interpretação realista ou distorcida do fato. 
Tabela 6 - Distribuição dos pacientes segundo a média de utilização dos mecanismos de coping. São Paulo, 2002.

\begin{tabular}{|c|c|c|c|c|c|c|}
\hline Fator & $\mathbf{N}$ & Média & d.p. & Mediana & Mínimo & Máximo \\
\hline Fator 1 - confronto & 40 & 0,54 & 0,46 & 0,50 & - & 1,66 \\
\hline Fator 2 - afastamento & 40 & 0,96 & 0,56 & 0,85 & - & 2,42 \\
\hline Fator 3 - autocontrole & 40 & 1,18 & 0,59 & 1,00 & - & 2,50 \\
\hline Fator 4 - suporte social & 40 & 1,57 & 0,74 & 1,66 & 0,16 & 2,83 \\
\hline $\begin{array}{l}\text { Fator } 5 \text { - aceitação de } \\
\text { responsabilidade }\end{array}$ & 40 & 0,80 & 0,60 & 0,71 & - & 2,14 \\
\hline Fator 6 - fuga e esquiva & 40 & 1,00 & 0,93 & 1,00 & - & 3,00 \\
\hline $\begin{array}{c}\text { Fator } 7 \text { - resolução de } \\
\text { problemas }\end{array}$ & 40 & 1,44 & 0,77 & 1,25 & 0,25 & 3,00 \\
\hline Fator 8 - reavaliação positiva & 40 & 1,41 & 0,69 & 1,44 & 0,22 & 3,00 \\
\hline
\end{tabular}
Segundo Kaplan, Sadock ${ }^{(41)}$, entre muitas estratégias de enfrentamento existentes, o que determina sua eleição é a natureza de estressor, as circunstâncias em que ele se reproduz, a história prévia de confronto e o próprio estilo que caracteriza o sujeito, ou seja, como ele enfrentou uma situação passada. Há dois tipos básicos de indivíduos, aqueles que tem tendência evitadora ou minimizadora e aqueles com estilo afrontativo ou vigilante.

Conforme cita Cade ${ }^{(40)}$, há vários estudos que tentam desvendar as estratégias mais comumente utilizadas, tanto em situações específicas, como em situações gerais. Porém os resultados são difíceis de serem generalizados, em razão da diferença nas amostras populacionais das situações estudadas e nos instrumentos utilizados para a verificação das 
estratégias, os quais categorizam as estratégias de enfrentamento de formas distintas.

Em relação ao estado de ansiedade relacionado à distribuição dos pacientes quanto ao sexo, temos que no sexo feminino a média foi de 38,8 pontos caracterizando-se assim como uma amostra de baixo estado de ansiedade, assim como nos pacientes do sexo masculino, porém com média de 33,8 pontos. Encontramos esses dados no gráfico 32 .

Gráfico 32 - Distribuição das médias de estado de ansiedade segundo o sexo. São Paulo, 2002.

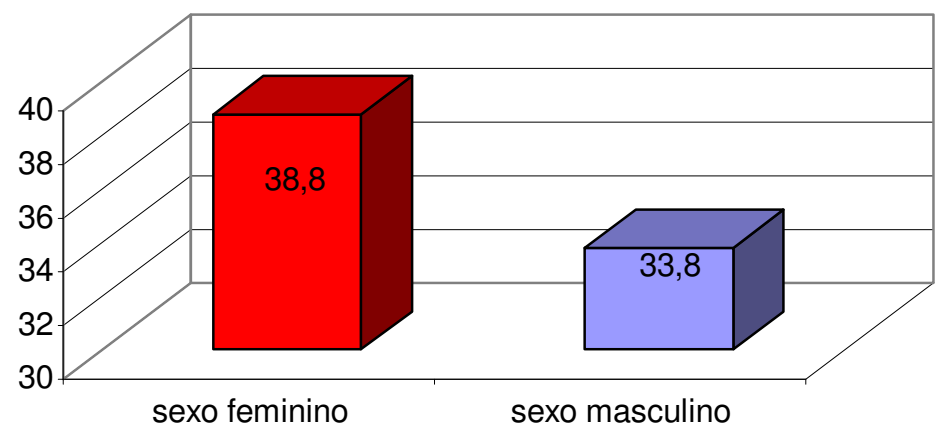

Pode-se dizer que as mulheres da amostra apresentaram maior média de estado de ansiedade com 5 pontos a mais do que os homens.

$\mathrm{Na}$ pesquisa de Peniche, Moraes ${ }^{(72)}$ as mulheres também foram as que apresentaram maior média de estado de ansiedade no período préoperatório. Esta variação foi da ordem de décimos e ainda de acordo com Peniche $^{(40)}$ que em seu estudo encontrou aumento de ansiedade nas mulheres, porém foi constatado que elas responderam positivamente quando expostas à cirurgia.

Com relação à variação de parâmetros clínicos, as mulheres apresentaram média de 2,0 pontos, ou seja, no mínimo 02 parâmetros clínicos alterados, já os homens obtiveram média de 1,1. O que mostra que 
os homens estavam clinicamente mais estáveis e possivelmente menos ansiosos que as mulheres e assim não apresentaram estado de ansiedade alto, nem variações clínicas significantes uma vez que os parâmetros refletem a atividade nervosa do sistema nervoso simpático, ou ainda que, como cita Farah ${ }^{(73)}$ ao comentar acerca das estratégias de coping, foram capazes de resolver os conflitos e não não foram necessárias grandes variações dos marcadores de ansiedade, ou seja exibiram uma estabilidade maior dos parâmetros clínicos.

Apesar do teste estatístico realizado, mostrar que entre o grupo dos homens e o das mulheres não foram encontradas diferenças significantes quanto à utilização dos mecanismos de coping, ao se analisar as médias dos homens e das mulheres encontrou-se que os homens utilizaram mais o agrupamento do suporte social enquanto que as mulheres o agrupamento mais utilizado foi 0 da reavaliação positiva. Esses dados estão representados no gráfico abaixo. 
Gráfico 33 - Distribuição dos agrupamentos de mecanismos de coping de acordo com a utilização entre homens e mulheres da amostra de pacientes cirúrgicos ambulatoriais. São Paulo, 2002.

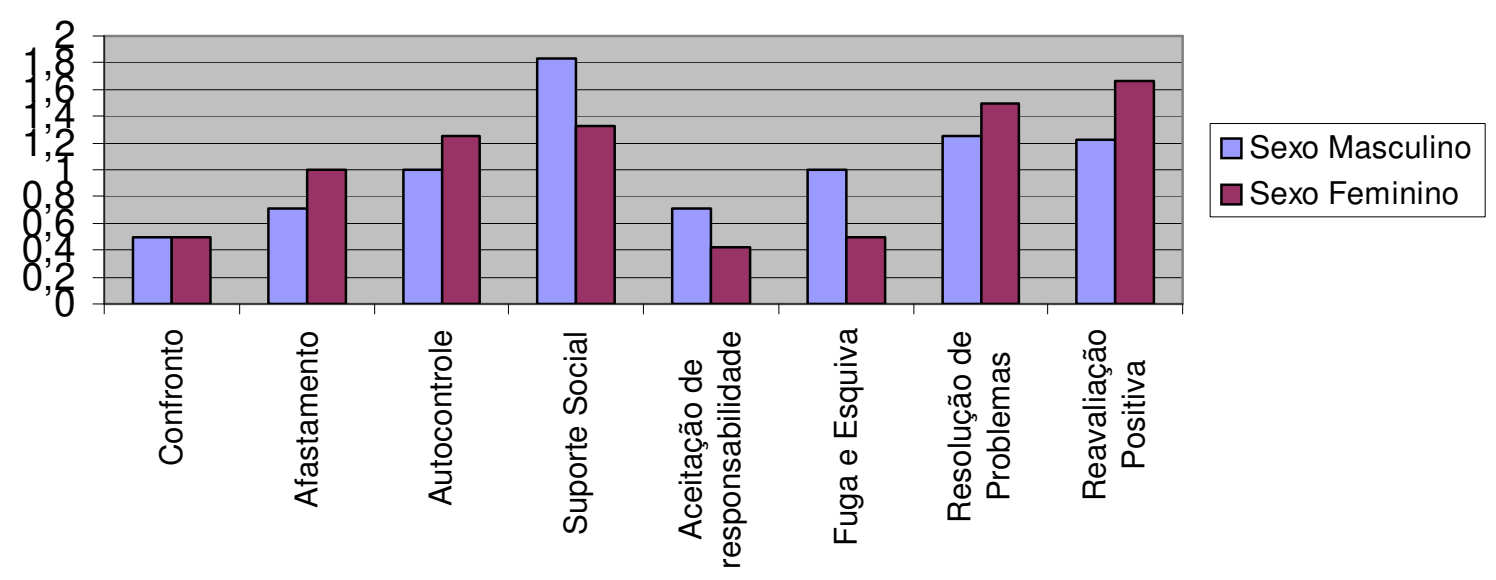

Em relação à idade, a faixa etária com maior média de estado de ansiedade foi a de 20-30 anos com 41,6 pontos, seguida pela faixa de 41-50 anos com média de 36,4 pontos.

A faixa etária menos ansiosa foi de 61-70 anos onde a média de estado de ansiedade foi de 31,7 pontos.

Encontra-se esta distribuição no gráfico 34. 
Gráfico 34 - Distribuição das médias de estado de ansiedade segundo a faixa etária. São Paulo, 2002.

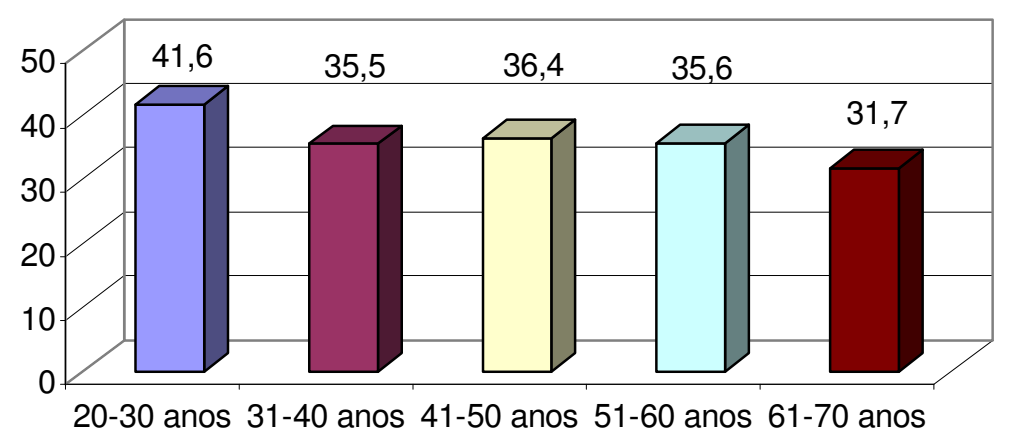

Para Galdino ${ }^{(46)}$ em seu estudo sobre a ansiedade, depressão e coping em idosos obteve resultados que evidenciaram a presença de médio a baixos níveis de ansiedade nesses pacientes.

Em relação à variação de parâmetros clínicos, temos a maior variação na faixa etária de 41-50 anos com média de 2,4 pontos. A faixa etária com menor média foi a de 31-40 anos com 0,8 ponto. As faixas etárias de 20-30 anos, 51-60 anos e 61-70 anos obtiveram médias de 1,4 nas duas primeiras e 1,8 na última.

Quanto à utilização dos mecanismos de coping, podemos observar na tabela que não há correlação significante entre coping e idade e estado de ansiedade de acordo com o teste de correlação de Spearman. 
Tabela 7 - Distribuição dos pacientes segundo a idade o estado de ansiedade e os mecanismos de coping de acordo com o teste de correlação de Spearman. São Paulo, 2002.

\begin{tabular}{lcc}
\hline Mecanismos de Coping (fatores) & Idade & Estado \\
\hline Fator 1 - confronto & $-0,04825=\mathrm{r}$ & $0,21519=\mathrm{r}$ \\
& $0,7675=\mathrm{p}$ & $0,1824=\mathrm{p}$ \\
Fator 2 - afastamento & $-0,13927=\mathrm{r}$ & $-0,05261=\mathrm{r}$ \\
& $0,3914=\mathrm{p}$ & $0,7471=\mathrm{p}$ \\
Fator 3 - autocontrole & $0,03033=\mathrm{r}$ & $0,11424=\mathrm{r}$ \\
& $0,8526=\mathrm{p}$ & $0,4827=\mathrm{p}$ \\
Fator 4 - suporte social & $0,04889=\mathrm{r}$ & $0,22207=\mathrm{r}$ \\
& $0,7645=\mathrm{p}$ & $0,1685=\mathrm{p}$ \\
Fator 5 - aceitação de responsabilidade & $-0,09636=\mathrm{r}$ & $0,29997=\mathrm{r}$ \\
& $0,5542=\mathrm{p}$ & $0,0600=\mathrm{p}$ \\
Fator 6 - fuga e esquiva & $-0,18254=\mathrm{r}$ & $0,30403=\mathrm{r}$ \\
& $0,2596=\mathrm{p}$ & $0,0565=\mathrm{p}$ \\
Fator 7 - resolução de problemas & $0,03427=\mathrm{r}$ & $0,06158=\mathrm{r}$ \\
& $0,8337=\mathrm{p}$ & $0,7058=\mathrm{p}$ \\
& $0,01510=\mathrm{r}$ & $0,00057=\mathrm{r}$ \\
& $0,9263=\mathrm{p}$ & $0,9972=\mathrm{p}$ \\
\hline
\end{tabular}

Nos pacientes com experiências cirúrgicas anteriores, a média de estado de ansiedade é de 34 pontos enquanto a média daqueles sem experiência é de 41,2 pontos. O que mostra que os pacientes que já passaram por situação similar responderam com menor ansiedade do que aqueles sem experiência, isto é, talvez por não terem nenhum conhecimento do que irá acontecer respondem com maior ansiedade, encontra-se representação desses dados no gráfico. 
Gráfico 35 - Distribuição das médias de estado de ansiedade segundo a realização de cirurgias anteriores. São Paulo, 2002.

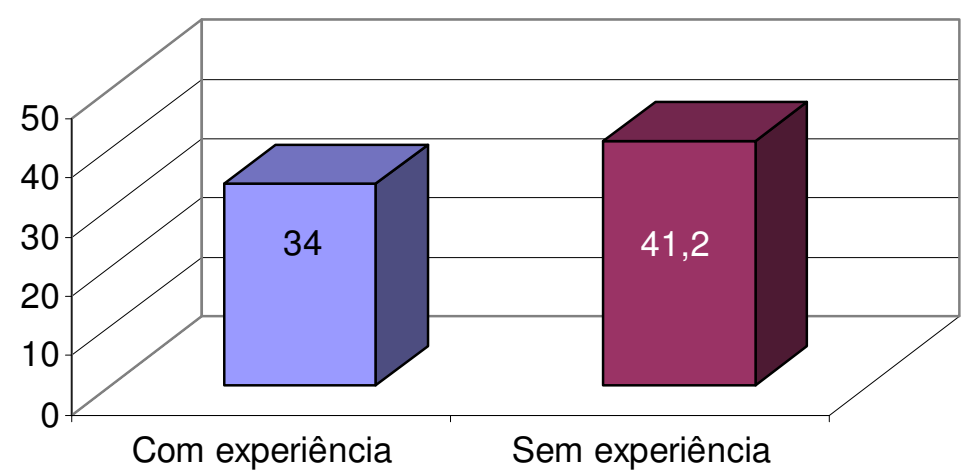

Na pesquisa Peniche, Moraes ${ }^{(72)}$, os dados obtidos quanto ao estado de ansiedade no período pré-operatório também apontaram para um estado maior de ansiedade nos pacientes sem experiências anteriores.

Para Gonçalves ${ }^{(74)}$ a tranqüilidade do paciente depende do mesmo uma visualização antecipada de todos os passos que irão ocorrer, inclusive da sala operatória.

Com relação à variação de parâmetros clínicos destes pacientes nos mostra que os sem experiência apresentaram média de 1,3 ponto enquanto os pacientes com experiência obtiveram uma média de 1,6 ponto.

Quanto aos mecanismos de coping utilizados, o teste estatístico realizado mostra que entre os dois grupos (com ou sem experiência cirúrgica anterior) não foram encontradas diferenças significantes, porém ao se analisar as médias simples encontra-se que o agrupamento mais utilizado pelos pacientes com ou sem experiências anteriores foi o de suporte social. E o agrupamento menos utilizado pelos dois grupos foi o de confronto. 
Gráfico 36 - Distribuição dos agrupamentos de mecanismos de coping de acordo com a utilização entre pacientes cirúrgicos ambulatoriais com ou sem experiência anterior da amostra. São Paulo, 2002.

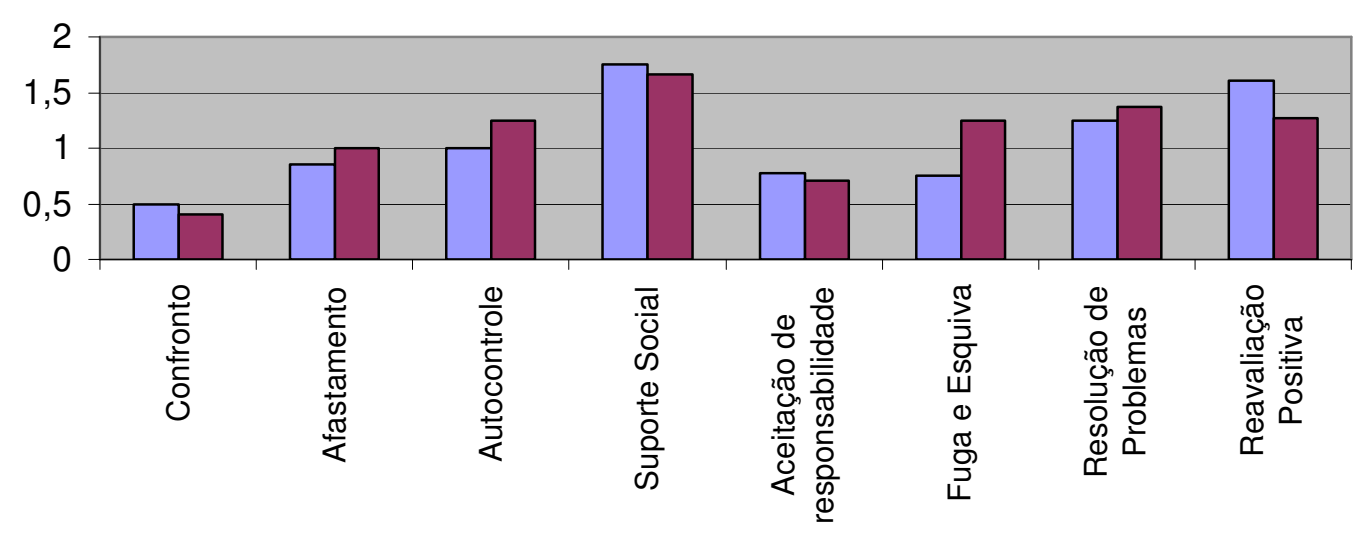

$\square$ Experiência Anterior $\square$ Sem Experiênci Anterior

Quanto à média do estado de ansiedade dos pacientes em relação à existência de intercorrências obteve-se que a média dos pacientes com intercorrências é de 37 pontos enquanto dos sem intercorrência é de 32,6 pontos. O que sugere que os pacientes com experiências anteriores e que apresentaram algum tipo de problema responderam com maior ansiedade do que aqueles que não apresentaram problemas. Esses dados são encontrados no gráfico abaixo. 
Gráfico 37 - Distribuição das médias de estado de ansiedade segundo a presença de intercorrências em cirurgias anteriores. São Paulo, 2002.

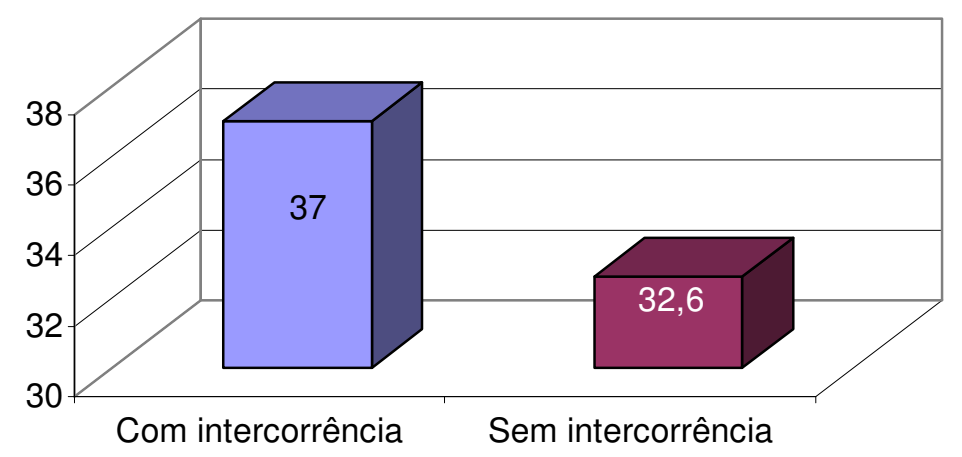

Encontram-se dados correspondentes na pesquisa de Peniche, Moraes ${ }^{(79)}$ onde também os pacientes com intercorrências apresentaram maior estado de ansiedade pré-operatória.

Em relação à variação dos parâmetros clínicos tem-se que o grupo com maior média na variação foi o dos pacientes com intercorrência com 2,2 pontos de média, enquanto os pacientes sem intercorrência apresentaram média de 1,3 pontos.

Quanto aos mecanismos de coping utilizados, o teste estatístico realizado nos mostra que entre os dois grupos (com ou sem intercorrência) não foram encontradas diferenças significantes, porém ao se analisar as médias simples encontrou-se que o agrupamento mais utilizado foi o de suporte social enquanto o menos utilizado foi o de confronto.

Os dados referentes aos mecanismos de coping utilizados por esse grupo encontram-se no gráfico 38. 
Gráfico 39 - Distribuição dos agrupamentos de mecanismos de coping de acordo com a utilização entre pacientes cirúrgicos ambulatoriais com ou sem intercorrências da amostra. São Paulo, 2002.

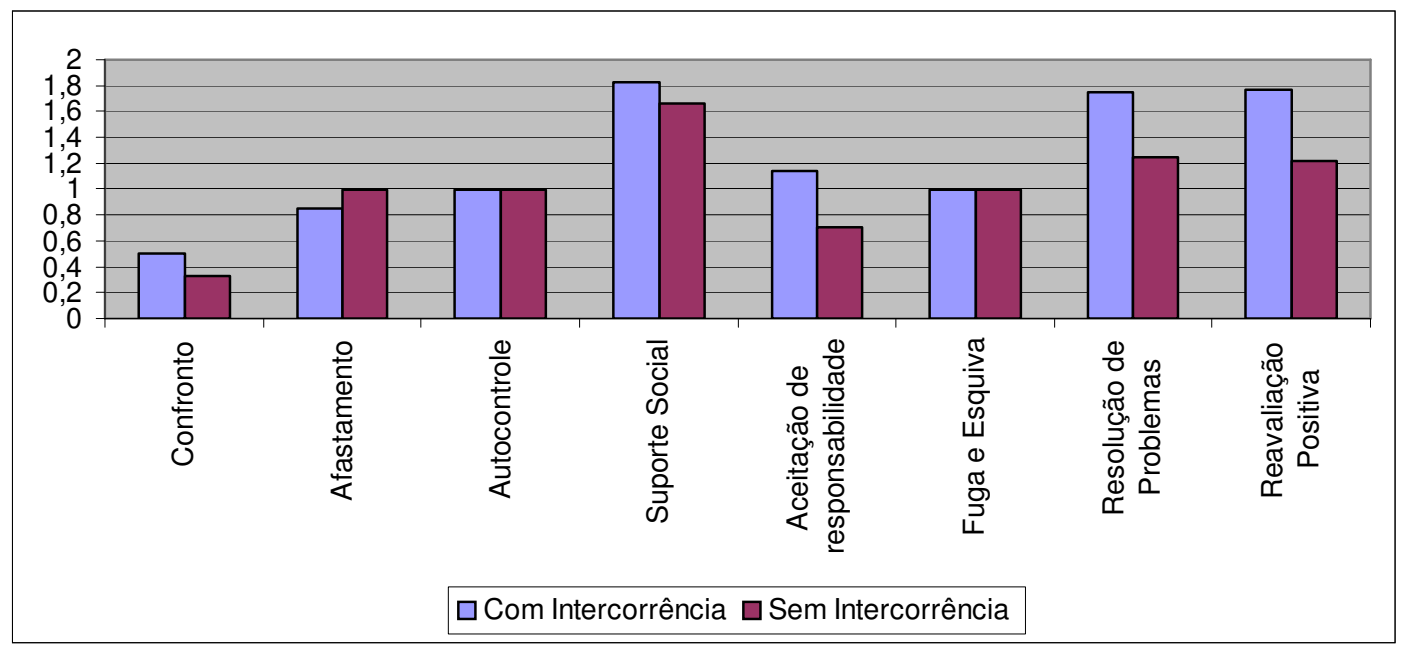

A tendência em escolher uma determinada estratégia de coping depende do repertório individual (muitas estratégias podem ser úteis para uma mesma situação) e de experiências tipicamente reforçadas.

\section{Relação das variáveis em estudo}

Como a amostra não apresentou uma distribuição normal dos mecanismos de coping entre os grupos de ansiedade baixa e média considerou-se necessário aplicar o teste de Mann-Whitney com a finalidade de compor os dois grupos.

$\mathrm{Na}$ tabela abaixo estão expressos os valores obtidos entre cada fator e os dois grupos de ansiedade, o grupo de baixa ansiedade, com 26 pacientes, e o de média ansiedade, com 14 pacientes. Os 02 pacientes com alta ansiedade foram inseridos no grupo de média ansiedade, pois estatisticamente não seria possível tratá-lo como um grupo distinto. 
Tabela 8 - Distribuição dos pacientes segundo o estado de ansiedade e mecanismos de coping (teste não paramétrico de Mann-Whitney). São Paulo, 2002.

\begin{tabular}{lllllllll}
\hline Fator & Ansiedade & $\mathbf{N}$ & Média & d.p. & Mediana & Mínimo & Máximo & p $^{*}$ \\
\hline Fator 1 & Baixa & 26 & 0,43 & 0,44 & 0,25 & - & 1,50 & 0,003 \\
Confronto & Média-alta & 14 & 0,73 & 0,44 & 0,58 & - & 1,66 & \\
Fator 2 Afastamento & Baixa & 26 & 0,89 & 0,45 & 0,92 & - & 1,85 & 0,540 \\
& Média-alta & 14 & 1,05 & 0,72 & 0,85 & - & 2,42 & \\
Fator-3 Autocontrole & Baixa & 26 & 1,09 & 0,51 & 1,00 & - & 2,00 & 0,295 \\
& Média-alta & 14 & 0,35 & 0,69 & 1,37 & 0,25 & 2,50 & \\
Fator 4 & Baixa & 26 & 1,37 & 0,66 & 1,33 & 0,16 & 2,83 & 0,001 \\
Suporte social & Média-alta & 14 & 1,96 & 0,75 & 2,16 & 0,33 & 2,83 & \\
Fator 5 & Baixa & 26 & 0,62 & 0,54 & 0,50 & - & 2,14 & 0,071 \\
Aceitação de & Média-alta & 14 & 1,15 & 0,57 & 1,21 & - & 2,14 & \\
responsabilidade & & & & & & & & \\
Fator 6 & Baixa & 26 & 0,80 & 0,91 & 0,50 & - & 3,00 & 0,032 \\
Fuga e esquiva & Média-alta & 14 & 1,35 & 0,88 & 1,50 & - & 3,00 & \\
Fator 7 & Baixa & 26 & 1,33 & 0,69 & 1,25 & 0,25 & 3,00 & 0,253 \\
Resolução de & Média-alta & 14 & 1,64 & 0,90 & 1,75 & 0,25 & 3,00 & \\
problemas & & & & & & & & \\
Fator 8 & Baixa & 26 & 1,31 & 0,64 & 1,33 & 0,33 & 2,66 & 0,261 \\
Reavaliação positiva & Média-alta & 14 & 1,58 & 0,77 & 1,72 & 0,22 & 3,00 & \\
\hline
\end{tabular}

${ }^{*} \mathrm{p} \leq 0,05$

Pode-se observar na tabela acima que houve diferença significante entre os dois grupos de ansiedade (pacientes com baixa e média ansiedade) no que se refere à utilização dos mecanismos de coping, ou seja, o fator 1confronto $(p=0,003)$ foi mais utilizado por aqueles pacientes com ansiedade média, assim como o fator 4-suporte social $(p=0,001)$, o fator 5-aceitação de responsabilidade $(p=0,071)$ e $\circ 6$ - fuga e esquiva $(p=0,032)$.

Portanto os pacientes com ansiedade média apresentaram valores significantemente maiores nas estratégias de enfrentamento confronto, 
suporte social, aceitação de responsabilidade e fuga e esquiva, ou seja, se utilizaram mais destas estratégias.

Continuando a análise entre as variáveis de estado de ansiedade e mecanismos de coping, foi realizado o teste de correlação de Spearman, onde não foram encontradas correlações estatisticamente significantes apesar de se utilizarem mais de uma estratégia que de outra.

Pode-se observar que mesmo não havendo uma correlação estatisticamente significante há uma tendência para tal nos mecanismos de coping relacionados à fuga e esquiva $(0,0565)$. $E$ ainda que, na medida em que o estado de ansiedade aumenta, existe uma tendência de utilização dos mecanismos de fuga e esquiva.

Como já citado na introdução, segundo Savoia ${ }^{(28)}$ em geral as formas de coping centradas na emoção são passíveis de ocorrer quando já houve uma avaliação de que nada pode ser feito para modificar as condições de dano, ameaça ou desafio ambiental, o que se acredita que seja a situação dos pacientes cirúrgicos pois os mesmos sabem da necessidade da realização da cirurgia e portanto não podem mudar a situação.

Essa análise se encontra expressa na tabela abaixo. 
Tabela 9 - Distribuição dos pacientes segundo o estado de ansiedade e mecanismos de coping (teste de correlação de Spearman). São Paulo, 2002.

\begin{tabular}{lc}
\hline Mecanismos de Coping (fatores) & Estado de Ansiedade \\
\hline Fator 1 - confronto & $0,21519=\mathrm{r}$ \\
& $0,1824=\mathrm{p}$ \\
Fator 2 - afastamento & $-0,5261=\mathrm{r}$ \\
& $0,7471=\mathrm{p}$ \\
Fator 3 - autocontrole & $0,11424=\mathrm{r}$ \\
Fator 4 - suporte social & $0,4827=\mathrm{p}$ \\
Fator 5 - aceitação de responsabilidade & $0,22207=\mathrm{r}$ \\
Fator 6 - fuga e esquiva & $0,1685=\mathrm{p}$ \\
& $0,29997=\mathrm{r}$ \\
Fator 7 - resolução de problemas & $0,0600=\mathrm{p}$ \\
& $0,30403=\mathrm{r}$ \\
& $0,0565=\mathrm{p}$ \\
& $0,06158=\mathrm{r}$ \\
& $0,7058=\mathrm{p}$
\end{tabular}

Segundo Farah ${ }^{(80)}$, se o coping for eficiente atenua o estresse. Porém quando as estratégias de coping não conseguem resolver os conflitos, as mudanças fisiológicas passam a atuar em função do coping. As estratégias de coping podem ser avaliadas quanto aos resultados produzidos. Quando conseguem controlar os eventos estressantes, adaptando os indivíduos às mudanças, considera-se que as estratégias foram eficientes. Se o indivíduo chega a uma situação de exaustão, essas estratégias não foram suficientes. Pode haver também estratégias de coping deficientes ou ainda paliativas, onde depois de algum tempo o indivíduo retorna à situação estressante. $\mathrm{O}$ 
indivíduo terá maior possibilidade de dominar a situação estressora quanto mais resolutivas forem as estratégias de coping de que dispõe.

\section{Os dados do protocolo 4 mostraram que:}

A maioria dos pacientes cirúrgicos ambulatoriais no período préoperatório apresentou baixo estado de ansiedade e com variação normal dos parâmetros clínicos, ou seja, compatíveis com o estado emocional apresentado.

Os mecanismos de coping mais utilizados foram o de suporte social, seguido pelo de resolução de problemas e reavaliação positiva.

Apesar de não existir uma correlação estatisticamente significante entre ansiedade e mecanismos de coping utilizados, encontra-se uma tendência na utilização do mecanismo de fuga e esquiva. 


\section{Conclusões}


Conclusão Protocolo 1: 
Com relação ao traço e estado de ansiedade identificamos uma amostra pouco ansiosa, respondendo no período pós-operatório com baixa ansiedade e sem alterações significativas estatisticamente dos parâmetros clínicos.

\section{Conclusão Protocolo 2:}

A maioria dos pacientes cirúrgicos ambulatoriais no período préoperatório apresentou baixo estado de ansiedade e com variação normal dos parâmetros clínicos, ou seja, compatíveis com o estado emocional apresentado.

Os mecanismos de coping mais utilizados foram o de suporte social, seguido pelo de resolução de problemas e reavaliação positiva.

Apesar de não existir uma correlação estatisticamente significante entre ansiedade e mecanismos de coping utilizados, encontramos uma tendência na utilização do mecanismo de fuga e esquiva.

\section{Conclusão Protocolo 3:}

A amostra compôs-se em sua maioria por pacientes do sexo feminino com uma idade média de 46 anos, com baixo grau de escolaridade, com experiência cirúrgica anterior, sem intercorrências e apresentando baixo e médio estado de ansiedade.

As estratégias de enfrentamento mais comumente utilizadas foram as de suporte social e a de resolução de problemas. 
Com relação à ansiedade e às estratégias de enfrentamento, obtevese uma correlação negativa entre o estado de ansiedade e o suporte social e estado de ansiedade e resolução de problemas.

Concluí-se que o ato anestésico-cirúrgico não elevou o estado de ansiedade da amostra estudada, independente do sexo, idade, tipo de cirurgia ou anestesia. Isto pode também estar relacionado com o tipo de população, as informações que estes pacientes obtiveram no pré-operatório, as suas experiências prévias e a sua maneira de avaliar a situação.

\section{Conclusão Protocolo 4:}

A análise dos resultados deste estudo permitiu as seguintes conclusões:

Os pacientes submetidos à revascularização do miocárdio apresentaram em sua maioria $(51,20 \%)$ um médio estado de ansiedade no período pré-operatório imediato.

Verificou-se a ocorrência de infecção do sítio cirúrgico em 11 pacientes $(8,66 \%)$.

Não observada a existência de relação estatisticamente significante entre estado de ansiedade no período pré-operatatório imediato e a infecção do sítio cirúrgico nestes pacientes $(p=0,120)$. 
CONSIDERAÇÕES FINAIS 


\section{CONSIDERAÇÕES FINAIS}

Parece não haver dúvidas, que existe uma correlação estreita entre a percepção sensitiva e cognitiva de uma ameaça, o surgimento da ansiedade e do stress e alterações fisiológicas perceptíveis clinicamente. No entanto, neste estudo, estas afirmações não são retratadas pela lógica da matemática, ou seja, quando aplicados os testes estatísticos aos resultados aqui obtidos nos protocolos, a oscilação numérica nem sempre resultou em relação de significância como era esperado.

Em todos os protocolos desenvolvidos partiu-se de uma hipótese comum, isto é, a ansiedade interfere não só os parâmetros clínicos dos pacientes no período pós-operatório como também pode influenciar no aparecimento de complicações neste mesmo período e em suas estratégias de enfrentamento.

O que se obteve como resultados, relacionados aos parâmetros clínicos e possíveis alterações e complicações no período pós-operatório, foi que a ansiedade interfere, mas não de uma forma estatisticamente significante.

É provável que isso decorra de limitações metodológicas existentes nos protocolos apresentados, sejam elas relacionadas ao método propriamente dito, ao tipo de amostra obtida e ao instrumento utilizado para se avaliar a ansiedade.

Com relação ao método científico utilizado as principais limitações se referem aos problemas de mensuração da ansiedade uma vez que ainda 
não foram desenvolvidas medidas que retratem numericamente o estado emocional.

Alguns testes estatísticos parecem ser mais apropriados para tal, como análise de correspondência múltipla utilizado no protocolo 3 , onde os itens do questionário utilizado para avaliar ansiedade são tratados como qualitativos, não agregando valor numérico às respostas. Sendo assim as 20 questões são consideradas como 20 variáveis, o que garante ao mesmo tempo a formação de grupos de pacientes e a individualidade de cada sujeito deste grupo.

A singularidade de cada ser humano é outra grande dificuldade encontrada para o desenvolvimento destas pesquisas, principalmente quanto se trata de um tema como a ansiedade, que envolve aspectos neuroendócrinos imbricados à percepção sensitiva e cognitiva, e que são analisados aqui de forma tão linear e pontual, isto é, a ansiedade do paciente cirúrgico avaliada em um momento pré-determinado pelos protocolos, e mesmo tendo ciência de todo o processo que envolve o paciente nesta situação, não se tem como medir esta compreensão, utilizando-se tal método.

Escolhido este paradigma para o desenvolvimento dos protocolos, outros marcadores de ansiedade poderiam dar suporte aos resultados obtidos.

Segundo Frazier ${ }^{(75)}$ importantes indicadores, além das variações dos parâmetros clínicos, como a agitação, verbalização e impaciência devem ser 
monitorados e conhecidos pelo enfermeiro para avaliar o estado de ansiedade dos pacientes críticos.

O enfermeiro de uma forma geral e principalmente aquele que presta o cuidado ao paciente submetido ao procedimento anestésico cirúrgico tem buscado estratégias que o auxiliem nesta avaliação.

Em âmbito nacional Jouclas; Salzano( ${ }^{59)}$ foram as precursoras na busca de instrumentos que respaldassem o enfermeiro na assistência perioperatória, uma vez que corroboravam com a influência da ansiedade, como uma das causas de cancelamento ou adiantamento da cirurgia, e com a probabilidade de elevação da morbimortalidade no período pós operatório.

A partir de então o enfermeiro de centro cirúrgico esta alerta para esta questão complexa, ou seja, como avaliar e intervir positivamente no estado emocional do paciente cirúrgico.

Silva ${ }^{(61)}$ identificou que o ato de conversar, tocar e ouvir o paciente são estratégias utilizadas pelos enfermeiros para prestar apoio emocional, mas que nem sempre produzem um resultado positivo, uma vez que estes atos, estão pautados exclusivamente na empatia e formação religiosa de ambos, evidenciando a necessidade de uma avaliação e intervenção que sejam embasadas cientificamente e não somente no senso comum.

Sendo a ansiedade um fenômeno adaptativo entre o paciente, o ambiente cirúrgico e os processos neurofisiológicos, aqueles com alto estado de ansiedade sugerem aumento de riscos e complicações no período pós operatório decorrente da exacerbação da resposta neuroendócrina e metabólica. ${ }^{(76 ; 5)}$. 
Porém há uma dificuldade prática em se demonstrar numericamente esta constatação, ou seja, 45 pacientes do protocolo 3 com alto nível de ansiedade, apresentaram uma relação estatisticamente não significante $\mathrm{p}=0,849)$ com aparecimento da infecção do sítio cirúrgico, como uma das complicações no período pós operatório provavelmente compatível com o aumento de cortisol.

Esta dificuldade em se constatar que o aumento de cortisol leva a imunodepressão, se acentuada quando já se sabe que o mesmo é liberado desde o período perioperatório. Vale ressaltar ainda que várias são as vias e os estímulos que atingem o eixo hipotálamo-hipófise com conseqüente liberação dos mediadores da resposta ao estresse cirúrgico ${ }^{(5)}$

Em estudo realizado ${ }^{(77)}$, com 39 pacientes submetidos à cirurgia eletiva de endarterectomia sob anestesia local, analisou-se as concentrações de cortisol e a catecolamina urinário em dois momentos(24 horas antes da cirurgia e na indução anestésica) e constatou-se que não houve significância estatística entre resposta neuroendócrina e as complicações, além do que os pacientes apresentaram um aumento de ansiedade pré-operatória associado a baixa concentração de cortisol no intra-operatório.

Se for possível relacionar, estado de ansiedade elevado com complicações no período pós-operatório, então, tanto os resultados obtidos com o protocolo 3 como os encontrados pelo estudo citado ${ }^{(85)}$ não constataram esta relação. 
É provável que esta comparação feita, entre estes dois estudos seja questionada, uma vez que a intensidade da resposta neuroendócrina tem correlação direta com a extensão e local da cirurgia. Porém, como é ressaltado em estudo realizado ${ }^{(5)}$ a resposta ao trauma pode ser atenuada somente em cirurgias infraumbelicais e de membros inferiores em associação com técnicas anestésicas, o que não ocorreu em ambos os estudos mencionados, uma vez que os pacientes do protocolo 3 são classificados como ASA 3 e ASA 4 submetidos à cirurgia revascularização do miocárdio, consideradas de grande porte enquanto a endarterectomia, apesar de ser considerada de pequeno porte é uma cirurgia infraumbelical e realizada sob sedação.

Porém um resultado que chama a atenção, ainda neste protocolo, é que os pacientes portadores de diabetes melittus apresentaram uma relação estatísticamente significante $(0,027)$ com ansiedade. É provável que esta associação esteja relacionada, não só pela possibilidade de descompensação metabólica, mas provavelmente pela incidência de complicações tão conhecidas pelos pacientes, até de uma maneira mais popular como "a ferida do diabético demora para fechar" mas que provavelmente intefere em seu estado emocional.

Segundo Tonelli, Toldo, Canga ${ }^{(78)}$ no paciente diabético as alterações neuroendócrinas desencadeadas pelo trauma anestésico cirúrgico dificultarão, ainda mais, o controle da doença, uma vez que a hiperglicemia, comum ao estresse cirúrgico, demandara doses maiores de insulina para prevenir a hiperglicemia e suas conseqüências deletérias no organismo. 
Com relação às características referentes ao estado de ansiedade dos pacientes pertencentes aos quatro protocolos desenvolvidos, estas se apresentaram com pequenas diferenças, isto é, os pacientes em sua maioria apresentaram baixo e médio estado de ansiedade, o que supõe uma resposta ao estresse sem grandes alterações dos parâmetros clínicos marcadores da ansiedade, diferentemente daqueles pacientes acometidos de transtorno de ansiedade, que apresentam alterações nos sistemas neuroquímico.

No que refere ao instrumento utilizado para avaliar o estado emocional (IDATE), acredita-se que, mesmo sendo uma escala já validada aqui no Brasil para pacientes cirúrgicos, a verificação da coerência interna retrataria o estado de ansiedade dos pacientes, sem a tendenciosidade comum na aplicação destas escalas.

Segundo Polit ${ }^{(29)}$ as tendências mais comuns são o fornecimento de "respostas compatíveis com as visões sociais dominantes", respostas enfocando sempre a mesma alternativa, respostas só afirmativas e que colaboram, com a ansiedade inconsciente, referida por Spielberger, Gorsush Lushene $^{(10)}$ e apresentada pelos pacientes em falsear a avaliação.

Nos protocolos 2 e 4 desenvolvidos, constata-se que as estratégias de enfrentamento utilizadas atingiram seu objetivo principal, ou seja, o restabelecimento do equilíbrio do organismo diante da agressão sofrida, uma vez que os pacientes estudados (protocolo 2) apresentaram uma correlação negativa entre o estado de ansiedade e as estratégias (suporte social e resolução de problemas) e no protocolo 4 apesar de não se observar a 
significância estatística mostraram uma tendência na utilização dos mecanismos de fuga e esquiva $(p=0,0565)$.

Retomando a necessidade do enfermeiro pautar sua avaliação e intervenção em métodos científicos, Policastro ${ }^{(79)}$ desenvolveu uma pesquisa que teve como objetivos, utilizando a orientação de enfermagem, minimizar a ansiedade e eventuais intercorrências imediatas alta em dois grupos de pacientes mastectomizadas. Concluiu que tanto a ansiedade quanto as eventuais intercorrências independem das orientações fornecidas.

Para Ramos ${ }^{(80)}$ a orientação de enfermagem aos pacientes pelo enfermeiro é um requerimento indispensável para a garantia da continuidade do tratamento após a alta . Os profissionais devem ter como objetivo auxiliar no desenvolvimento de mecanismos que permitam a integração do indivíduo no seu contexto social.

Porém, para o enfermeiro de centro cirúrgico é uma tarefa complexa a ser desenvolvida em um período curto de interação, onde os objetivos muitas vezes são divergentes, isto é, nem sempre, as informações dadas pelos profissionais são aquelas esperadas pelos pacientes. Como enfoca Gómez ${ }^{()}$, muitas anseios apresentados pelos pacientes, ainda no período pré-operatório, referem-se às necessidades psicológicas e físicas do paciente ao momento da alta hospitalar.

Este fato é um complicador nesta interação perseguida pelo enfermeiro de centro cirúrgico, além de potencializar as reações emocionais do paciente no período pré-operatório, sendo assim, considerar a individualidade do mesmo parece ser a melhor estratégia a ser utilizada. 
Segundo Takahashi $^{(81)}$ as informações devem ser ajustadas às necessidades de cada um, e mesmo assim, pode não ter efetividade esperada pelo profissional para o paciente naquele momento, uma vez que o ser humano percebe a realidade por meios de "filtros "que se ajustam conforme suas experiências passadas e problemas vivenciados.

Como destaca Policastro ${ }^{(79)}$ é evidente que cada paciente merece orientações próprias e a disponibilidade do enfermeiro para expor suas necessidades daquele momento.

A necessidade emitida pelo paciente naquele momento é sentida pelo enfermeiro de centro cirúrgico, porém ainda não é inteiramente decodificada, uma vez que estímulos variados se agregam àqueles próprios da cirurgia.

Existe a consciência do profissional de que a ansiedade referente à cirurgia é muitas vezes a "ponta do iceberg", uma vez os problemas financeiros, familiares e outros interferem, tanto ou mais ainda, do que a própria cirurgia, repercutindo na interação com 0 paciente e conseqüentemente na sua avaliação.

Isto retrata a complexidade do ser humano que utiliza uma simbologia complexa para lidar com os sentimentos e construir estratégias de enfrentamentos, como por exemplo, a atenção seletiva ou ainda o desejo de não ser orientado.

Estudos de Caldwel ${ }^{(58)}$ e Costa ${ }^{(20)}$ exemplificam esta constatação quando, identificam como mecanismos de enfrentamentos utilizados pelos pacientes, a recusa na orientação. 
Neste sentido, Chaves et al ${ }^{(82)}$ sugerem 0 referencial de enfrentamento utilizado pela Psicologia ao enfermeiro como uma possibilidade de atuação neste processo adaptativo. Assim instrumentalizado daria ao paciente, condições de realizar uma reavaliação cognitiva, além de lhe proporcionar a oportunidade de fazer opções possíveis e conseqüentemente ter sua percepção aumentada, o que the faria refletir sobre suas expectativas.

. Porém este é um caminho a ser explorado e que exige esforço, dedicação e preparo do enfermeiro de centro cirúrgico não só no âmbito hospitalar como também no ensino e na pesquisa.

A rigor tem-se conhecimento da conseqüência neuro-humoral do procedimento anestésico cirúrgico, mas o porquê este evento determina esta ou aquela reação emocional no paciente, ainda é uma incógnita para o enfermeiro. Medem-se as variações biológicas, porém existe a grande dificuldade em abordar a dimensão singular do ser humano.

Segundo Castiel $^{(83)}$ singularidade não significa apenas a referência à anatomia, fisiologia, temperamento, condutas, mas também estrutura molecular, particularidade bioquímica, responsável pela especificidade de proteínas e de modos de interação, ou seja "O homem não é um composto de corpo e alma, é um centauro ontológico, é um drama e uma luta para chegar a ser".

Porém, este é um caminho a ser explorado e que exige esforço, dedicação e preparo do enfermeiro de centro cirúrgico não só no âmbito hospitalar como também no ensino e na pesquisa, além de utilizar outras 
ciências que possam auxiliá-lo na assistência de enfermagem ao paciente cirúrgico. 
REFERÊNCIAS BIBLIOGRÁFICAS 


\section{Referências Bibliográficas}

(1) Dubos, R. Um animal tão humano, como somos moldados pelo ambiente e pelos acontecimentos. São Paulo: EDUSP, 1974. cap. 3, p. 63-99: Lembrança biológica de coisas passadas.

(2) Descartes, R Discurso do método: meditações, objeções e respostas, as paixões da alma, carta. São Paulo, abril, 1973 (Os pensadores).

(3) Selye, H. Stress: a tensão da vida. 2 ${ }^{a}$..ed. São Paulo: IBRASA, 1959.

(4) Moore, F.D. Homeostase: alterações corporais no traumatismo e cirurgia. In: Sabiston, D,C. Tratado de Cirurgia. $2^{2}$.ed.Rio de Janeiro. Interamericana, 1979.cap. 2, p.24-60

(5) Stocche, RM; Garcia, LV; Klamt, JG. Anestesia e resposta neuroendócrina e humoral ao estresse cirúrgico. Rev. Bras. Anestesiol. 2001; 51, (1): 59-69.

(6)Vasconcellos, EG. O modelo psiconeuroendocrinológico de stress. In: Seger, L. editor Psicologia e odontologia uma abordagem integradora. $2^{\mathrm{a}}$. ed. São Paulo, Santos; 1992. p.25-35.

(7) Lazarus RS, Folkman S. Cognitive appraisal processes. In: Stress appraisal and coping. New York: Springer Publishing Company; 1984. p. 2254.

(8) Chaves EC. Stress e trabalho do enfermeiro: a influência de características individuais no ajustamento e tolerância ao turno noturno. [tese] São Paulo (SP): Instituto de Psicologia da USP; 1994.

(9) Spielberger, C. Tensão e ansiedade, Nova Deli: Harper \& Row do Brasil; 1979.

(10) Spielberger C; Gorsuch RL; Lushene RE. Inventário de ansiedade traçoestado. Trad. por Biaggio, AMB; Natalicio L. Rio de Janeiro, CEPA, 1979.

(11) Aldrete JA.; Kroulik D A postanesthetic recovery score. Curr Rev.Anesth. 1970; 49 (6): 924-33.

(12) Posso, MBS. Avaliação das condições dos pacientes na sala de recuperação pós-anestésica. Rev. Esc.Enferm. USP 1975; 9 (3):9-23.

(13) Beland, I.; Passos, J. Enfermagem clínica: aspectos fisiológicos e psicológicos. São Paulo(SP): EPU, 1978. : Defesas e respostas do corpo contra a agressão; p. 319-79. 
(14) Bevilacqua RG. Alterações endócrinas e metabólicas no trauma. In: Allgower M.; Bevilacqua, RG, editores. Manual de cirurgia. São Paulo, EPU, 1981. p. 21-33.

(15) Castaños C.. Índices de recuperação. Rev.Bras.Anestesiol. 1982;.32 (6): 441-2.

(16) Schneider, M. Meeting the criterio for discharge. Curr Rev.Recov.Room Nurses 1982; 4 (6):41-8.

(17) Griffin, DN. A tool to develop standarts of quality care in PACUS. J. Post. Anesth. Nurs. 1989; 4; 99-102.

(18) De Lucia, R; Planeta CS. Ansiolíticos. In: Valle, L B. de S. et al, editors. Farmacologia integrada: fundamentos farmacológicos da terapêutica. São Paulo: Ateneu; 1991. p. 87-91.

(19) Jensen MP; Karoly P.; Brauer, S. The measurement of clinical pain intensity: a comparison of six methods. Pain. 1986; 27: 117-26.

(20) Costa ALS. Análise do stress nas situações de vida diária e do préoperatório imediato de pacientes cirúrgicos urulógicos. [mestrado] São Paulo (SP): Escola de Enfermagem da USP; 1997.

(21) Andrade LHSG, Gorenstein C. Aspectos gerais das escalas de avaliação de ansiedade. Psiq Clin 1998;25 (6ª̂ed esp): 285-90.

(22) Andreatini R, Leite J R. IDATE - traço: adaptação para avaliação da ansiedade durante sete dias. J Bras Psiq 1994; 43(5): 259-65.

(23) Stone AA; Neal JM. New measure of daily coping: development and preliminary results. J Pers Soc Psychol 1984; 46(4): 892-906.

(24) Lipp M. Stress e suas complicações. Est Psicol;1(3):5-19.

(25) Mc Crae R. Situational determinants of coping responses: loss, therat and challenge. J. Pers Soc Psychol 1984; 46(4):919-28.

(26) Aldwin C, Revenson TA. Does coping help? A reexamination between coping and mental health. J. Pers Soc Psychol 1987; 53(2):337- 48.

(27) Cerqueira Atar. O conceito e metodologia de coping; existe consenso e necessidade? In: Kerbauy RR,organizadora. Sobre o comportamento e cognição. São Paulo: Atheneu; 2000. p.279-89.

(28) Savoia, MG, Santana Pr, Meijas NP. Adaptação do inventário de estratégias de coping de folkman e Lazarus para o português. Psicologia USP 1996; 7(1/2): 183-201. 
(29) Polit DF . fundamentos da pesquisa em enfermagem. $3^{\text {a }}$ ed. Porto Alegre: Artes Médicas; 1995.cap.10,p.223-67.

(30) Dally P, Harrington H Psicologia e psiquiatria na Enfermagem. São Paulo: EPU; 1978. Psicologia; cap. 1,p. 3-81

(31) Hoffer JL. Anestesia. In: Meeker MH, Roth RJC. Alexandre cuidados de enfermagem ao paciente cirúrgico. $10^{\mathrm{a}}$ ed. Rio de Janeiro: Guanabara Koogan; 1997. p. 134-68.

(32) Ortenzi AV. avaliação e medicação pré-anestésica. In : SAESPSociedade de Anestesiologia do Estado de São Paulo, organizadora. Anestesiologia. 5ㄹ ed. São Paulo: Atheneu; 2001.cap.24, p.467-97

(33) Stanicia S. Bloqueios subaracnóideo e peridural. In: SAESP- Sociedade de Anestesiologia do Estado de São Paulo, organizadora. Anestesiologia. 5a ed. São Paulo: Atheneu; 2001.cap.30, p.597-611.

(34) Imbeloni , LE. Anestesia e o sistema imunológico. Rev. Bras. Anestesiol; 1987; 37 ( 2):119-26.

(35) Vianna PYG. Anestesia venosa: técnicas e indicações. In: SAESPSociedade de Anestesiologia do Estado de São Paulo, organizadora. Anestesiologia. 5르 ed. São Paulo: Atheneu; 2001.cap 27,p.539-49.

(36) Mitchell M. Psychological preparation for patients undergoing day sugery. Ambulatory surgery; 2001; (8)1:19-29.

(37) Molina, O.F. Classificação do estresse. In: Estresse no cotidiano. São Paulo; Pancast ,1996. cap,13, p.124-28.

(38) Peniche, ACG. A influência da ansiedade na resposta do paciente no período pós-operatório imediato. São Paulo, [tese] São Paulo(SP): Escola de Enfermagem da USP; 1998.

(39) Martin D. Pré operative visits to reduce patient anxiety: a study. Nurs Stand 1996;10(23); 33-8

(40) Cade, N.V. O modelo cognitivo-comportamental em grupo e seus efeitos sobre as estratégias de enfrentamento, os estados emocionais e a pressão arterial de mulheres hipertensas. [Tese]- Escola de Enfermagem da USP. Paulo, 2002.

(41) Kaplan HI, Sadock BJ. Compêndio de psiquiqtria dinâmica. $3^{a}$ ed. Porto Alegre: Artes Médicas; 1984.p.413-8.

(42) Ridder D, Schreus K Developing interventions for chronically ill patients:is coping a helpful concept? Clin Psychol Rev 2001; 21 (2) 205-40. 
(43) Ostell A. Coping, problem solving and stress: a framework for intervention strategies. J.Med Psychol 1991; 64:11-24.

(44) Blackburn, GL et al Nutritional and metabolic assessment of the hospitalized patient. JPEN J.Parenter. Enteral Nutr.1977;1(1):11-22.

(45) Blaggio, AMB; Natalicio, L; Spielberger, CD. Desenvolvimento da forma experimental em português do inventario de Ansiedade Traço - Estado (IDATE) de Spielberger. Arq. Bras. Psicol. Apl., 1977;29( 3): 31-44.

(46) Galdino, JMS. Ansiedade, depressão e coping em idosos. [Dissertação] (SP): Escola de Enfermagem da USP;2000..

(47) Lacerda., AR. (coord.) Buscando compreender a infecção hospitalar no paciente cirúrgico. São Paulo: Atheneu, 1992.

(48) Fernandes, AT, Filho, NR Fernandes. Infecção hospitalar: desequilibrio ecológico na interação do homem com sua microbiota. In: AT , Fernandes, MOV, Filho, NR (org) Infecção hospitalar e suas interfaces na área da saúde, São Paulo: Atheneu, 2000.p163-214.

(49) Luepker, RV. Epidemiologia das enfermidades arterosclerosas em grupos populacionais. In: PEARSON, TA. et al. Compêndio de cardiologia preventiva. São Paulo: EPUC, 1997. v.1, p.26-35.

(50) Camargo, AMB.De que morrem os idosos em São Paulo? Conjnt Demogra., 23,p.21-42,1993

(51) Drain, CB; Shipley, SB. Enfermagem na sala de recuperação. Rio de Janeiro: Interamericana, 1981. cap. 32, p.581-3: Assistência na sala de recuperação geral.

(52) Laurenti, R; Buchalla, CM; Caratin, CVS. Doença isquêmica do coração: internações, tempo de permanência e gastos: Brasil, 1993 a 1997. Arq. Bras. Cardiol.;2000;74(6): 483-7.

(53) Organização Mundial de Saúde - OMS. Identificación de enfermedades relacionadas con el trabajo y medidas para combatirlas. Geneva, 1985. (Informe de Comité de Expertos de la OMS).

(54) Candeias, NMF et al. Stress em um Instituto de Cardiologia da Cidade de São Paulo. Rev. Bras. Saúde Ocup. 1988; 16 (64): 33-40.

(55) Ferreira, BA. Fatores de risco para doença coronariana: comportamentos e percepção de pacientes pós intervenção hemodinâmica. [dissertação] São Paulo (SP): Escola de Enfermagem da USP; 1999.

(56) Levine, DM. Fatores comportamentais e psicossociais, processos e estratégias. In: Pearson, TA et al. Compêndio de cardiologia preventiva. São Paulo: EPUC, 1997. v.3, p.217-26. 
(57) Panza, AMM. Efeito da visita pré-operatória da enfermeira de centro cirúrgico sobre o estresse do paciente no período pré- operatório, no dia da cirurgia e no período pós-operatório.[ dissertação] São Paulo (SP). Escola de Enfermagem, USP. 1977.

(58) Caldwel, LM. Surgical outpatient concerns: What every perioperative nurse should know? AORN J., v. 3, n. 3, p.761-3, 766-7,1991.

(59) Jouclas VMG. ; Salzano, S.DT. Planejamento de uma ficha préoperatória de enfermagem. Rev. Esc. Enf.. USP. 1981; 15 (1): 5-16.

(60) Bianchi ERF. Estresse em enfermagem: análise da atuação do enfermeiro de centro cirúrgico. [tese] São Paulo (SP): Escola de Enfermagem da USP; 1990.

(61) Silva, A. A visita pré-operatória de enfermagem realizada pela enfermeira do centro cirúrgico. Rev. Esc. Enf. USP 1987; 21(2):145-60.

(62) Martins, IS. Doenças cardiovasculares arteroscleróticas, dislipidemias, hipertensão, obesidade e diabetes melito em população da área metropolitana da região sudeste do Brasil. Rev. Saúde Públ.1993;27 (4): 250-61.

(63) Smeltzer, SC; Bare, BG. Tratado de enfermagem médico-cirúrgica. 7. ed. Rio de Janeiro: Guanabara Koogan, 1994. p. $551-552$.

(64) Surwit, RS et al. Stress management improves long-term glycemic control in type 2 diabetes. Diabetes Care. 2002; 25( 1);. 30-40.

(65) Collins, VJ. Princípios da anestesiologia. 2a ${ }^{a}$ ed. Rio de Janeiro: Guanabara Koagan, 1978. cap. 6, p.886 - 97: Regulação da temperatura e problemas provocados pelo calor.

(66) White, PF. (org.). Tratado de anestesia venosa. Trad. de Arneth Rodrigues Ribeiro. Porto Alegra: Artemed, 2001.

(67) Rabhae, GN; Ribeiro Filho, N; Fernandes, AT. Infecção do sítio cirúrgico. In: FERNANDES, AT (ed.). Infecção hospitalar e suas interfaces na área de saúde. São Paulo: Atheneu.; 2000. cap. 19, p. 479-505.

(68) Caetano, D; Caetano, SC; Kramer, $\mathrm{MH}$. Psiconeuroimunoendocrinologia. J. Bras. Psiq. 1999;48(7): 307-14.

(69) Khansari, DN, Murgo,AJ, Faith,RE Effects of stress on the immune system. Imumunol today.1990;11(5):170-5.

(70) Bianchi, ERF. Estresse. In: Lacerda, RA. (coord.). Buscando compreender a infecção hospitalar no paciente cirúrgico. São Paulo: Atheneu, 1992. p. 44-5. 
(71) Faintuch J, Faintuch JJ. Observação clínica pré-operatória. In: Faintuch J, Machado MCC, Raia AA. Manual de pré e pós -operatório. São Paulo: Manole; 1978. p. 03-13.

(72) Peniche ACG, Moraes LO. Ansiedade no paciente cirúrgico ambulatorial. Relatório final de pesquisa apresentado CNPq-PIBIC, 2001.

(73) Farah, OGD. Stress e coping no estudante de graduação em enfermagem: investigação e atuação. [tese]São Paul(SP):Escola de Enfermagem da USP; 2001

(74) Gonçalves, T. C.S de A Percepção dos pacientes cirúrgicos sobre a ansiedade pré-operatóriae aspectos interacionais relativos à equipe de saúde e ao ambiente. Anais do II Sibracen, ribeirão Preto, 1990.

(75) Frazier, Susan K. Critical care nurse'assessment of patient'anxiety: reliance on physiological and behavioral parameters.American Journal of Critical Care, http:// www.findarticles.com/p/articles/mi impresso em $19 / 11 / 2004$ ]

(76) Parris, W.C.V. et al Anxiety and postoperative recovery in ambulatory sugery patients. Anesth.Prog. v35,p. 61-4,1988.

(77) Pearsosn, Sue; Maddern, Guy; Fitridge, Robert. The role of pré-operatve stat-anxiety in the determination of intra-perative neuroendocrine responses and recovery. http;// www.ingentaconnect.com/content/ bpsoc/bjhp impresso em 27/07/05

(78) Tonelli, D; Toldo; Canga.JC Sistema Endócrino e anestesia. In: SAESPSociedade de Anestesiologia do Estado de São Paulo, organizadora. Anestesiologia. 5a ed. São Paulo: Atheneu; 2001.cap. 33, p.645 677.

(79) Policastro, S . Orientação de enfermagem: um estratégia para minimizar a ansiedade e eventuais intercorrências imediats à alta hospitalar doas pacientes mastectomizadas.[dissertação]. São Paulo (SP): Escola de Enfermagem da USP; 2002

(80) Ramos Alfonso MR, et al . Nursing report for patient discharge. A pratical service experience. Ver. Enferm. 1999; 22 (2):143-8

(81) Gomez N la enfermeria em cirurgia del câncer. Introducion a la enfermeria oncologica. Bueno Aires; 1986. p.30-1.

(82) Takahashi OC. Necessidades psicossociais de pacientes submetidos à cirurgia do aparelho digestivo: uma assistência sistematizada[ dissertação]. São Paulo(SP): Escola de Enfermagem da USP;1987. 
(83) Chaves, EC. et al. Coping: Significados, interferência no processo saúde-doença e relevância para a enfemagem. Rev. Esc.Enf. USP, v.34,n.4,p.370-5,2000.

(84) Casteil, LD O estresse na pesquisa biomédica e epidemiológica: as limitações do modelo de risco no estudo do proceso saúde/doença. In: O buraco e o avestruz: a singularidade do adoecer humano. Campinas. Papiro. Cap. 4, p.127-170. 
Anexos

\section{ANEXOS}


ANEXO 1

\section{Formulário1}

\section{Parte I}

Identificação: Idade:

Hospitalização com cirurgias anteriores:

Intercorrências:

\section{Parte II}

\begin{tabular}{|l|l|l|}
\cline { 2 - 3 } \multicolumn{1}{l|}{} & $\begin{array}{l}\text { Valores } \\
\text { Obtidos }\end{array}$ & Categorização \\
\hline Freqüência de pulso & & \\
\hline Pressão arterial & & \\
\hline Freqüência respiratória & & \\
\hline Temperatura & & \\
\hline Reflexos protetores & & \\
\hline Expansibilidade torácica & & \\
\hline Atividade muscular & & \\
\hline Sensibilidade cutânea & & \\
\hline Dor & & \\
\hline Coloração & & \\
\hline Consciência & & \\
\hline Comportamento & & \\
\hline Sinais vegetativos & & \\
\hline Total & & \\
\hline
\end{tabular}




\section{ANEXO 2}

Inventário 1 - Questionário auto aplicável

Leia cada pergunta e faça um $\mathbf{X}$, à direita, que melhor indicar como você, geralmente, se sente. Não gaste muito tempo numa única afirmação, mas tente dar a resposta que mais se aproximar de como você se sente geralmente.

\begin{tabular}{|c|c|c|c|c|c|}
\hline & & $\begin{array}{l}\text { QUASE } \\
\text { NUNCA }\end{array}$ & $\begin{array}{l}\dot{A} S \\
\text { VEZES }\end{array}$ & $\begin{array}{l}\text { FREQÜEN } \\
\text { TEMENTE }\end{array}$ & $\begin{array}{l}\text { QUASE } \\
\text { SEMPRE }\end{array}$ \\
\hline 01 & Sinto-me bem & & & & \\
\hline 02 & Canso-me facilmente & & & & \\
\hline 03 & Tenho vontade de chorar & & & & \\
\hline 04 & $\begin{array}{l}\text { Gostaria de poder ser tão feliz } \\
\text { quanto os outros parecem }\end{array}$ & & & & \\
\hline 05 & $\begin{array}{l}\text { Perco oportunidades porque não } \\
\text { consigo tomar decisões } \\
\text { rapidamente. }\end{array}$ & & & & \\
\hline 06 & Sinto-me descansado & & & & \\
\hline 07 & $\begin{array}{l}\text { Sou calmo, ponderado e senhor de } \\
\text { mim mesmo. }\end{array}$ & & & & \\
\hline 08 & $\begin{array}{l}\text { Sinto que as dificuldades estão se } \\
\text { acumulando de tal forma que não } \\
\text { consigo resolver }\end{array}$ & & & & \\
\hline 09 & $\begin{array}{l}\text { Preocupo-me demais com as coisas } \\
\text { sem importância }\end{array}$ & & & & \\
\hline 10 & Sou feliz & & & & \\
\hline 11 & Deixo-me afetar muito pelas coisas & & & & \\
\hline 12 & $\begin{array}{l}\text { Não tenho muita confiança em mim } \\
\text { mesmo }\end{array}$ & & & & \\
\hline 13 & Sinto-me seguro & & & & \\
\hline 14 & $\begin{array}{l}\text { Evito ter que enfrentar crises ou } \\
\text { problemas }\end{array}$ & & & & \\
\hline 15 & Sinto-me deprimido & & & & \\
\hline 16 & Estou satisfeito & & & & \\
\hline 17 & $\begin{array}{l}\text { Idéias sem importância me entram } \\
\text { na cabeça e ficam me preocupando }\end{array}$ & & & & \\
\hline 18 & $\begin{array}{l}\text { Levo os desapontamentos tão a } \\
\text { sério que não consigo tirá-los da } \\
\text { cabeça }\end{array}$ & & & & \\
\hline 19 & Sou uma pessoa estável & & & & \\
\hline 20 & $\begin{array}{l}\text { Fico tenso e perturbado quando } \\
\text { penso em meus problemas do } \\
\text { momento }\end{array}$ & & & & \\
\hline
\end{tabular}




\section{ANEXO 3}

Inventário 2 - Questionário auto-aplicável

Leia cada pergunta e faça um $\mathbf{X}$, à direita, que melhor indicar como você se sente Agora, nesse exato momento antes da realização da cirurgia.

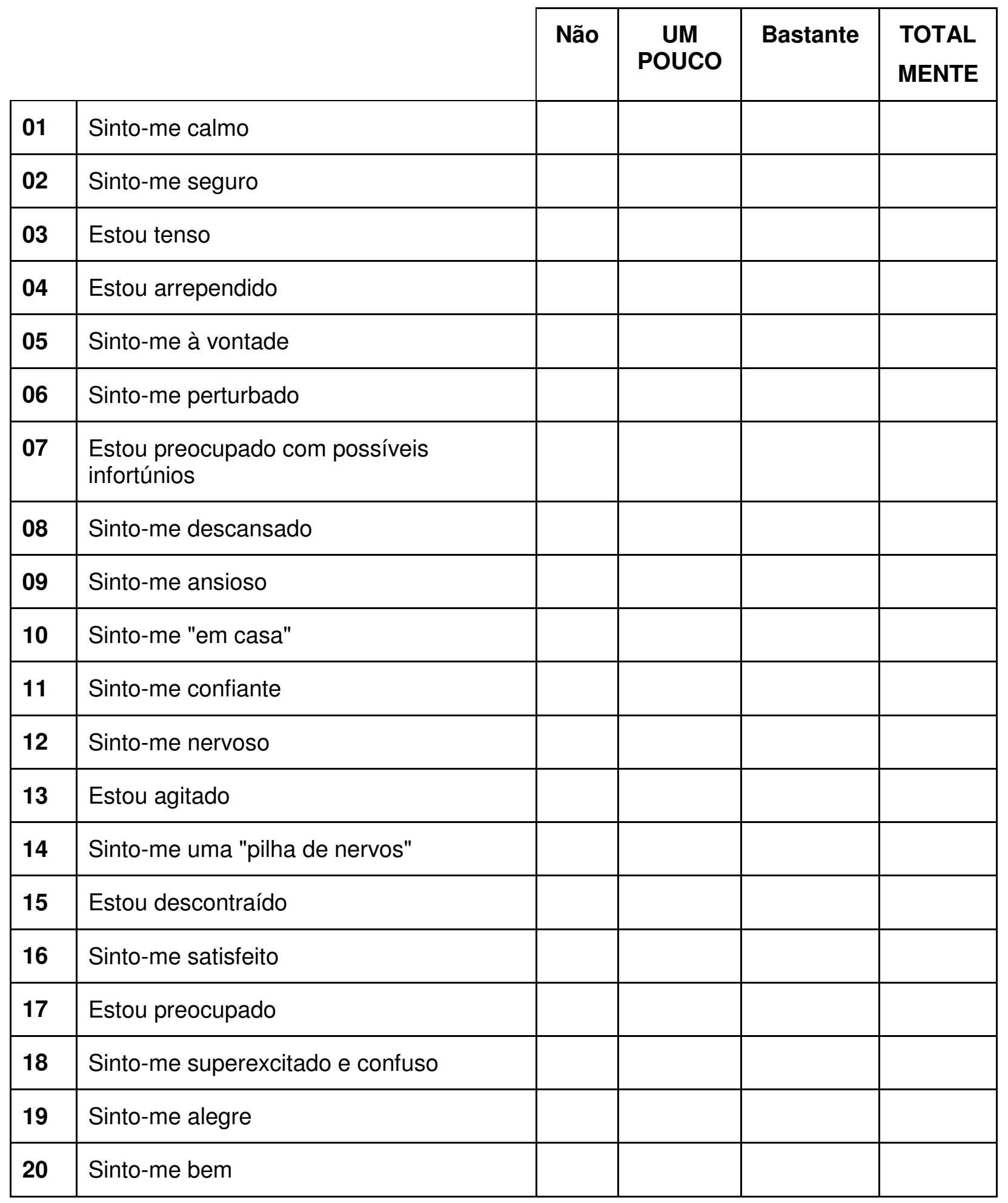


ANEXO 4

Formulário 2

\begin{tabular}{|l|l|l|}
\hline & $\begin{array}{l}\text { Valores } \\
\text { Obtidos }\end{array}$ & Categorização \\
\hline Pulso & & \\
\hline Pressão arterial & & \\
\hline Frequência respiratória & & \\
\hline Temperatura & & \\
\hline Reflexos protetores & & \\
\hline Expansibilidade torácica & & \\
\hline Atividade muscular & & \\
\hline Sensibilidade cutânea & & \\
\hline Dor & & \\
\hline Coloração & & \\
\hline Consciência & & \\
\hline Comportamento & & \\
\hline Sinais vegetativos & & \\
\hline Total & & \\
\hline
\end{tabular}




\section{ANEXO 5}

Formulário 1- parte I

Registro geral:

Idade: sexo

Cirurgia:

Anestesia

Cirurgias anteriores:

Intercorrências apresentadas

Porte cirúrgico:

Escolaridade: 


\section{ANEXO 7 \\ Inventário 2 - Questionário auto-aplicável}

Leia atentamente cada item abaixo e indique, fazendo um círculo na categoria apropriada ao que você fez na situação indicada, de acordo com a seguinte classificação:

$$
\begin{aligned}
& 0 \text { - não usei esta estratégia } \\
& \mathbf{1} \text { - usei um pouco } \\
& \mathbf{2} \text { - usei bastante } \\
& \mathbf{3} \text { - usei em grande quantidade }
\end{aligned}
$$

1. Concentrei-me no que deveria ser feito em seguida, no próximo passo. 01 23

2. Tentei analisar o problema para entendê-lo melhor. $\begin{array}{llll}0 & 1 & 2\end{array}$

3. Procurei trabalhar ou fazer alguma atividade para me distrair. 0123

4. Deixei o tempo passar, a melhor coisa que poderia fazer era esperar, o tempo é o melhor remédio. 0123

5. Procurei tirar alguma vantagem da situação. $\begin{array}{llll}0 & 1 & 2 & 3\end{array}$

6. Fiz alguma que acreditava que não daria resultado, mas ao menos eu estava fazendo alguma coisa. 0123

7. Tentei encontrar a pessoa responsável para mudar sua idéia procurando mais dados sobre o assunto. 0123

8. Conversei com outras pessoas sobre o que estava acontecendo. 0123

9. Critiquei-me. 0123 
10. Tentei não fazer nada que fosse irreversível, procurando deixar outras opções. 0123

11. Esperei que um milagre acontecesse. $\begin{array}{llll}0 & 1 & 2 & 3\end{array}$

12. Concordei com o fato, aceitei o meu destino. 0123

13. Fiz como se nada tivesse acontecido. $\begin{array}{llll}0 & 1 & 2 & 3\end{array}$

14. Procurei guardar para mim mesmo os meus sentimentos. 01 23

15. Procurei encontrar o lado bom da situação. $\begin{array}{llll}0 & 1 & 2 & 3\end{array}$

16. Dormi mais que o normal. 0123

17. Mostrei a raiva que sentia para as pessoas que causaram o problema. 0123

18. Aceitei a simpatia e compreensão das pessoas. 0123

19. Disse coisas a mim mesmo que me ajudassem a me sentir bem. 0123

20. Inspirou-me a fazer algo criativo. $\begin{array}{llll}0 & 1 & 2 & 3\end{array}$

21. Procurei esquecer a situação desagradável. $\begin{array}{llll}0 & 1 & 2 & 3\end{array}$

22. Procurei ajuda profissional. 0123

23. Mudei ou cresci como pessoa de uma maneira positiva. $\begin{array}{lll}0 & 12\end{array}$ 3

24. Esperei para ver o que acontecia antes de fazer alguma coisa.

0123

25. Desculpei ou fiz alguma coisa para repor os danos. $\begin{array}{llll}0 & 1 & 3\end{array}$

26. Fiz um plano de ação e segui. $\begin{array}{llll}0 & 1 & 2 & 3\end{array}$

27. Tirei o melhor que poderia da situação, que não era o esperado. 0123 
28. De alguma forma extravasei meus sentimentos. $\begin{array}{llll}0 & 123\end{array}$

29. Compreendi que o problema foi provocado por mim. 0123

30. Saí da experiência melhor do que eu esperava. 0123

31. Falei com alguém que poderia fazer alguma coisa concreta sobre o problema. 0123

32. Tentei descansar, tirar férias a fim de esquecer o problema. 0 123

33. Procurei me sentir melhor, comendo fumando, utilizando drogas ou medicação. 0123

34. Enfrentei como um grande desafio, fiz algo muito arriscado. 0 123

35. Procurei não fazer nada apressadamente ou seguir o meu primeiro impulso. 0123

36. Encontrei novas crenças. 0123

37. Mantive o meu orgulho não demonstrando os meus sentimentos. 01223

38. Redescobri o que é importante na vida. 0123

39. Modifiquei aspectos da situação para que tudo desse certo no final. 0123

40.Procurei fugir das pessoas em geral. $\begin{array}{llll}0 & 1 & 2 & 3\end{array}$

41. Não me deixei impressionar, me recusava a pensar muito sobre o assunto. 0123

42. Procurei um amigo ou um parente para pedir conselhos. 012 
43. Não deixei que os outros soubessem da verdade da situação. 0123

44. Minimizei a situação me recusando a preocupar-me seriamente com ela. $\quad 0123$

45. Falei com alguém sobre como estava me sentindo. 0123

46. Recusei recuar e batalhei pelo que queria. 0123

47. Descontei minha raiva em outras pessoas. 0123

48. Busquei nas experiências passadas uma situação similar. 01 23

49. Eu sabia o que deveria ser feito, portanto dobrei os meus esforços para fazer o que fosse necessário. $\begin{array}{llll}0 & 1 & 2 & 3\end{array}$

50. Recusei acreditar que aquilo estava acontecendo. 0123

51.Prometi a mim mesmo que as cosas serão diferentes da próxima vez. $\quad 0123$

52. Encontrei algumas soluções diferentes para o problema. 012 3

53. Aceitei, nada poderia ser feito. 0123

54.Procurei não deixar que meus sentimentos interferissem muito nas outras coisas que estava fazendo. $\begin{array}{llll}0 & 1 & 2 & 3\end{array}$

55. Gostaria de poder mudar o que tinha acontecido ou como me senti. 0123

56. Mudei alguma coisa em mim, me modifiquei de alguma forma. 0123

57. Sonhava acordado ou imaginava um lugar ou tempo melhores do que aqueles em que estava. $\begin{array}{llll}0 & 1 & 2 & 3\end{array}$ 
58. Desejei que a situação de alguma forma desaparecesse. 01 23

59. Tinha fantasia de como as coisas iriam acontecer, como se encaminhariam. 0123

60. Rezei. 0123

61. Preparei-me para o pior. 0123

62. Analisei mentalmente o que fazer e o que dizer. 0123

63. Pensei em uma pessoa que admiro e em como ela resolveria a situação e a tomei como modelo. 0123

64. Procurei ver as coisas sob o ponto de vista de outra pessoa. 0 123

65. Eu disse a mim mesmo que "as coisas poderiam ter sido piores". 01223

66. Corri ou fiz exercícios. 0123 


\section{ANEXO 8}

Formulário I PARTE:

Dados Demográficos

Nome:

Idade (anos):

Sexo: ( ) 1 Masculino 0 Feminino

Peso $(\mathrm{Kg})$ :__ Altura $(\mathrm{m})$ :

№ de Registro:

Tempo de doença coronariana:

Data de internação:

Patologia pré-existentes:

Diabétes Mellitos

Hipertensão arterial sistêmica

0 não $1 \mathrm{sim}$

0 não $1 \mathrm{sim}$

\section{Dislipidemia 0 não 1 sim}

II PARTE: Inventário - estado de ansiedade

\begin{tabular}{|l|l|l|l|l|}
\cline { 3 - 5 } \multicolumn{1}{c|}{} & NÃO & UM POUCO & BASTANTE & TOTALMENTE \\
\hline 1- Sinto-me calma & & & & \\
\hline 2- Sinto-me segura & & & & \\
\hline 3- Estou tensa & & & & \\
\hline 4- Estou arrependida & & & & \\
\hline 5- Sinto-me a vontade & & & & \\
\hline 6- Sinto-me perturbada & & & & \\
\hline $\begin{array}{l}\text { 7- Estou preocupada com } \\
\text { possíveis infortúnios }\end{array}$ & & & & \\
\hline 8- Sinto-me descansada & & & & \\
\hline 9- Sinto-me ansiosa & & & & \\
\hline 10- Sinto-me em casa & & & & \\
\hline 11- Sinto-me confiante & & & & \\
\hline 12- Sinto-me nervosa & & & & \\
\hline 13- Estou agitada & & & & \\
\hline 14- Sinto-me uma pilha de nervos & & & & \\
\hline 15- Estou descontraída & & & & \\
\hline 16- Sinto-me satisfeita & & & & \\
\hline $\mathbf{1 7 - ~ E s t o u ~ p r e o c u p a d a ~}$ & & & & \\
\hline $\begin{array}{l}\text { 18- Sinto-me super excitada e } \\
\text { confusa }\end{array}$ & & & & \\
\hline 19- Sinto-me alegre & & & & \\
\hline 20- Sinto-me bem & & & & \\
\hline
\end{tabular}




\section{ANEXO 9}

\begin{tabular}{|c|c|}
\hline Grupo 1: (Baixa Ansiedade) & $(n=17), 13,4 \%$ \\
\hline Questão: & Resposta Característica do Grupo \\
\hline Sinto-me calma & totalmente \\
\hline Sinto-me a vontade & totalmente \\
\hline Sinto-me confiante & totalmente \\
\hline Sinto-me segura & totalmente \\
\hline Sinto-me alegre & totalmente \\
\hline Sinto-me descansada & totalmente \\
\hline Sinto-me nervosa & não \\
\hline Estou descontraída & totalmente \\
\hline Sinto-me satisfeita & totalmente \\
\hline Sinto-me em casa & totalmente \\
\hline Sinto-me bem & totalmente \\
\hline Estou preocupada & não \\
\hline Sinto-me super excitada e confusa & totalmente \\
\hline Estou tensa & não \\
\hline Grupo 2: (Média Ansiedade) & $(n=65), 51,2 \%$ \\
\hline Questão: & Resposta Característica do Grupo \\
\hline Sinto-me a vontade & bastante \\
\hline Sinto-me uma pilha de nervos & não \\
\hline Sinto-me confiante & bastante \\
\hline Sinto-me super excitada e confusa & não \\
\hline Estou agitada & não \\
\hline Sinto-me segura & bastante \\
\hline Sinto-me descansada & bastante \\
\hline Sinto-me bem & bastante \\
\hline Sinto-me perturbada & não \\
\hline Sinto-me satisfeita & bastante \\
\hline Sinto-me calma & bastante \\
\hline Estou preocupada com possíveis infortúnios & não \\
\hline Sinto-me em casa & bastante \\
\hline Sinto-me ansiosa & Um pouco \\
\hline Estou preocupada & Um pouco \\
\hline Grupo 3: (Alta Ansiedade) & $(n=45), 35,4 \%$ \\
\hline Questão: & Resposta Característica do Grupo \\
\hline Estou preocupada & bastante \\
\hline Sinto-me nervosa & bastante \\
\hline Sinto-me confiante & Um pouco \\
\hline Estou preocupada com possíveis infortúnios & bastante \\
\hline Estou agitada & bastante \\
\hline Sinto-me a vontade & Um pouco \\
\hline Sinto-me bem & Um pouco \\
\hline Sinto-me uma pilha de nervos & bastante \\
\hline Sinto-me segura & Um pouco \\
\hline Sinto-me super excitada e confusa & Um pouco \\
\hline Sinto-me perturbada & bastante \\
\hline Sinto-me ansiosa & bastante \\
\hline Sinto-me alegre & não \\
\hline Sinto-me satisfeita & Um pouco \\
\hline Estou tensa & bastante \\
\hline
\end{tabular}


ANEXO 10

\begin{tabular}{|c|c|c|c|c|c|}
\hline & NÃO & UM POUCO & BASTANTE & TOTALMENTE & TOTAL \\
\hline \multirow[t]{2}{*}{ Sinto-me Calma } & 20 & 55 & 31 & 21 & 127 \\
\hline & $16 \%$ & $43 \%$ & $24 \%$ & $17 \%$ & $100 \%$ \\
\hline \multirow[t]{2}{*}{ Sinto-me segura } & 12 & 50 & 44 & 20 & 126 \\
\hline & $10 \%$ & $40 \%$ & $35 \%$ & $16 \%$ & $100 \%$ \\
\hline \multirow[t]{2}{*}{ Estou tensa } & 35 & 55 & 33 & 4 & 127 \\
\hline & $28 \%$ & $43 \%$ & $26 \%$ & $3 \%$ & $100 \%$ \\
\hline \multirow[t]{2}{*}{ Estou arrependida } & 108 & 12 & 7 & 0 & 127 \\
\hline & $85 \%$ & $9 \%$ & $6 \%$ & $0 \%$ & $100 \%$ \\
\hline \multirow[t]{2}{*}{ Sinto-me a vontade } & 15 & 46 & 45 & 21 & 127 \\
\hline & $12 \%$ & $36 \%$ & $35 \%$ & $17 \%$ & $100 \%$ \\
\hline \multirow[t]{2}{*}{ Sinto-me perturbada } & 67 & 45 & 12 & 3 & 127 \\
\hline & $53 \%$ & $35 \%$ & $9 \%$ & $2 \%$ & $100 \%$ \\
\hline \multirow{2}{*}{$\begin{array}{l}\text { Estou preocupada } \\
\text { com possíveis } \\
\text { infortúnios }\end{array}$} & 51 & 43 & 27 & 6 & 127 \\
\hline & $40 \%$ & $34 \%$ & $21 \%$ & $5 \%$ & $100 \%$ \\
\hline \multirow[t]{2}{*}{ Sinto-me descansada } & 11 & 47 & 43 & 26 & 127 \\
\hline & $9 \%$ & $37 \%$ & $34 \%$ & $20 \%$ & $100 \%$ \\
\hline \multirow[t]{2}{*}{ Sinto-me ansiosa } & 26 & 55 & 39 & 7 & 127 \\
\hline & $20 \%$ & $43 \%$ & $31 \%$ & $6 \%$ & $100 \%$ \\
\hline \multirow[t]{2}{*}{ Sinto-me em casa } & 32 & 43 & 28 & 24 & 127 \\
\hline & $25 \%$ & $34 \%$ & $22 \%$ & $19 \%$ & $100 \%$ \\
\hline \multirow[t]{2}{*}{ Sinto-me confiante } & 5 & 34 & 59 & 29 & 127 \\
\hline & $4 \%$ & $27 \%$ & $46 \%$ & $23 \%$ & $100 \%$ \\
\hline \multirow[t]{2}{*}{ Sinto-me nervosa } & 45 & 57 & 24 & 1 & 127 \\
\hline & $35 \%$ & $45 \%$ & $19 \%$ & $1 \%$ & $100 \%$ \\
\hline \multirow[t]{2}{*}{ Estou agitada } & 70 & 36 & 18 & 3 & 127 \\
\hline & $55 \%$ & $28 \%$ & $14 \%$ & $2 \%$ & $100 \%$ \\
\hline \multirow[t]{2}{*}{$\begin{array}{l}\text { Sinto-me uma pilha } \\
\text { de nervos }\end{array}$} & 86 & 24 & 14 & 3 & 127 \\
\hline & $68 \%$ & $19 \%$ & $11 \%$ & $2 \%$ & $100 \%$ \\
\hline \multirow[t]{2}{*}{ Estou descontraída } & 28 & 65 & 23 & 11 & 127 \\
\hline & $22 \%$ & $51 \%$ & $18 \%$ & $9 \%$ & $100 \%$ \\
\hline \multirow[t]{2}{*}{ Sinto-me satisfeita } & 12 & 45 & 51 & 19 & 127 \\
\hline & $9 \%$ & $35 \%$ & $40 \%$ & $15 \%$ & $100 \%$ \\
\hline \multirow[t]{2}{*}{ Estou preocupada } & 40 & 61 & 26 & 0 & 127 \\
\hline & $31 \%$ & $48 \%$ & $20 \%$ & $0 \%$ & $100 \%$ \\
\hline \multirow{2}{*}{$\begin{array}{l}\text { Sinto-me super } \\
\text { excitada e confusa }\end{array}$} & 80 & 36 & 8 & 3 & 127 \\
\hline & $63 \%$ & $28 \%$ & $6 \%$ & $2 \%$ & $100 \%$ \\
\hline \multirow{2}{*}{ Sinto-me alegre } & 28 & 53 & 33 & 13 & 127 \\
\hline & $22 \%$ & $42 \%$ & $26 \%$ & $10 \%$ & $100 \%$ \\
\hline \multirow{2}{*}{ Sinto-me bem } & 11 & 46 & 49 & 21 & 127 \\
\hline & $9 \%$ & $36 \%$ & $39 \%$ & $17 \%$ & $100 \%$ \\
\hline
\end{tabular}




\section{ANEXO 11}

Formulário 2: I Parte:

\section{Dados referentes ao período intra-operatório}

Duração da cirúrgia

( ) $\min$

Tempo de intubação

( ) $\min$

Tempo de extracorpórea

( ) $\min$

Intercorrências nos período intra-operatório sim ( ) não ( )

Quais

\section{Parte:}

Dados referentes ao período pós-operatório

Tempo de permanência na recuperação pós-operatório

Data da alta hospitalar

Infecção do sítio cirúrgico Sim ( ) Não ( )

Temperatura $\left({ }^{\circ} \mathrm{C}\right)$

Dor local

Sim ( ) Não ( )

Presença de secreção $\operatorname{Sim}(\quad)$ Não( )

Hiperemia local $\quad \operatorname{Sim}($ ) Não( )

Aspecto de secreção: Local de infenção:

Purulenta

Sero- sanguinolenta

Sero-purulento

radial

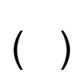

Resultado de cultura:

Positivo ( ) Negativo ( ) 


\section{Anexo 12}

\section{Parte I}

Registro geral: Idade:

Hospitalização com cirurgias anteriores:

Intercorrências:

\section{Parte II}

\begin{tabular}{|l|l|l|}
\cline { 2 - 3 } \multicolumn{1}{l|}{} & VALORES OBTIDOS & CATEGORIZAÇÃO \\
\hline Freqüência de pulso & & \\
\hline Pressão arterial & & \\
\hline Freqüência respiratória & & \\
\hline Temperatura & & \\
\hline Reflexos protetores (tosse, deglutição). & & \\
\hline Expansibilidade torácica & & \\
\hline Atividade muscular & & \\
\hline Sensibilidade cutânea & & \\
\hline Dor & & \\
\hline Coloração & & \\
\hline Consciência & & \\
\hline Comportamento & & \\
\hline Sinais vegetativos (vômitos, náuseas, \\
sialorréia, sudorese). & & \\
\hline Total & & \\
\hline
\end{tabular}

